U.S. Department

of Transportation

National Highway

Traffic Safety

Administration

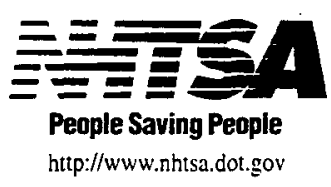

DOT HS 808548

December 1996

Final Report

\title{
Feasibility of New Simulation Technology to Train Novice Drivers
}


This publication is distributed by the U.S. Department of Transportation, National Highway Traffic Safety Administration, in the interest of information exchange. The opinions, findings and conclusions expressed in this publication are those of the author(s) and not necessarily those of the Department of Transportation or the National Highway Traffic Safety Administration. The United States Government assumes no liability for its contents or use thereof. If trade or manufacturers' name or products are mentioned, it is because they are considered essential to the object of the publication and should not be construed as an endorsement. The United States Government does not endorse products or manufacturers. 
Technical Report Documentation Page

\begin{tabular}{|c|c|}
\hline $\begin{array}{l}\text { 1. Report No. } \\
\text { DOT HS } 808548\end{array}$ & 3. Recipient's Catalog No. \\
\hline 4. Title and Subttile & $\begin{array}{l}\text { 5. Report Date } \\
\text { December } 1996\end{array}$ \\
\hline $\begin{array}{l}\text { FEASIBILITY OF NEW SIMULATION TECHNOLOGY } \\
\text { TO TRAIN NOVICE DRIVERS }\end{array}$ & $\begin{array}{l}\text { 6. Performing Organization Code } \\
1469\end{array}$ \\
\hline $\begin{array}{l}\text { Lawrence E. Decina, Kenneth W. Gish, Loren Staplin, and } \\
\text { Albert H. Kirchner }\end{array}$ & $\begin{array}{l}\text { 8. Performing Organization Report No. } \\
\qquad \overline{4} 69 / \mathrm{FR} \\
\end{array}$ \\
\hline \multirow{2}{*}{$\begin{array}{l}\text { 9. Performing Organization Name and Address } \\
\text { The Scientex Corporation } \\
\text { Transportation Safety Division } \\
\text { 1722 Sumneytown Pike, P.O. Box } 1367 \\
\text { Kulpsville, PA } 19443\end{array}$} & 10. Work Unit No. (TRAIS) \\
\hline & $\begin{array}{l}\text { 11. Contract or Grant No. } \\
\text { DTNH22-95-C-05104 }\end{array}$ \\
\hline \multirow{3}{*}{$\begin{array}{l}\text { 12. Sponsoring Agency Name and Address } \\
\text { National Highway Traffic Safety Administration } \\
\text { Office of Research and Traffic Records } \\
400 \text { Seventh Street, SW } \\
\text { Washington, D.C. } 20590\end{array}$} & 13. Type of Report and Period Covered \\
\hline & $\begin{array}{l}\text { Final Report } \\
\text { Sept. } 1995 \text { - Sept. } 1996 \\
\end{array}$ \\
\hline & 14. Sponsoring Agency Code \\
\hline
\end{tabular}

15. Supplementary Notes

Contracting Officer's Technical Representative: Michael F. Smith, NTS-30

\section{Abstract}

This project examined the feasibility of using existing simulation and other electronic device technology with the potential for the safety training of novice drivers. Project activities included: a literature review; site visits and telephone inquiries to software and hardware firms; a workshop with a panel of experts; a task report with recommendations for training applications and platforms; and a final report.

It was found that current driver training products geared for the PC primarily focus on knowledge-based training applications; and have limited simulation and interactivity characteristics. The gaming world uses more dynamic and realistic scenarios and has greater driving function-related interactivity, but has significantly greater development and proprietary concerns. Most driving simulators are primarily used for research and training; and due to their high cost, and limited accessibility are not applicable for the training intended under the scope of this project.

Recommendations are provided for training elements, software and hardware applications, and research needs. The most amenable training elements for novice drivers include hazard anticipation, visual scanning behavior, foveal/peripheral visual performance, and knowledge elements. Other training elements considered include peripheral visual performance, performance degradation, and speed and headway choice. Several programming languages, packages, and pre-production storyboard software packages are available to use in development. The most practical device to use for development and training is the IBM-compatible PC, because of its versatility, cost, accessibility, and popularity. Research should focus on human factors issues relating to trainee feedback and evaluation, criterion, incentives, incidental learning, transfer-oftraining, and non-driving-related and strategic learning. Research needs to address fidelity and scope of simulation for motion and visual systems; and to better understand network training applications across remote locations.

17. Key Words

Novice Driver Console (Set-Top) DriverTraining

Simulation

Personal Computer

Electronic Device Hand-Held Device
19. Securtity Classif. (of this report)

Unclassified
20. Security Classif. (of this page) Unclassified
18. Distribution Statement

No restrictions. This document is available to the public through the National Technical Information Service, Springfield, VA 22161. 


\section{PREFACE}

The purpose of this project was to identify innovative and feasible applications of existing simulation and other electronic device technology with clear potential for the safety training of novice drivers.

The authors wish to thank many individuals and organizations for their time and effort. The authors would first like to express their appreciation to the panelists who. were involved with reviewing task reports and participating in the project workshop. They include John F. Brock (InterScience America, Inc., Leesburg, VA), Neil Lerner (Comsis Corporation, Silver Spring, MD), Lawrence P. Lonero (Northport Associates, Baltimore, Ontario, Canada), Deborah A. Quackenbush (Doron Precision Systems, Inc., Binghamton, NY), Thomas H. Rockwell (R \& R Research, Inc., Columbus, $\mathrm{OH}$ ), Jerry A. Wachtel (The Veridian Group, Baltimore, MD), and Ginger Watson (The University of Iowa, Iowa City, IA).

Thanks are in order to Daniel R. Mayhew (Traffic Injury Research Foundation of Canada, Ottawa, Ontario, Canada) for sharing information from his research activities on young drivers.

Thanks go to Michael L. Brachman (Visual Software Solutions, Inc., Media, PA) for providing insight into the software development issues, as well as Laurie Hodell and Deborah Blank (Electronic Learning Facilitators, Inc., Bethesda, MD) for sharing information about their multimedia training products.

Thanks also go to several vendors and publishers who provided information on current and upcoming products that were important to include in this report.

Final thanks to staff members, Linda M. Montella and Kathy H. Lococo for assisting in numerous research and report production activities throughout the course of the project. 


\section{TABLE OF CONTENTS}

EXECUTIVE SUMMARY $\ldots \ldots \ldots \ldots \ldots \ldots \ldots \ldots \ldots \ldots \ldots$ vii

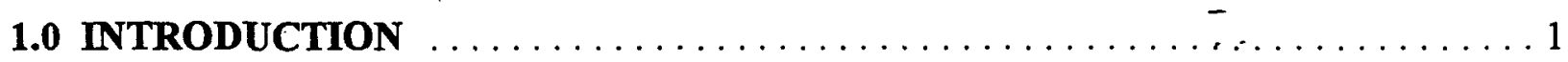

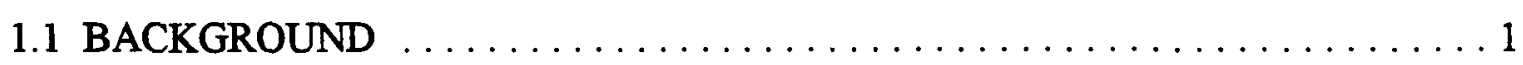

1.2 PROJECT OBJECTIVES AND SCOPE OF WORK $\ldots \ldots \ldots \ldots \ldots \ldots \ldots$

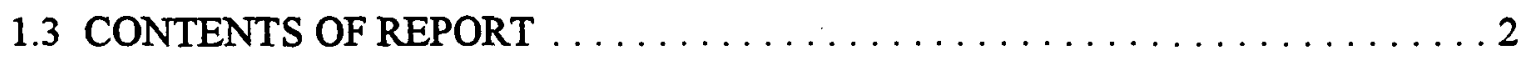

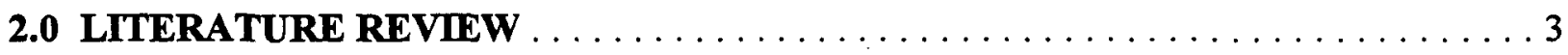

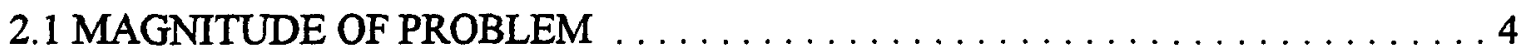

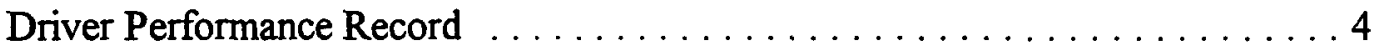

Situational Factors and Behaviors Contributing to the Problem $\ldots \ldots \ldots \ldots 8$

Age-related factors $\ldots \ldots \ldots \ldots \ldots \ldots \ldots \ldots \ldots \ldots \ldots$

Experience-related factors $\ldots \ldots \ldots \ldots \ldots \ldots \ldots \ldots$

2.2 TRAINING ELEMENT CRITERIA $\ldots \ldots \ldots \ldots \ldots \ldots \ldots \ldots \ldots \ldots \ldots \ldots$

2.3 PRE-WORKSHOP TRAINING ELEMENT SELECTIONS $\ldots \ldots \ldots \ldots \ldots 15$

General Abilities Training Elements $\ldots \ldots \ldots \ldots \ldots \ldots \ldots \ldots \ldots$

Specific Driving Skills Training Elements $\ldots \ldots \ldots \ldots \ldots \ldots \ldots \ldots \ldots \ldots$

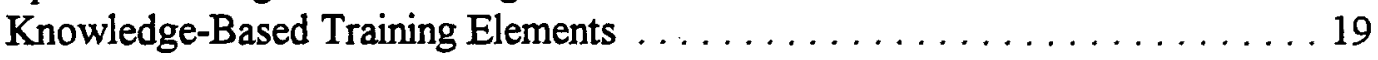

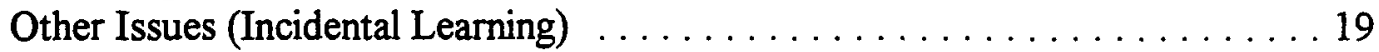

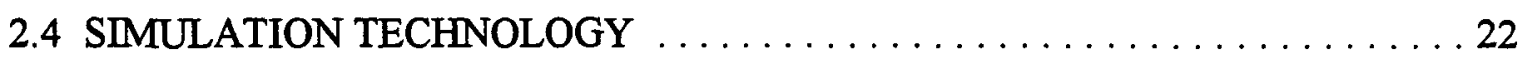

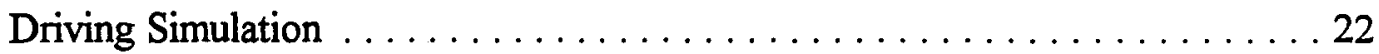

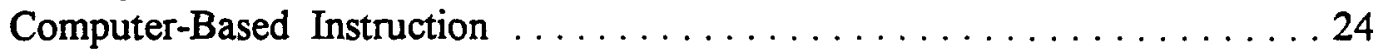

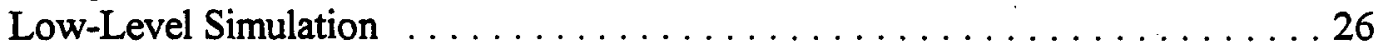

Mid/High-Level Simulation . . . . . . . . . . . . . . . . . 30

\subsection{EVALUATION OF SOFTWARE AND HARDWARE AND OTHER}

TECHNOLOGY FOR SIMULATION $\ldots \ldots \ldots \ldots \ldots \ldots \ldots \ldots \ldots \ldots \ldots \ldots$

3.1 CURRENTLY APPLICABLE SOFTWARE $\ldots \ldots \ldots \ldots \ldots \ldots \ldots \ldots \ldots$

3.2 EVALUATION PROCEDURES FOR HARDWARE PLATFORMS . . . . . . . . . 34

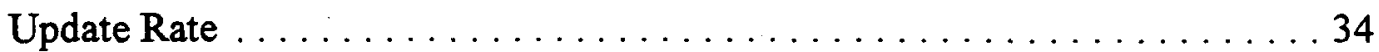

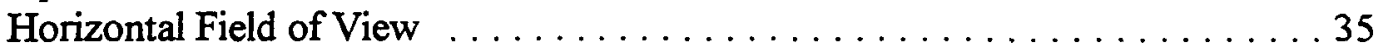

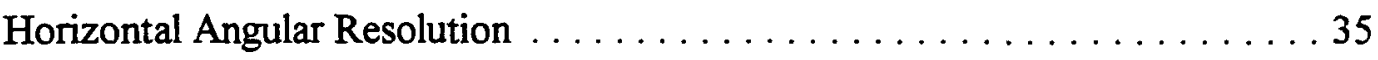

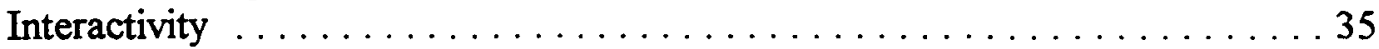


3.3 PLATFORMS AND OTHER DEVICES AND TECHNOLOGIES $\ldots \ldots \ldots \ldots \ldots$

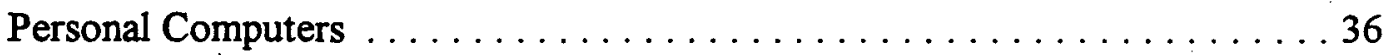

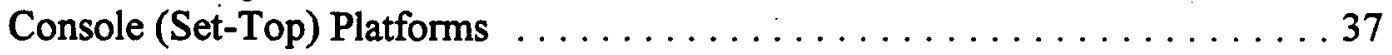

Hand-Held Devices . . . . . . . . . . . . . . . . . . . . 38

Virtual Environment ................................. 39

Cable Modem . . . . . . . . . . . . . . . . . . . . . . 40

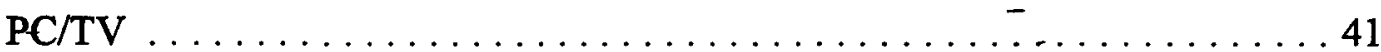

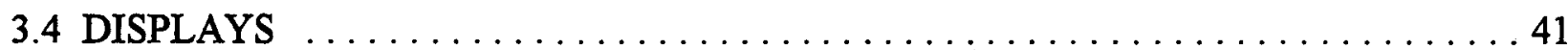

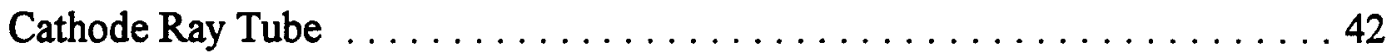

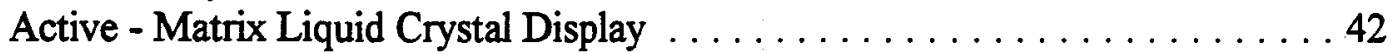

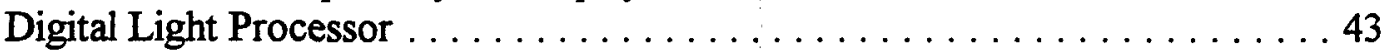

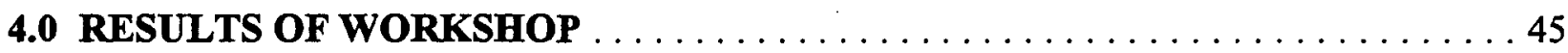

4.1 WORKSHOP AGENDA AND ACTIVITIES $\ldots \ldots \ldots \ldots \ldots \ldots \ldots \ldots \ldots$

4.2 SUMMARY AND RECOMMENDATIONS $\ldots \ldots \ldots \ldots \ldots \ldots \ldots \ldots \ldots$

Training Validity/Effectiveness $\ldots \ldots \ldots \ldots \ldots \ldots \ldots \ldots \ldots \ldots \ldots$

Platform/Display . . . . . . . . . . . . . . . . . . . . . 48

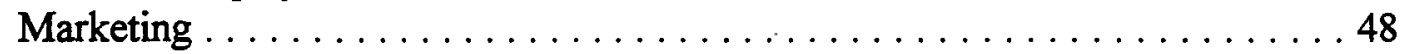

Learning/Instruction ......................... 48

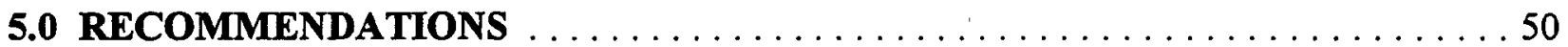

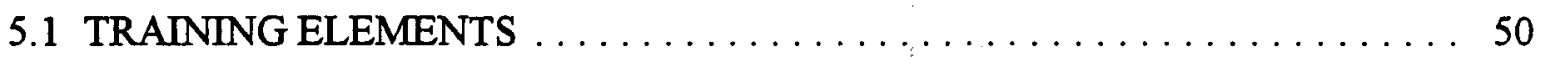

Training Elements Most Amenable to Simulation and Other Electronic

Device Technology . . . . . . . . . . . . . . . . . . . . . . 52

Hazard anticipation ........................... 53

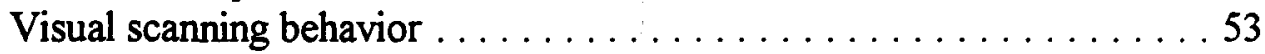

Foveal/peripheral visual performance $\ldots \ldots \ldots \ldots \ldots \ldots \ldots 54$

Knowledge elements ........................ 55

Training Elements Least Amenable to Simulation/Electronic Device

Technology ................................ 56

Peripheral visual performance $\ldots \ldots \ldots \ldots \ldots \ldots \ldots \ldots 6$

Performance degradation $\ldots \ldots \ldots \ldots \ldots \ldots \ldots \ldots \ldots \ldots$

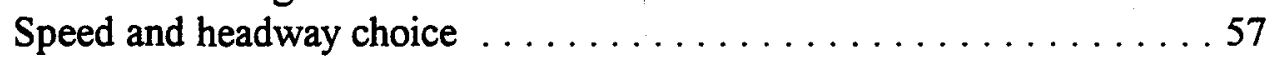

5.2 DEVELOPMENT OF NEW SOFTWARE $\ldots \ldots \ldots \ldots \ldots \ldots \ldots \ldots \ldots \ldots \ldots$

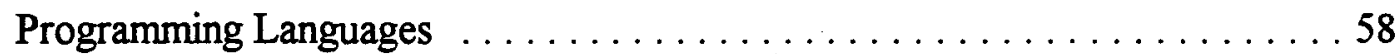

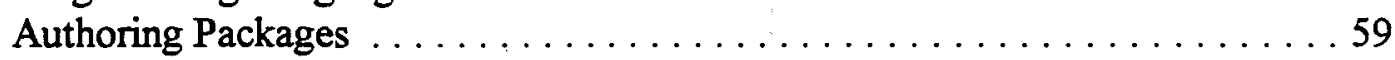

Product Development Costs . . . . . . . . . . . . . . . . . . . . . . 59

Ramifications for Hardware Selection . . . . . . . . . . . . . . . . 61

Recommendations for Novice Driver Training Applications Development . . . . 63 


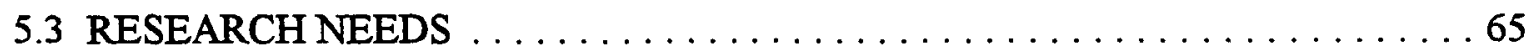

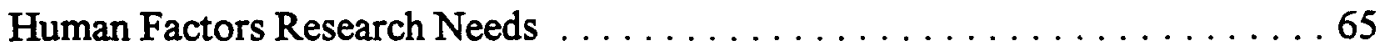

Structure and content of trainee feedback ..............66 66

Process versus content learning $\ldots \ldots \ldots \ldots \ldots \ldots \ldots \ldots 6$

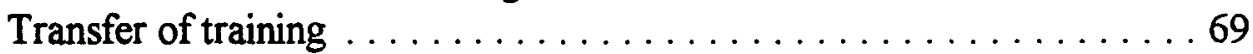

Validation of novice driver training devices . . . . . . . . . . 70

Hardware Needs ................................ 72

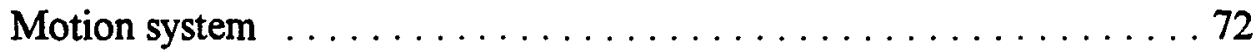

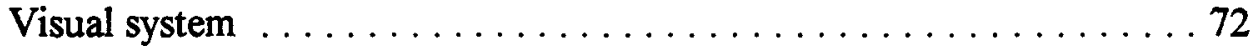

Simulator sickness $\ldots \ldots \ldots \ldots \ldots \ldots \ldots \ldots \ldots \ldots \ldots$

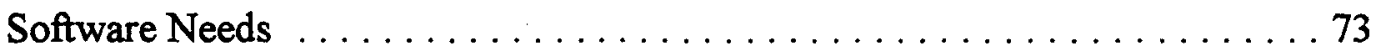

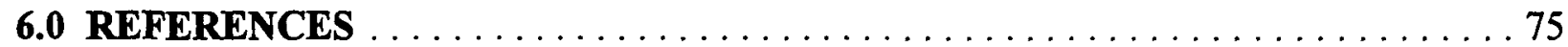

\subsection{APPENDIX}

Appendix A - Workshop Participants . . . . . . . . . . . . . . . . . . . .

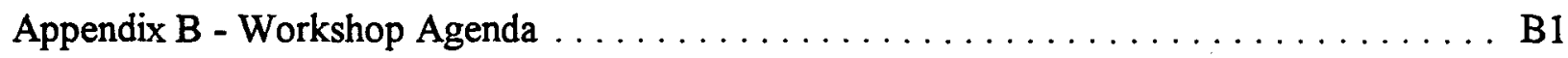




\section{LIST OF TABLES}

Table 1. Percentage of fatal crashes with various characteristics, by driver age. $\ldots \ldots \ldots \ldots 6$

Table 2. Description of General Abilities Training Elements, their implementation and difficulties as related to PCs, consoles, and hand-held devices.

Table 3. Description of Specific Driving Skills Training Elements, their implementation and difficulties as related to PCs, consoles, and hand-held devices. . . 20

Table 4. Driving performance measures of selected low-level simulation studies . . . . . . 28

Table 5. Definitions of terminology established at workshop $\ldots \ldots \ldots \ldots \ldots \ldots$

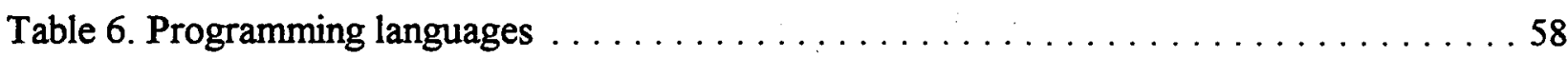

Table 7. Authoring packages used for game development $\ldots \ldots \ldots \ldots \ldots \ldots 6$

Table 8. Comparison of hardware standardization and documentation availability for candidate hardware platforms

\section{LIST OF FIGURES}

Figure 1. Age differences in crash rates (per $10,000 \mathrm{~km}$ ) among males/females $\ldots \ldots \ldots \ldots 4$

Figure 2. Age differences in violation rates (per 10,000 km) among males/females . . . . . . 5

Figure 3. Driver Fatalities (per billion km of travel) by gender and age $\ldots \ldots \ldots \ldots \ldots 6$

Figure 4. Crash rates for 30-year-old males/females with limited driving experience $\ldots \ldots \ldots 7$

Figure 5 . Fatal involvements by age and day vs. night. $\ldots \ldots \ldots \ldots \ldots \ldots \ldots$ 


\section{EXECUTIVE SUMMARY}

The purpose of this study was to identify innovative, feasible applications of existing simulation and other electronic device technology with the potential for the safety training of novice drivers. The project objectives included the following: identify the deficits in knowledge, skills, or attitudes among novice drivers that are most amenable to enhancement through training using simulation or other electronic devices; recommend the most desired instructional and training elements to address such deficits, and the user interface (display and control) requirements to convey program content to novice drivers; determine the most-cost-effective, accessible devices to meet the training program content and user interface requirements; and suggest research necessary, in terms of human factors, software, and hardware issues, to implement the planned safety training applications.

The effort included a literature review identifying novice driver deficits; their training needs; potential uses of simulation and other electronic devices; and other related issues. Telephone inquiries and site visits were made with software and hardware firms to address cost and accessibility of current and innovative devices. Information from these activities was made available to a panel of experts and used in a workshop to identify the training elements and potential simulation and other electronic device applications. Based on the results of these activities, recommendations were made for candidate training elements; software and hardware tools that could be used for development of training products using simulation or other electronic devices; and research needs.

\section{LITERATURE REVIEW}

An information and literature search was conducted using online and manual methods to identify relevant documents and other information relevant to the review. The literature review identified young and novice driver skill deficits and other statistical evidence of their driving problems; covered potential training elements that could be applied to simulation and other electronic devices; and included simulation technology of low, medium, and high-end devices.

A preliminary list of general and specific abilities training elements was developed from the literature review. A description of each training element included how they would be implemented and on which platforms (i.e., personal computer, console (set-top), and hand-held).

\section{WORKSHOP}

A workshop was held with a select group of experts in the traffic safety, training, and simulation fields to discuss issues associated with using simulation or other electronic device technology to train novice drivers. The panelists reviewed and commented on the literature review prior to the meeting. The critical issues and research suggestions expressed by the panelists were discussed at the workshop.

\section{RECOMMENDATIONS}

Based on the project task activities, recommendations are provided for training, software and hardware applications, and research needs. It is recommended that all training should share common 
human performance attributes, including situational awareness, divided attention, selective attention, workload variation, and psychomotor coordination. In addition, training should follow a general four-phase script, including instruction, preparation, response, and feedback phases. It was also determined that to enhance the "look and feel" of the training there is a need to: identify techniques which will produce reliable and desirable peer influences on safe driving behavior; identify the relative influences of instructional versus motivational components in driver training; accommodate gender and cultural differences in the training approach; determine how to combine intentional and incidental learning goals in the same training program; and determine how to best train strategic and tactical goals conveniently in same program. Assumptions were made about the minimum device specifications needed for the recommended training. A platform that provides a 60 degree horizontal field-of-view, $30 \mathrm{~Hz}$ update rate (non-interlaced), and $800 \times 600$ pixel resolution (or greater) would be adequate for the training.

The most amenable elements for novice driver training, which fall within the capabilities of existing low-cost hardware and software technology include hazard anticipation, visual scanning behavior, foveal/peripheral visual performance, and knowledge elements. The least amenable training elements include peripheral visual performance, performance degradation, and speed and headway choice.

Given the limited availability of current training products which can be used for novice drivers, it is recommended that new training elements be developed. Programming languages that could be used for developing training applications include $\mathrm{C} / \mathrm{C}^{++}$, Assembler, Delphi, and Visual Basic. Several off-the-shelf, multimedia packages are also suitable; and offer cross-platform development schemes. These products are not as fast as programming languages and are limiting across certain application types. The more common packages include Director, mTropolis, Oracle Media Objects, Strata Media Forge, and Quark Immedia. There are pre-production storyboard software packages on the market that could also be useful for development.

Recommending a hardware platform involves reconciling a series of conflicting goals ranging from meeting low-cost and accessibility issues; to supporting high fidelity display and vehicle-like controls; and provisions for sufficient processing power to eliminate temporal artifacts during diagnostic scenes. There is no ideal platform to meet all these goals. However, the most realistic choice for hardware platform at this time on which to host a driver training application is the IBM compatible PC, because of its versatility, cost, accessibility, and popularity.

Future human factors research needs to be conducted to better understand the criterion problem (what constitutes a safe driver), incentive issues, incidental learning effects, training situation awareness, and non driver-related and strategic learning. There is also a need to better understand the relationship between fidelity and transfer-of-training issues and cost factors. In addition, there will be a need to validate any novice driver training device that is being considered for use.

Research pertaining to simulator hardware is needed to establish whether motion is required to maximize training benefits. In addition, there has been little systematic research undertaken to demonstrate the relationship between training effects and simulation visual system characteristics. Further investigation into the tradeoffs between different approaches to hardware development and implementation needs to be examined for their potential effects on simulation sickness. 
Future software research needs to be conducted to better understand sharing or network training applications across remote locations, and the benefits that can accrue from it. Also, the design and presentation of instruction is of great importance when training is conducted in an unattended setting as may partially be the case in future training. 


\subsection{INTRODUCTION}

This chapter briefly covers background information, project objectives and scope of work, and contents of this final report.

\subsection{BACKGROUND}

The effect of age on driving performance has been well documented. .Young, novice drivers are disproportionately represented in all manners of traffic injuries and fatalities. Traffic crashes are the number one cause of death for youth and represent $2 / 5$ ths of all deaths of people between 15 and 20 years of age. Teenagers are over represented in traffic accidents and each year over 5,000 teenagers die of motor vehicle crash injuries. Many studies have attributed these problems of young drivers to driving inexperience and lack of adequate driving skills, excessive driving during nighttime hours, alcohol involvement, risk-taking/immaturity, speeding, and other behaviors reflecting poor driving judgment and decision-making (Tannahill, 1985; IIHS, 1995; Williams, 1995).

The current NHTSA research agenda and plan of action for a research program in driver education is centered around a two-stage driver education program that is an integral part of a graduated licensing system. Basic vehicle handling skills would be covered in the first driver education stage. The second stage of driver education would provide the novice drivers the opportunity to learn other safe driving skills, such as enhanced perceptual and decision-making skills needed to reduce risk-taking and other behaviors possibly related to driving inexperience and other factors.

One activity of NHTSA's agenda and plan of action is to take advantage of current simulation and other electronic technologies to provide cost-effective, highly accessible, and possibly, unique learning capabilities in the training of young and novice drivers. With this in mind, consideration can be given to "low-end" simulation and other platforms that can support training, including: general purpose computers that support multimedia applications, console (set-top) gaming systems, which use conventional television sets for the display, and even hand-held, self-contained, gaming devices.

\subsection{PROJECT OBJECTIVES AND SCOPE OF WORK}

The objective of this project was to identify innovative, feasible applications of existing simulation and other electronic device technology with the potential for the safety training of novice drivers. Additional objectives included identifying deficits of young and novice drivers and determining training elements which are applicable with simulation or other electronic devices; examining the most cost-effective, accessible devices to meet the program content and user interface requirements; evaluating the software and hardware necessary for training program implementation; and suggesting future research needs in terms of human factors and training development issues.

To meet the objectives of this project, the following tasks were performed; work plan to review scope of work; literature review to identify training applications for simulation and other electronic device technology; site visits/telephone inquiries with software and hardware firms to identify cost and accessibility issues for using current and new technologies; workshop with experts 
and future research needs; task report of recommendations to provide training elements, suggest appropriate software and hardware platforms, and identify necessary research; and a final report to highlight the findings of the project activities and provide recommendations for training programs which use low-cost, easily accessible simulation or other electronic device technology.

\subsection{CONTENTS OF REPORT}

This final-report includes an abridged version of the literature review which contains the magnitude of the young and novice driver problem, training needs for this group, and a review of driving simulation technology. The report also includes chapters on current applicable software and hardware for simulation and other electronic devices, and a description of workshop activities and panelist recommendations. The report concludes with recommendations for appropriate training elements that can be used with devices; software and hardware tools to use for training application development; and research needs on issues of human factors and hardware and software development. 


\subsection{LITERATURE REVIEW}

To meet the literature review objectives, the first step involved conducting a comprehensive literature and information search, covering several topics including: young and novice driver skill deficits and statistical evidence of their driving problems; instructional materials, and programs used to train this group; gaming, simulation, and computer-based instruction (CBI) systems that have potential application for training novice drivers; and driving simulation technology.

The literature search involved an online computerized literature/information search conducted in the DIALOG Information Retrieval Service system (Dialog Information Service, Inc., a KnightRidder company). The search was conducted in databases that covered traffic safety and driver licensing issues, human factors, driver training and education issues, psychology and sociology, electronic and computer applications, products and manufacturers, and other scientific and technical topics. These databases covered national and international sources. Additional online searches were conducted in the following libraries: Northwestem University's Transportation Library File and four Philadelphia-area university library files (Penn, Drexel, Temple, and West Chester). A search in Digital's Alta Vista web index, which contains full text of more than 13,000 news groups was also conducted, and advantage was taken of a recent literature search printout on the topic of "driving simulators" obtained from the Crew System Ergonomics Information Analysis Center (CSERIAC) military and ergonomic databases.

A manual search was also conducted. This involved searching through in-house staff collections and asking panelists, consultants and NHTSA staff for relevant documents and information. Other organizations were also asked for relevant material, including The Insurance Institute for Highway Safety (IIHS), Traffic Injury Research Foundation of Canada (TIRF), American Association of Motor Vehicle Administrators (AAMVA), American Driver and Traffic Safety Education Association (ADTSEA), AAA Foundation for Traffic Safety (AAA/FTS), Human Factors and Ergonomics Society, Transportation Research Board (TRB) Committees (A3B06 Simulation and Measurement of Vehicle and Operator Performance, A3B03 - Operator Education and Regulation), National Safety Council (NSC), and the California Department of Motor Vehicle Research and Development Section (CADMV). In addition, several dozen manufacturers and distributors of gaming, simulation, computer-based instruction, and other educational products were contacted to obtain information and brochures about potentially relevant products and applications.

Numerous references and product titles were identified in the literature and information search tasks for being potentially relevant to the aims of this report and overall project. Documents and information were obtained from several sources, including government and academic library institutions, document supply vendors, professional organizations, manufacturers/distributors of products and services, and experts and other contacts in the field. Literature searching and document acquisition activities were performed between October 1995 and March 1996. 


\subsection{MAGNITUDE OF THE PROBLEM}

The literature review examined the driver performance record (crash and violation types and frequencies), and the situational factors and behaviors contributing to poor driving performance with this population. Potential training elements were developed from these driver deficiencies.

\section{Driver Performance Record}

The effect of age on driving performance has been studied extensively. Young, novice drivers are disproportionately represented in all manners of traffic injuries and fatalities. Traffic crashes are the number one cause of death for youth, representing approximately 40 percent of all deaths of people between 15 and 20 years of age. In addition, while this age category only includes approximately 7 percent of the population, they account for roughly 14 percent of motor vehicle-related deaths. Data show that teenagers are over represented in traffic crashes; and the crash rate per mile driven is four times higher for teenagers, than for adults (Smith, 1994). In 1992, the National Safety Council reported that 30 out of every 100 teenage drivers were involved in a traffic crash (Hans, 1994); and in the following year, over 5,400 teenagers (13-19 years old) died of motor vehicle crash injuries (IIHS, 1995).

Various measures relating crash and violation involvement to age have contributed to the concerns regarding the driving performance of young drivers. Figures 1 and 2 illustrate age differences in crash and violation rates, controlled for distance traveled as reported by Jonah (1990).

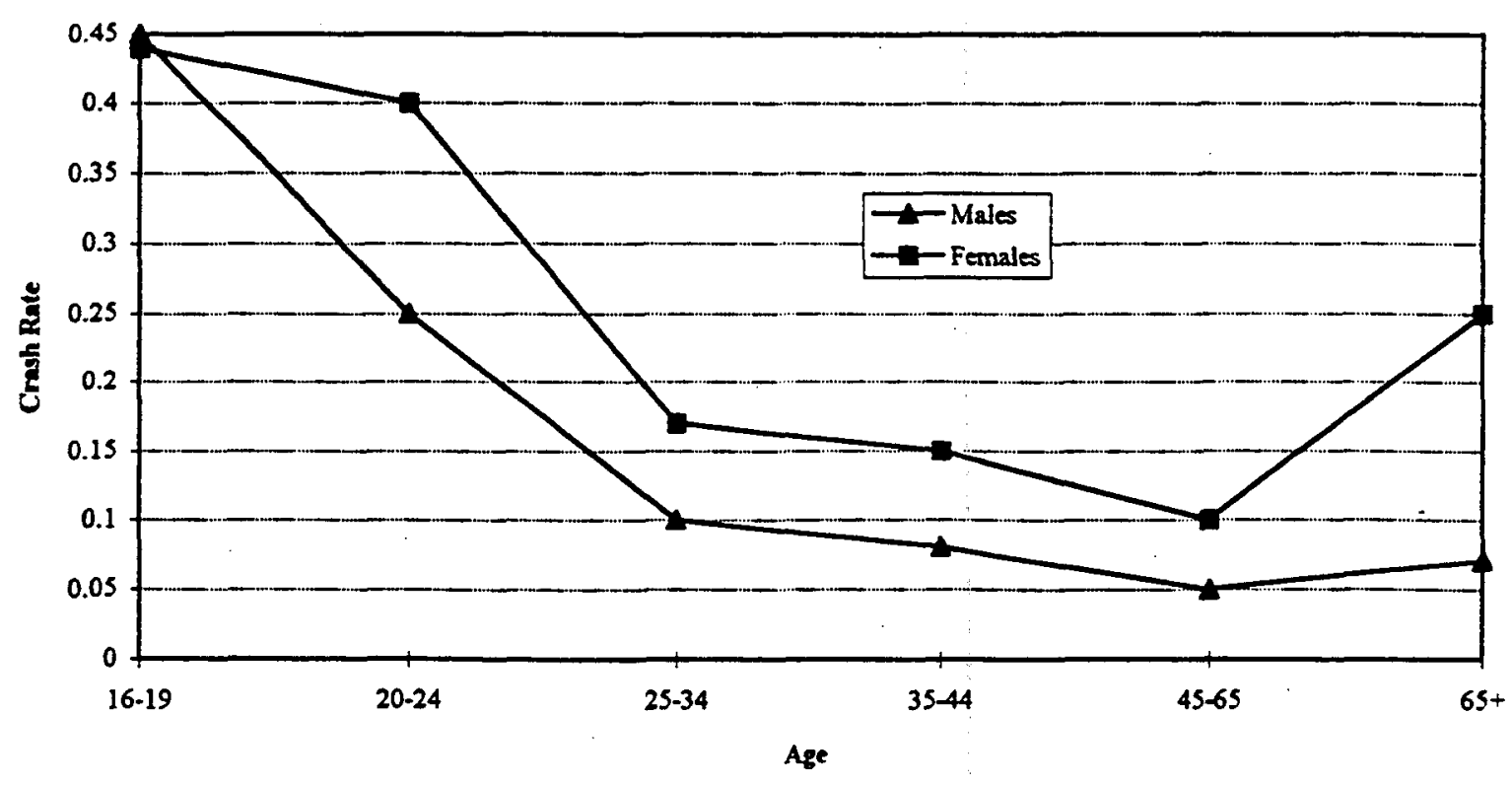

Figure 1. Age differences in crash rates (per $10,000 \mathrm{~km}$ ) among males/females (Jonah, 1990). 


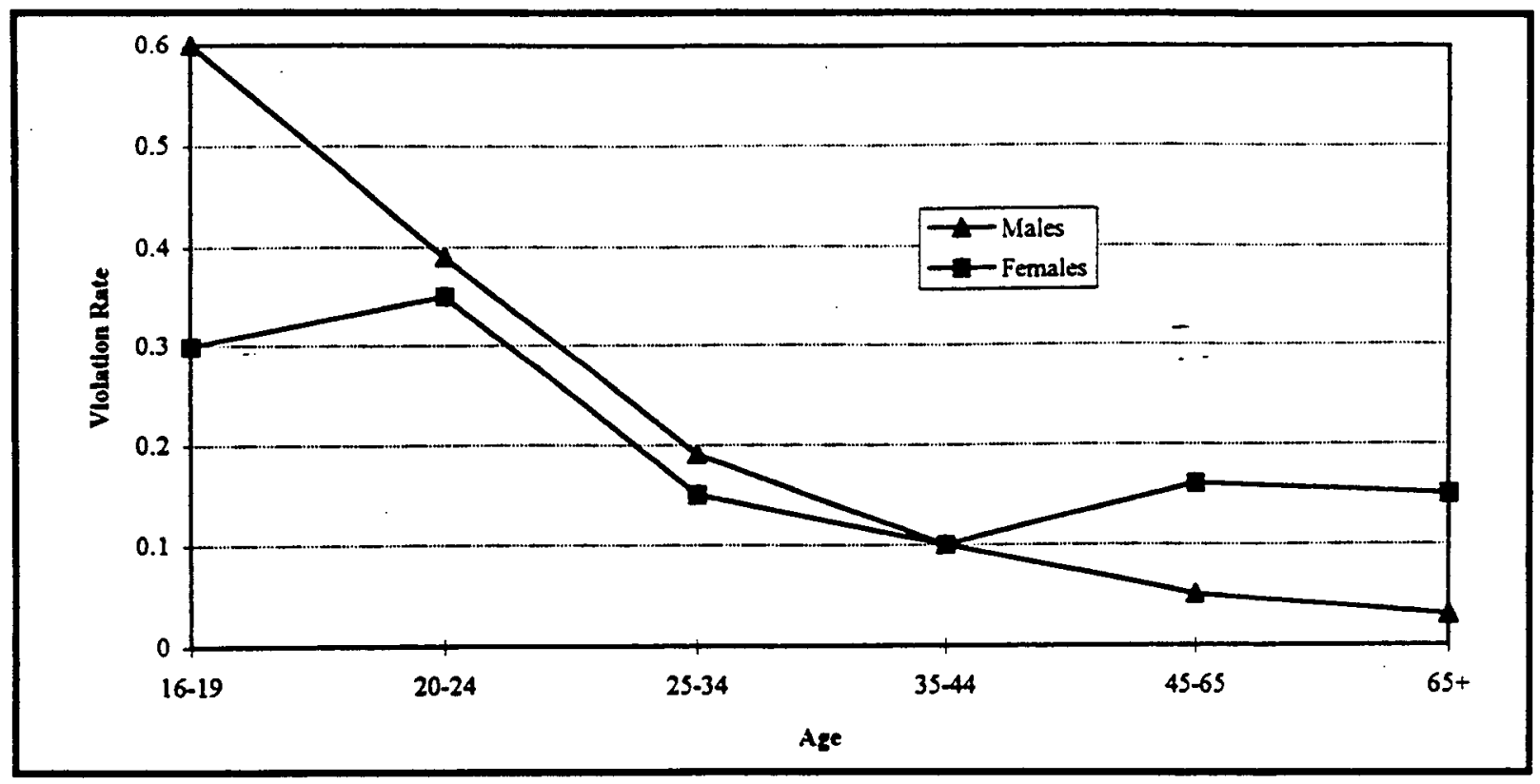

Figure 2. Age differences in violation rates (per 10,000 km) among males/females (Jonah, 1990).

Figure 3 illustrates differences in fatal crash involvement by both age and gender, showing driver fatalities per billion kilometers of travel. These data clearly show the highest peak for driver fatalities for both males and females falling in the under-20-years-of-age category. It has also been reported that more than twice as many male teenagers as female teenagers are killed in motor vehicle crashes (IIHS, 1995). For severe crash involvements per billion kilometers of travel, similar patterns in accident data (sorted by age and gender) have been demonstrated.

There is particular concern regarding special problems experienced in the first year of licensed driving (typically the 16th year of age in the U.S.). While evidently teenage drivers as a group have the highest exposure-based crash rate among all drivers, sixteen-year-olds have by far the highest for any age (Williams, 1995). Sixteen-year-olds are over represented in several characteristics of fatal crash statistics, including single-vehicle, driver error, speeding, 3-plus occupants, and female driver. These data are supported in Table 1. A NHTSA report from a decade ago (Tannahill, 1985) reported that drivers age 16 and 17 have more than twice the average number of crashes compared to drivers in other age groups. The report mentioned that experts have attributed these problems of the young driver to driving inexperience and lack of adequate driving skills, excessive driving during nighttime (high risk) hours, alcohol involvement, risk-taking/immaturity, speeding, and other behaviors reflecting poor driving judgment and decision making.

A recent study (IIHS, 1995) based on Fatal Accident Reporting System (FARS) data, found that in multiple-vehicle and pedestrian collisions, 16-year-olds were cited for driving errors more frequently than any other age group. In multiple vehicle crashes, 62 percent of the errors committed by 16 year-olds were described by failure to stay in the proper lane, failure to obey traffic signals 


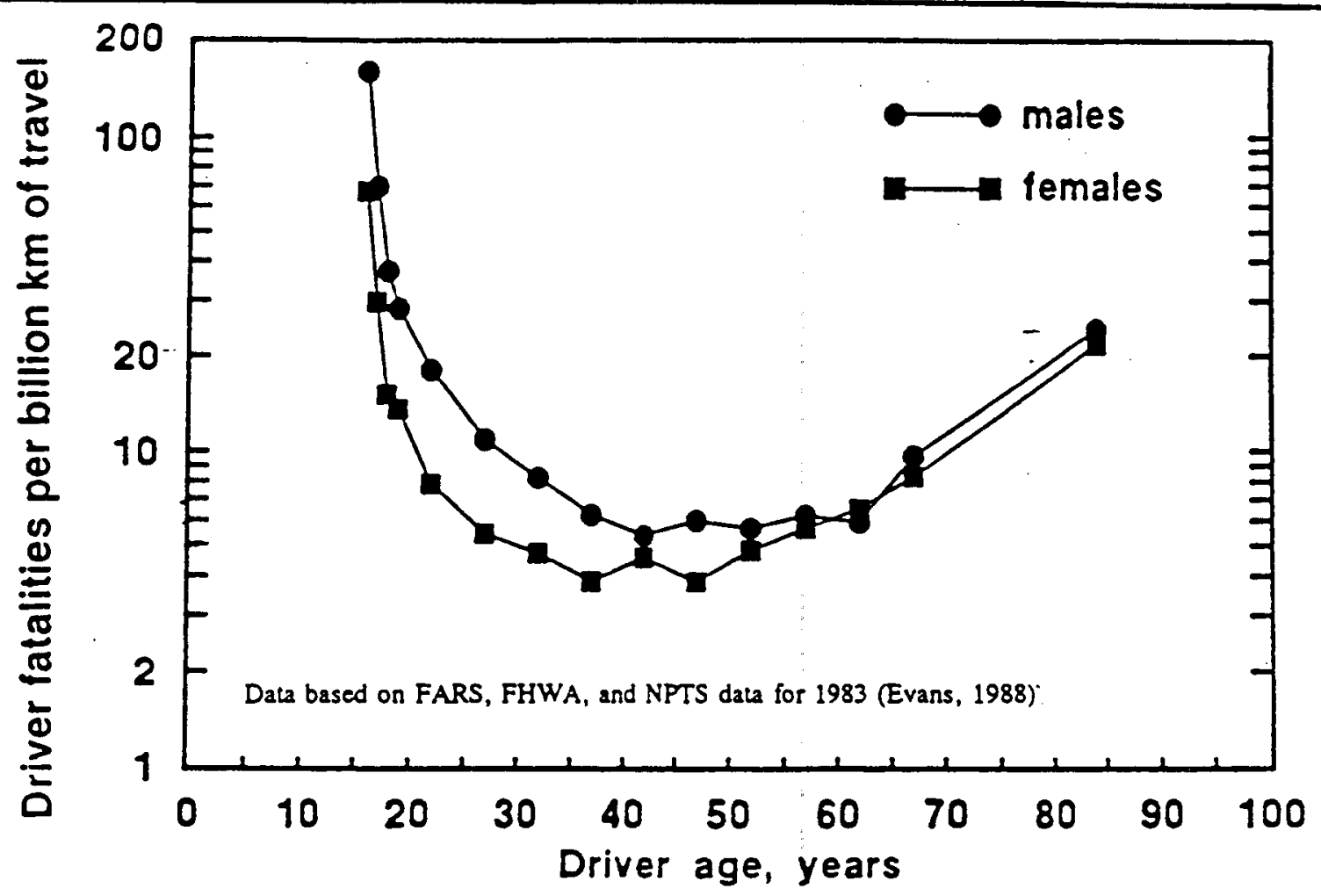

Figure 3. Driver fatalities (per billion $\mathrm{km}$ of travel) by gender and age (IHS, 1995).

Table 1. Percentage of fatal crashes with various characteristics, by driver age (IIHS, 1995).

\begin{tabular}{|l|c|c|c|}
\hline \multirow{2}{*}{$\begin{array}{c}\text { Crash } \\
\text { Characteristics }\end{array}$} & \multicolumn{3}{|c|}{ Driver Age } \\
\cline { 2 - 4 } & $\mathbf{1 6}$ & $\mathbf{1 7 - 1 9}$ & $\mathbf{2 0 - 4 9}$ \\
\hline Single-Vehicle & 44 & 37 & 29 \\
\hline Driver Error & 82 & 74 & 62 \\
\hline Speeding & 37 & 33 & 23 \\
\hline 3+ Occupants & 33 & 27 & 18 \\
\hline 0.10+ Percent BAC* & 5 & 28 & 48 \\
\hline Female Driver & 34 & 27 & 29 \\
\hline
\end{tabular}

* BAC - Blood alcohol concentration 
or signs, erratic operation of the vehicle, and failure to yield the right of way. Single vehicle crashes among this group more often occurred at nighttime (between the hours of 10:00 p.m. and 5:59 a.m.) and mainly involved speeding and high vehicle occupancy with other teenagers.

Older novice drivers are also disproportionately represented in traffic crashes compared with more experienced drivers. Although it is most likely that a novice driver would be a young adult (16-24), there is an increasing percentage of the population that acquires a drivers license at a later point in life. These drivers are at far greater risk of a crash than drivers of the same age who have been licensed for a few years. As shown in Figure 4, even older drivers with a couple of years of driving experience have a lower crash rate than older drivers with less than one year driving experience (Insurance Bureau of Canada, 1991).

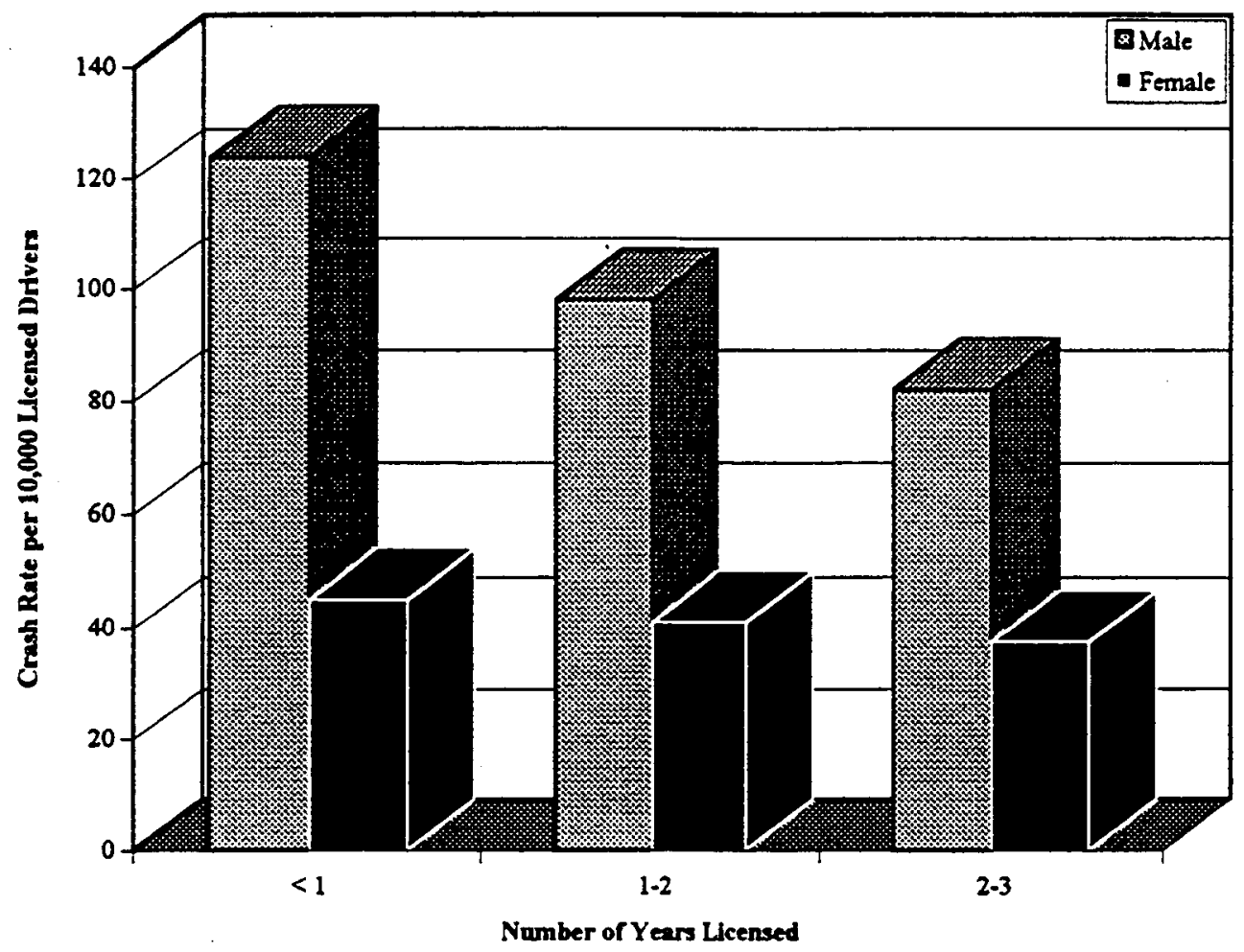

Figure 4. Crash rates for 30-year-old males/females with limited driving experience (Insurance Bureau of Canada, 1991).

Although there remains sufficient risk for older novice drivers, there appears to be a qualitative difference between what makes an older, novice driver risky and that which places young drivers at risk. The characteristics of young, novice drivers which place them at highest risk are believed to relate to a significant--though undetermined-- extent to the characteristics inherent to youth itself (e.g., a sense of immortality, a desire to take risks and seek thrills, vulnerability to peer pressure, etc.) while an older novice driver experiences increased risk primarily due to 
misinterpretation of language, fear or anxiety about driving, or lack of familiarity with the driving task (Insurance Bureau of Canada, 1991).

\section{Situational Factors and Behaviors Contributing to the Problem}

The problems of the young driver may be attributed in part to age-related and to experiencerelated factors. A brief discussion of the most widely recognized problems follows. For a more comprehensive examination of this topic see Basch, De Cicco, and Malfetti (1987); Lemer, Williams, and Sedney (1988); Insurance Bureau of Canada (1991); Ziskind (1991); Young (1993); Lonero, Clinton, Brock, Wilde, Wilde, Laurie, and Black (1995); AAMVA (1995); Comsis (1995); and Mayhew and Simpson (1996).

\section{Age-related factors}

Age-related factors include peer influence/social factors, risk-taking, and alcohol consumption. Various attitudes and motivations of younger drivers serve to reduce their safe driving performance. These factors relate to a lower level of concern for safety and less willingness to exercise responsible, safe driving behavior.

Peer influence/social factors. There is substantial evidence that in the case of young drivers, when teenage passengers are present, their risk of crash involvement increases. This may be attributed to the fact that teenage passengers increase driver distraction and encourage risk-taking behavior (Farrow, 1987; IIHS, 1994). "Extra motives" seem to also play an important role in the elevated crash rates for younger drivers. Competitiveness, popularity, aggression, sense of power and control, independence, or more generally the pursuit of sensual pleasure for its own sake are part of these motives (Naatanen and Summala, 1975; Farrow; 1987; and Evans, 1991).

Risk-taking. Many young drivers are aware of the consequences of risk-taking behavior (i.e., speeding, swerving, driving too closely to another vehicle, lack of seat belt use, etc.), but choose to engage in these behaviors anyway. Many take risks because they believe their reaction times are much faster than the average driver. It has been well documented that crash types associated with risk-taking are much more prevalent in younger drivers (Jonah, 1986; Comsis, 1995; Staplin and Lyles, 1992; Staplin, et al., 1996).

Research has established a clear linkage between lifestyle and risky driving. Some young people adopt a risky lifestyle that is characterized by thrill seeking and health-compromising behaviors, such as smoking, insufficient sleep, and the use of alcohol/drugs. Such young people are also more likely to possess other characteristics, such as impulsiveness, aggression, and social deviance. They also tend to have other problem behaviors (e.g., low grades) and tolerate deviant behavior among peers. Youth who adopt such a lifestyle are more likely than those who adopt a conventional lifestyle to engage in risky driving behaviors, both intentionally and unintentionally, and become involved in more crashes (Insurance Bureau of Canada, 1991; Mayhew and Simpson, 1996).

Alcohol consumption. Alcohol consumption is also an issue. It has been suggested that although younger drivers cited for driving under the influence have a lower BAC than older drivers on average, they are at a greater risk of being involved in a crash since they are both learning to 
drive as well as learning to drink. A recent study suggests that younger drivers are more likely to show impairment at lower BAC than older drivers (Gebers, Romanowicz and McKenzie, 1993). In another study, Jonah (1990) concluded that young drivers who were more likely to report drinking and driving manifested the following characteristics: (1) more likely to believe that they could drink more before becoming impaired; (2) less likely to believe that impaired drivers would be charged; and (3) more likely to report knowing other drivers who have driven while impaired. All of these variables were significantly correlated with self-reported drinking and driving. These results suggest that efforts should be made to educate young drivers about the impairing effects of alcohol, to increase the perceived risk of apprehension for impaired driving either through greater enforcement activity or through greater publicity of enforcement--or preferably both--and to expose young people to role models who do not drive impaired.

\section{Experience-related factors}

These factors involve psychomotor, perceptual, and cognitive skills. Psychomotor skills relate to those skills necessary for "handling" the vehicle (i.e., steering, braking, accelerating); perceptual skills relate to the ability to perceive the driving environment accurately; and cognitive skills relate to the ability to make appropriate decisions and judgments.

Several of these factors play a role in driving safety deficiencies associated with young and novice drivers, including steering and maintaining speed; driving during high risk/nighttime periods; inefficient/inappropriate scanning behavior; hazard recognition; and poor driving judgment/decision making.

Young and novice drivers lack important skills, particularly those needed to acquire and process information. They are less able to maintain full attention and less likely to sample information they need from the driving environment (AAA, 1994). Frequently, driver errors occur in reaction to emergency situations for which driving under emergency conditions provides almost no practice. Other studies have concluded that young drivers have a tendency to speed, use higher approach speeds to intersections, accept shorter gaps, tailgate, and adopt shorter headways (Harrington, 1972; Konecni, Ebbesen, and Konecni, 1976; Evans and Wasielewski, 1983; Jonah, 1986; and Jonah and Dawson, 1987; McKnight and Stewart, 1990; Staplin and Lyles, 1992; Mayhew and Simpson, 1996). Although many factors contribute to crashes among young drivers, the incomplete development of driving skills based on sensory/perceptual response factors is partially linked to the over-involvement of youth in crashes.

Steering and maintaining speed. While a wide range of psychomotor skills are critical to the driving task, young drivers show deficiencies in their ability to integrate skills and perform several of them simultaneously. As a result, reducing steering errors and inappropriate speed choice are identified as being important in reducing the risk of young driver crashes. Novice drivers have difficulty in coordinating steering, lateral positioning and maintaining the appropriate speed (Kimball, Ellingstad, and Hagen, 1971; Blaauw, 1982, Mayhew and Simpson, 1996). They tend to concentrate on performing only one skill at a time. This means they must switch attention from one aspect of the driving task to another rather than dealing with these tasks simultaneously. This increases the demand of the driving task, to the point where the capacity of the young driver to process and respond to information in a limited timeframe may be exceeded, overloading his/her 
abilities. Thus, novice drivers perform less efficiently and effectively than experienced drivers (Mayhew and Simpson, 1996).

To make matters worse, researchers have noted that young drivers typically do not perceive speeding as risky. Yet it is associated as a major factor in many crashes and violations in which they are involved (Evans, 1991). Research suggests that the primary underlying mechanisms in speeding among novice drivers are lack of high-level decision-making skills, inadequate experience, and poor integration of tasks (Kimball, et al., 1971, Blaauw, 1982, Huston, 1986; Evans, 1991; and Ziskind, 1991).

Driving during high risk periods. The AAMVA (1989) and Williams (1985) identified driving at high risk hours, especially at night, as an explanation for high crash involvement of young drivers. In a recent crash involvement study, it was concluded that novice drivers between the ages of 16-19 have the highest nighttime fatality rate among any other age group, due to factors such as not compensating for reduced visibility, fatigue, and higher incidence of alcohol use (Massie, Campbell, and Williams, 1995). Figure 5 illustrates this finding.

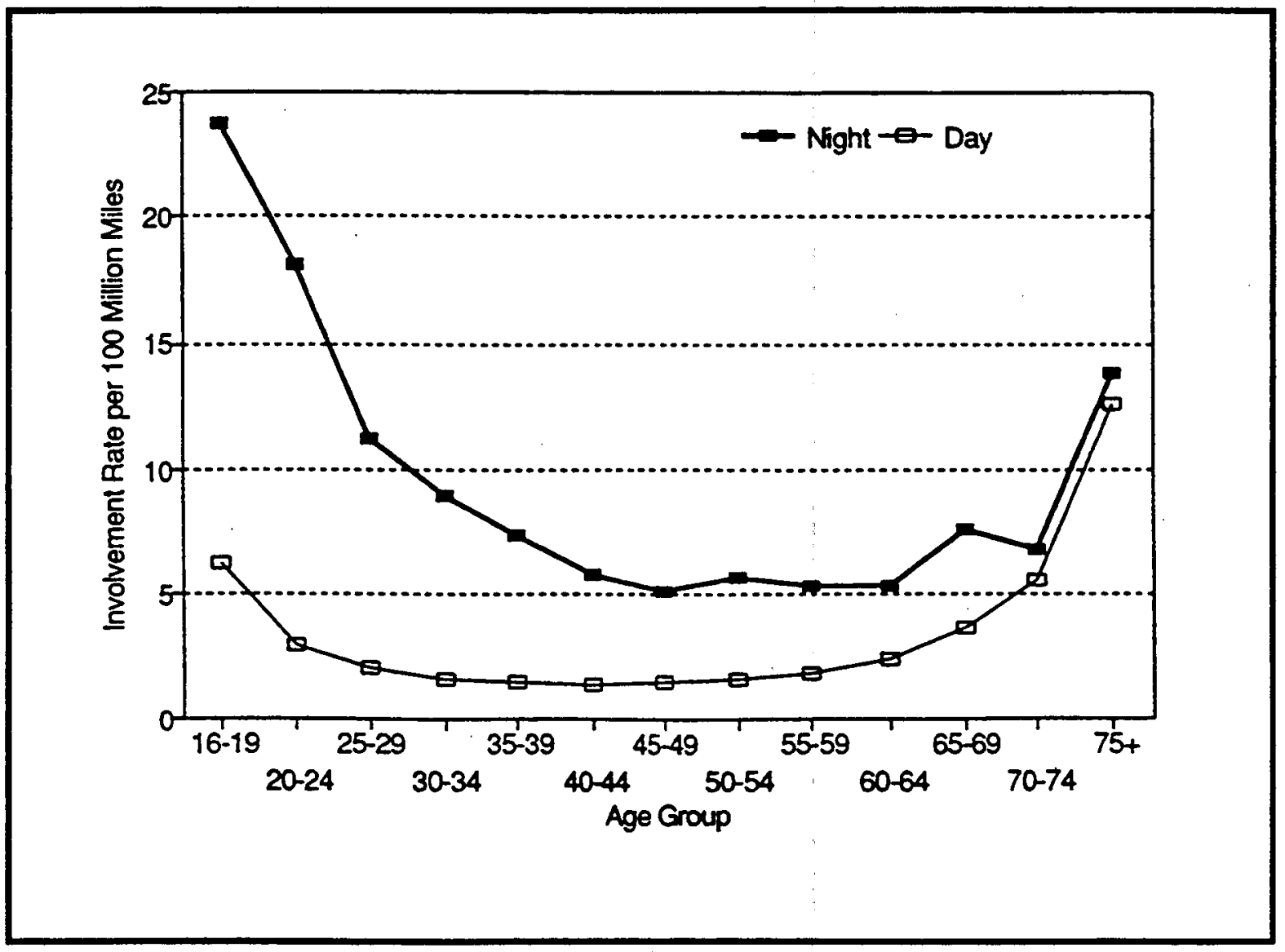

Figure 5. Fatal involvements by age and day vs. night (Massie, Campbell and Williams, 1995). 
Inefficient/inappropriate scanning behavior. It has been reported that experienced drivers use their eyes differently than novice drivers, by scanning the road ahead, while inexperienced drivers fixate on specific objects (i.e., a road sign, the curb, the hood of their car) (Ziskind, 1991). Young drivers fail to make effective use of information registered in their periphery (Mayhew and Simpson, 1996). Mourant and Rockwell (1970) reported that in the first hours of driving experience, drivers tend to scan over a wide area, including points well above the horizon. After approximately one month's driving experience, the fixations are more confined in the vertical direction, but still vary a great deal horizontally; and after three months' experience, eye-fixations are more concentrated at the focus of expansion of the roadway, with a much greater reliance on peripheral vision for cues to control the vehicle's lateral position in the lane. In a later study comparing novice and experienced drivers, Mourant and Rockwell (1972) found additional evidence that as drivers gain experience, they concentrate their eye fixations in a smaller area. Novice drivers looked closer in front of the vehicle and more to the right of the vehicle's heading than did experienced drivers. They found that novice drivers frequently sample the curb to estimate the vehicle's lane location, and sample rear-view mirrors much less frequently than the experienced drivers. They concluded that novice drivers are unskilled and overloaded in their visual acquisition task. These studies suggest that as experience is gained, peripheral vision is used more to locate the vehicle in the lane, with fixations focused further down the road to allow more time to process information that becomes of increasing relevance as the vehicle's speed increases.

Hazard recognition. Confirming and extending the findings of Mourant and Rockwell, (1972); Groeger and Brown (1989) reported that there is a difference between novice and experienced drivers in their ability to detect or recognize imminent hazards in the driving environment. Their study suggested that novice drivers scan their environment less efficiently than do experienced drivers. Mayhew and Simpson (1996) summarize several problems young and novice drivers have, compared to more experienced older drivers, in detecting hazards. They lack good hazard detection skills, are less aware of hazards, are more likely to identify stationary objects as hazards, less likely to identify moving objects as hazards, take longer to perceive and respond to hazards, and identify fewer hazards. There are also other perceptual skill differences between novice and experienced drivers. Groeger and Brown (1989) reported that young, novice drivers did not differ from older drivers in identification of near hazards; however, young drivers are poorer at identifying distant hazards and are less likely to respond to a set of simulated traffic hazards than older drivers.

There is also evidence that inexperienced drivers fail to recognize road signs. Naatanen and Summala (1975) reported that inexperienced drivers missed more signs than experienced drivers, even when instructed to pay attention to the road signs.

Poor driving judgment/decision making. Driving judgment in the present research context is concerned primarily with the awareness (or lack of awareness) of risk-taking behaviors. Driver risks involving poor judgement or decision making due to lack of awareness or knowledge tend to be associated with experience-related factors (Jonah, 1986). Research shows that young drivers generally tend to underestimate the risk involved in certain driving situations, but overestimate their own driving ability and ability to avoid crashes. They perceive themselves as less vulnerable to a crash than their peers (Bragg and Finn, 1982; Finn and Bragg, 1986; Jonah and Dawson, 1987; Jonah, 1990; Mayhew and Simpson, 1996). In fact, the higher crash rates at intersections for younger drivers may be partially explained by the differences in risk perception among young drivers. Lerner, Williams and Sedney (1988) reported that when approaching an intersection, the 
risk ratings of youngsters tended to either drop or stay the same, while older subjects showed a sharp increase in risk ratings at the same point. These results are similar to those found for merging onto an interstate or arterial. Young drivers are also more likely than older drivers to follow too closely, leaving shorter headways (Evans and Wasielewski, 1983; Jonah, 1986), and are more likely than older drivers to engage in tailgating. Teenagers are also about five times more likely to get into a left-turn crash than adult drivers, except for the "old-old" (75+) age group. They have difficulty in deciding when a turn can be performed safely, do not provide themselves with adequate time to judge the situation, and often underestimate their own speed and that of oncoming vehicles (PennDOT, 1992).

In summary, young and novice drivers have not yet mastered the ability to make appropriate decisions in a wide variety of driving situations. A problem is that beginners face a myriad of decisions that always involve several options or conflicting alternatives. Often these decisions involve judgments of uncertain events that may have unknown consequences (e.g., vehicle approaching from a hidden view), and although such decisions can be influenced by many factors, the basic ability to make appropriate decisions and solve problems encountered on the road is rooted in experience, which provides the foundation of cues for generating expectancies-- i.e., inducing from particular experience in past situations about what might be expected now. The experienced driver applies this knowledge gained from past experience to new situations that have similar characteristics. The young driver lacks this experience and is therefore at a disadvantage. To improve their decision making abilities, young and novice drivers need to acquire the benefits of experience earlier in the learning curve (Mayhew and Simpson, 1996).

\subsection{TRAINING ELEMENT CRITERIA}

Training elements must have specific selection criteria in order to be effective for training novice drivers. Each training element considered for simulation and other electronic device applications was evaluated according to the following criteria:

- An association with driving skills, characteristic of experienced drivers must be established to insure valid training procedures.

- The "trainability" of a given deficiency, preferably in a relatively short time frame and with lasting effects is essential.

- A given deficiency (to be corrected through training) must be recognized as a "novice driver problem."

- Training outcomes must clearly be associated with improved safety, not merely an increase in skill level.

- Psychomotor skills components, when embedded in training procedures, should not violate control movement sequences required for a subject driving task/scenario.

For the first criterion, association with critical driving skills, validity with training is important. Although there are many types of validity, the primary concern with training is external validity which is the extent to which the training measures generalize to actual driving performance. 
External validity can be enhanced by including one or more of the following components:

- Multiple-task paradigm - More than one task must be performed concurrently in order to impose realistic workloads on trainees.

- Speeded responses - Because of the importance of the rate of information processing in driving, all responses in the training task should be timed.

- Dynamic, cluttered visual scenes - Performance must be emphasized within a "rich" visual context containing distractors within a dynamic (moving) scene.

- Representative levels of uncertainty - Care must be taken to minimize the extent to which trainees can predict when a stimulus will occur, where in the visual field it will be presented, and/or what the stimulus will be.

The second criterion, trainability, is important because not every driver skill deficiency identified as a problem for novice drivers (and other groups) can be easily remedied through training. As one consequence, training elements intended to alter perceived risk are of dubious value. Although young and novice drivers clearly misperceive risk (Lerner, Williams, and Sedney, 1988), it is highly questionable whether training will have a direct impact in enhancing risk perception. The factors that underlie risk perception are not well-understood and they may be related to factors other than driving experience (e.g., maturation, social, situational). Even if it is assumed that risk perception could be improved among young and novice drivers, the feedback mechanisms are too random in behind-the-wheel driving to reinforce such training. At the same time, this does not mean that training cannot incidentally impact risk perception. Enhanced perception of risk may be facilitated as the result of enhanced perception of the roadway environment through knowledge and visual/perceptual and motor skills training, which serve as surrogates for experience.

There are also transfer-of-training issues to consider. This concern is with how the training is implemented which, in turn, influences how much of the training transfers to the driving task. It has been suggested (Gopher, Weil, and Baraket, 1994) that transfer-of-training is highest when whole-task, as opposed to part-task, methods are used. In whole-task training, the time to reach a criterion level of performance may be longer than part-task training. However, the time to reach criterion performance on the real-world task (e.g., driving) is significantly faster for those trained using a whole-task approach. Thus, if the goal is quick training to criterion then the research suggests use part-task training. If the training goal is maximum transfer-of-training--as in driver training using simulation--the whole-task, or at least a multiple-task, approach is desirable. Gopher, Weil, and Bareket (1994) suggest a hybrid approach which combines the best of both methods. Specifically, at all times the trainees must perform the whole task but they are instructed to emphasize various components of the whole task in their performance (termed emphasis-change training). It is presumed that this method works best because it trains attention strategy on complex tasks. Attention strategy is defined as the vector of attention weights assigned to each of the covarying elements of a complex task (Gopher, 1982). This is simply not learned in a strictly parttask (i.e., single-task) training methodology. Thus, emphasis-change training will be advocated in the development and implementation of training targets as discussed next. 
Although positive transfer-of-training is typical for simulation studies, simulations do not always result in the best transfer. Baron and Williges (1975) investigated the effects of two types of pre-training. Positive transfer was demonstrated for students who viewed 6 hours of instructional driving films and for a separate group of students using an open-loop simulator. However, the simulator group had more steering errors than the film group during the first road test. The implication is that only driving tasks that result in relatively high transfer-of-training should be identified as training targets for driving simulation.

What training targets result in high transfer-of-training? Data presented by Staplin, Lococo, and Sim (1993) suggest that valid gap acceptance judgments are more likely to be obtained from displays with correct perspective and high resolution. Whereas the former constraint can be preserved with most displays, the resolution of CRT-based displays is marginal for many driving tasks. Thus, the technological constraints of specific simulation platforms are important to consider if the implementation of training targets that require detection and/or recognition of targets with small visual angles (e.g., reading a traffic sign), detection of near-threshold motion cues (e.g., subtle differences in relative velocity caused by lead-vehicle braking), or wide fields-of-view (e.g., making a left turn at an unsignalized intersection) is desired.

It is also acknowledged that training will exclude many social/personality influences which can contribute directly or indirectly to the crash over-involvement among young and novice drivers. Can such influences be changed through training exercises? It is believed that visual/perceptual and knowledge skills training may indirectly minimize the negative effects of social/personality factors. Most driver instruction programs address such issues using knowledge-based techniques. For example, teaching young and novice drivers about the effects of alcohol have been explained using "alcohol impairment charts" which show the effects of alcohol, by body weight and levels of impairment, and the legal limits. However, non-traditional type training for these social influences may be possible. For example, special goggles have been developed to simulate perceptual and motor impairments due to alcohol consumption. In driver training, performance with and without the goggles could be used to provide trainees with direct, immediate feedback regarding the magnitude of simulated alcohol-related performance deficits. Regardless of whether this feedback contributes to safer driving, the approach can be justified simply on the basis that it provides more effective information than knowledge-based training alone.

Regarding the third criterion, training must focus upon the specific deficiencies associated with young and novice drivers, such as inability to compensate for reduced visibility conditions, inefficient/inappropriate scanning behavior, poor hazard/sign recognition, and poor driving judgment and decision making. Knowledge-based training target procedures also deserve mention; despite a lack of empirical evidence to determine the most effective training formats and procedures, basic driving skills and an understanding of the "rules-of-the-road" do define a core set of training elements.

The fourth training selection criterion, emphasizes that evaluation criteria must be developed that are explicitly safety-based. This criteria gives higher weight to safety (e.g., target detection) in evaluating trainee performance. On the other hand, skill-based criteria place more weight on meeting a particular goal (e.g., minimum time to destination under high workload conditions) with little or no reward for safety aspects of performance. To illustrate this distinction, consider skills that might be learned from playing a video arcade game such as Atari's Hard Drivin'. Intuitively, 
it may seem that high performance on this game would yield increases in skill which generalize to behind-the-wheel driving. Skill-based criteria are provided to the game player, and the game does facilitate hand-eye coordination and scanning behavior under high workload conditions which are all characteristics of good training protocols (such as safety-based training) that will be advocated in the following discussion. However, games such as this reward responses that would generally be considered dangerous driving behaviors. This example illustrates the importance of careful selection of training criteria to evaluate trainees' performance with simulation, since this is the most direct feedback provided to trainees.

The last criterion in the list of selection criteria for training targets, indicates that appropriate psychomotor skills components should be embedded within training target procedures. This does not require specialized peripherals (such as a steering wheel). Although such peripherals are readily available for gaming devices at a unit cost of approximately $\$ 100$ (1995 dollars), costs to equip the home user or even large-scale training facilities (e.g., school) may preclude their use for this project's purposes. For the simulation applications intended, trainees must certainly be able to interact with the training device; however, the exact nature of the response may not be critical.

Even so, two aspects of the response hardware are assumed to be critical to minimize negative transfer-of-training: (1) psychomotor response integration and response competition must be an aspect of training and (2) the same effectors (e.g., hands for steering control, feet for accelerator/brake control) must be required for the responses. Psychomotor response integration is a more specific example of skill integration that is important in training complex tasks, such as driving. Skill integration involves learning to coordinate skills that are perceptual, cognitive, or psychomotor. Since coordination must take place within and among these categories, psychomotor response integration is a special case of skill integration in which the coordination of multiple psychomotor responses needs to be trained.

\subsection{PRE-WORKSHOP TRAINING ELEMENT SELECTIONS}

Through the course of the literature review activities, several training elements were formulated as meeting the selection criteria previously outlined. These training elements were divided into two categories: general abilities and specific driving skills.

\section{General Abilities Training Elements}

General abilities training elements are fundamental visual/perceptual information processing skills with potential benefits for a wide range of specific driving skills. When training general abilities, it is assumed that skills developed will generalize to a wide range of driving tasks. As an example, training that emphasizes scanning the environment for potential hazards would have benefits for multiple driving tasks such as lane changing, speed choice, and left turn decisions.

At the same time, caution is warranted. Competence on a general ability may only be loosely, or not at all, related to competence for specific driving skills for at least two reasons: (1) there are typically many underlying mechanisms involved in a specific driving task, and (2) it is the efficient allocation among these underlying mechanisms that results in competence performance. In addition, although general abilities training targets are components of specific driving skills, this does not imply that they must necessarily be implemented in a part-task (i.e., single-task) training protocol. 
What will be advocated in the following discussion is that training targets be performed in a driving context at all times and that specific components within the task be emphasized (Gopher, et al., 1994). This ensures that trainees learn efficient resource allocation strategies for specific driving skills.

In addition, all of the identified training elements can be implemented as either self-paced or task-paced procedures. In self-paced mode, the trainee is in control of the stimulus event rate of the task either by controlling apparent vehicle speed, automatic adjustment of the presentation rate based on the trainee's performance, or some combination of these techniques. Although this has more face validity for a simulated driving task, it will tend to produce ceiling effects in performance which reduces the procedure's diagnosticity. Self-paced modes of training can be given for initial training as well as at various events along the training course to facilitate familiarization with the training procedure. Following this, the event rate should be controlled by the task (i.e., task-paced) and standardized among observers. In addition, instructions for each general abilities training element can be provided through hard copy (i.e., worksheet, booklet, etc.) or through the display monitor of the device using CBI. The amount of CBI (in terms of embedded instructions/visuals, format of presentation, etc.) will vary depending on the design, storyboard, and costs for developing each training element. The intent of all the training elements is primarily for individual instruction with the assumption that users can either access PCs at home, school, or business; or be able to use more portable devices in any setting. However, there is no compelling reason to dismiss the notion that these training elements could not be used in a classroom environment with an instructor.

The following general abilities training elements were identified in the literature review: (1) scanning behavior, (2) useful field-of-view (UFOV), (3) peripheral visual performance, (4) foveal visual performance, and (5) visual performance degradation feedback. Table 2 summarizes a description of these training elements.

\section{Specific Driving Skills Training Elements}

Specific driving skills training elements combine a number of general abilities in the training of a driving skill. These targets can be readily implemented within a multiple-task training protocol. One advantage of specific skills training is high face validity. However, for some of the driving skills identified, external validity may be limited by the hardware (i.e., resolution and FOV). Specifically, driving tasks that involve detecting motion cues for distant targets (e.g., when making a decision to overtake a lead vehicle on a two-lane rural road) and/or targets displaced more than 30 degrees left or right of the forward line of sight (e.g., when making decisions to merge at the end of a highway on-ramp or driving scenarios that involve overhead views) are difficult or impossible to simulate with low-cost simulators. Fortunately, many driving tasks do not require high resolution/large field-of-view displays. For those driving tasks that do "push the limits" of available technology, innovative techniques can be used to put the demands of the driving task for resolution/FOV within the system capability for low-cost simulator platforms.

The following specific driving skills training elements address problem areas for novice drivers. These training elements include hazard anticipation, headway choice, gap judgment, and reaction to emergency situations, which deal with specific driving situations, and can potentially be implemented using low-cost simulation technology. 
Table 2 . Description of General Abilities Training Elements, their implementation and difficulties as related to PCs, consoles, and hand-held devices.

\begin{tabular}{|c|c|c|c|c|}
\hline $\begin{array}{l}\text { Training } \\
\text { Elements }\end{array}$ & Definition & Implementation & Dimriculties for Devices & Platiorm(s) \\
\hline $\begin{array}{l}\text { Scanning } \\
\text { Behavior }\end{array}$ & $\begin{array}{l}\text { Scanning Behavior requires combinations of } \\
\text { eye, head, neck, and upper torso movements } \\
\text { to foveally acquire information from areas in } \\
\text { the road environment where potential } \\
\text { hazards exist. }\end{array}$ & $\begin{array}{l}\text { Trainee must acknowledge } \\
\text { cueing targets (such as LEDs), } \\
\text { placed in strategic locations. } \\
\text { These locations depend upon the } \\
\text { type of maneuver presented to the } \\
\text { trainee. }\end{array}$ & $\begin{array}{l}\text { Direct scanning of adjacent } \\
\text { lanes cannot be implemented } \\
\text { via large FOV required. } \\
\text { Alternatively, mirror } \\
\text { scanning/sampling can be } \\
\text { trained using video/graphic } \\
\text { overlays. }\end{array}$ & $\begin{array}{l}\text { Personal Computer } \\
\text { Console (Set-Top) }\end{array}$ \\
\hline $\begin{array}{l}\text { Useful Field } \\
\text { of View } \\
\text { (UFOV) }\end{array}$ & $\begin{array}{l}\text { Useful Field of View is a measure of the } \\
\text { ability to detect and recognize targets } \\
\text { concurrently presented in peripheral vision } \\
\text { while maintaining criterion performance on a } \\
\text { central vision task. It has also been shown to } \\
\text { be sensitive to visual attentional deficits } \\
\text { which would not be detected by standard } \\
\text { perimetry. }\end{array}$ & $\begin{array}{l}\text { Typical implementation uses a } \\
60^{\circ} \text {, circularly symmetric FOV. } \\
\text { Assuming that the vertical FOV } \\
\text { can be reduced somewhat, a } 60^{\circ} \\
\text { horizontal FOV can be realized } \\
\text { with current display technology. }\end{array}$ & $\begin{array}{l}\text { May not be amenable to } \\
\text { existing hand-held gaming } \\
\text { device platforms due to their } \\
\text { small display size. }\end{array}$ & $\begin{array}{l}\text { Personal Computer } \\
\text { Console (Set-Top) }\end{array}$ \\
\hline $\begin{array}{l}\text { Peripheral } \\
\text { Visual } \\
\text { Performance }\end{array}$ & $\begin{array}{l}\text { Peripheral Visual Performance is the ability } \\
\text { to extract motion and orientation cues using } \\
\text { peripheral vision only. Experience makes } \\
\text { lane-keeping an automatic task, and foveal } \\
\text { vision is no longer required. }\end{array}$ & $\begin{array}{l}\text { Provide a fixation point near the } \\
\text { focus of expansion in the driving } \\
\text { scene, and require trainees to } \\
\text { fixate upon it while performing a } \\
\text { steering task. Once a criterion } \\
\text { level of proficiency has been } \\
\text { reached in this task, a second task } \\
\text { would be added to train response } \\
\text { integration and resource } \\
\text { allocation strategies. A } 60^{\circ} \\
\text { horizontal FOV is minimally } \\
\text { adequate for obtaining sufficient } \\
\text { orientation information. }\end{array}$ & $\begin{array}{l}\text { Since the central task requires } \\
\text { detecting distant targets, the } \\
\text { angular size of each pixel in the } \\
\text { display must approach the } \\
\text { resolution limit for a normal } \\
\text { observer. Implementation ' } \\
\text { would require a reduced } \\
\text { horizontal FOV (i.e., }<60^{\circ} \\
\text { horizontal FOV)and/or larger } \\
\text { angular pixel sizes. }\end{array}$ & $\begin{array}{l}\text { Personal Computer } \\
\text { Console (Set-Top) }\end{array}$ \\
\hline
\end{tabular}


Table 2 (Con't). Description of General Abilities Training Elements, their implementation and difficulties as related to PCs, consoles, and hand-held devices.

\begin{tabular}{|c|c|c|c|c|}
\hline $\begin{array}{l}\text { Training } \\
\text { Glements }\end{array}$ & Definition? & Implementation & Difriculties for Devices & Platform(s) \\
\hline $\begin{array}{c}\text { Foveal } \\
\text { Visual } \\
\text { Performance }\end{array}$ & $\begin{array}{l}\text { Foveal Visual Performance involves judging } \\
\text { distance and time-to objects, while varying } \\
\text { amounts and directions of motion relative to } \\
\text { the trainee's perspective. }\end{array}$ & $\begin{array}{l}\text { The trainee is asked to press a } \\
\text { button when they perceive the } \\
\text { target to be a set amount of time } \\
\text { from their simulated perspective } \\
\text { view. It is critical that the } \\
\text { stimuli, whether they are filmed } \\
\text { road scenes or computer } \\
\text { generated graphics, are presented } \\
\text { in correct perspective. }\end{array}$ & $\begin{array}{l}\text { To avoid ceiling effects in } \\
\text { training foveal visual } \\
\text { performance, the display must } \\
\text { have high angular resolution } \\
\text { (less than } 1 \text { min arc per pixel) } \\
\text { to minimize temporal artifacts } \\
\text { "jumpiness" in the graphics. }\end{array}$ & Personal Computer \\
\hline $\begin{array}{l}\text { Visual } \\
\text { Performance } \\
\text { Degradation } \\
\text { Feedback }\end{array}$ & $\begin{array}{l}\text { Visual Performance Degradation Feedback is } \\
\text { used to demonstrate the hazards which are } \\
\text { associated with night driving (and alcohol } \\
\text { consumption). One way in which hazards } \\
\text { can be demonstrated is through simulated } \\
\text { degradation (i.e., specialized goggles). }\end{array}$ & $\begin{array}{l}\text { The trainee wears special goggles } \\
\text { while performing the tasks for } \\
\text { which they have been trained to } \\
\text { some acceptable level of } \\
\text { performance. To simulate } \\
\text { reduced visibility conditions, a } \\
\text { representative level of neutral } \\
\text { density could be interposed } \\
\text { between the trainee's eyes and the } \\
\text { CRT screen. }\end{array}$ & $\begin{array}{l}\text { None, since simulated } \\
\text { degradation is independent of } \\
\text { the display. }\end{array}$ & $\begin{array}{l}\text { Personal Computer } \\
\text { Console (Set-Top) } \\
\text { Hand-Held }\end{array}$ \\
\hline
\end{tabular}


Each of the following training elements can be implemented as either self-paced or task-paced procedures. However, it is suggested that self-paced modes of training should be limited to initial training and at various events along the training course to facilitate familiarization with the training procedure, then followed by task-paced procedures. Like the general abilities training elements, specific driving skills training elements can also use hard copy instructions or some degree of CBI involvement. The amount of CBI to be used for each training elements, will vary depending on the design, storyboard, and costs. The intent of these specific driving skills training elements is for individual instruction. Again, however, the notion that these training procedures could be used in a classroom environment with an instructor should not be dismissed. Table 3 summarizes a description of these training elements.

\section{Knowledge-Based Training Elements}

Knowledge-based training elements have traditionally involved classroom settings with instructors teaching topics developed from a lesson plan, and students using course material and instructional books to complement the formal instruction. Self-instruction courses are also available; they include traditional instructional material, but also offer audio and video components in their approach. Text instruction (including multimedia) does not require high visual fidelity for the display, and therefore could accommodate all types of display and aforementioned device platforms. At the current time, CBI formats using PC-based platforms are available on the market.

\section{Other Issues (Incidental Learning)}

Incidental learning refers to those aspects of training that are not intentionally designed into the training procedure a priori but may have implications for the safety of behind-the-wheel driving. Occasionally, incidental learning can be linked to limited or negative transfer-of-training as well as unexpectedly high transfer-of-training. Limited transfer might result, for example, if the training targets gave trainees higher incentives for finishing a route in the minimum time rather than rewarding peripheral object detection. Although this would never be intentionally designed into a training element, the payoff matrix (or system rewards and punishments for trainee responses) that is set up may not be perceived the same way by different trainees. In other words, the incentive value of a particular reward or punishment is highly subjective. Clearly, the incentives provided to trainees must be explicit, adjusted to individual capabilities and limitations, and carefully selected to avoid this situation.

Incidental learning can also result in spurious training improvements and, therefore, negative transfer-of-training. This is a significant problem for training because it is extremely difficult or impossible to simulate certain aspects of the driving environment. As an example, the maximum temporal uncertainty (that is, when an object appears) is limited by the session length. Since the temporal uncertainty in actual driving is much higher, object detection performance on the training elements may not generalize. However, if care is taken to randomly vary the inter-stimulus interval, trainees will not learn any temporal rhythms that would allow them to adjust their level of alertness in anticipation of stimulus onset. In addition, other types of uncertainty (such as spatial and stimulus uncertainties) can be used to minimize anticipatory responses. 
Table 3. Description of Specific Driving Skills Training Elements, their implementation and difficulties as related to PCs, consoles, and hand-held devices.

\begin{tabular}{|c|c|c|c|c|}
\hline $\begin{array}{l}\text { Training } \\
\text { Elements }\end{array}$ & Definition & Implementation & Difriculties for Devices & Platiorm $(\mathrm{s})$ \\
\hline $\begin{array}{c}\text { Hazard } \\
\text { Anticipation }\end{array}$ & $\begin{array}{l}\text { Hazard Anticipation is the ability to make } \\
\text { appropriate speed, lane change and } \\
\text { braking responses in anticipation of } \\
\text { potential hazard and/or changing } \\
\text { demands. }\end{array}$ & $\begin{array}{l}\text { The trainee responds to potential } \\
\text { hazards by making an appropriate } \\
\text { brake steering or accelerator } \\
\text { adjustment which, in turn, controls } \\
\text { the simulated road scene. Feedback } \\
\text { for inappropriate responses to } \\
\text { potential hazards would be given in } \\
\text { terms of simulated driving outcomes } \\
\text { and tutorial feedback describing } \\
\text { appropriate response(s). }\end{array}$ & $\begin{array}{l}\text { Ideally, simulation platforms } \\
\text { for this type of scenario must } \\
\text { have both high resolution and } \\
\text { high horizontal FOV. As for } \\
\text { peripheral visual performance, } \\
\text { it may be possible to design } \\
\text { scenarios that can be } \\
\text { implemented on PCs and } \\
\text { Consoles (Set-Top). }\end{array}$ & $\begin{array}{l}\text { Personal } \\
\text { Computer } \\
\text { Console (Set-Top) }\end{array}$ \\
\hline $\begin{array}{c}\text { Headway } \\
\text { Choice }\end{array}$ & $\begin{array}{l}\text { Headway Choice is the ability to maintain } \\
\text { appropriate "safe" distance with other } \\
\text { vehicles on the road. }\end{array}$ & $\begin{array}{l}\text { Similar to that for hazard } \\
\text { anticipation, except that the targets } \\
\text { are lead vehicles with initially zero } \\
\text { velocity difference (relative to the } \\
\text { traince's perspective) followed by a } \\
\text { sudden, unpredictable deceleration of } \\
\text { the lead vehicle. }\end{array}$ & $\begin{array}{l}\text { Simulation is particularly well- } \\
\text { suited for training appropriate } \\
\text { Headway Choice since the } \\
\text { target distances are near; and } \\
\text { the targets are typically } \\
\text { centered in the forward line of } \\
\text { sight. The requirement for } \\
\text { correct perspective makes the } \\
\text { hand-held platform unusable. }\end{array}$ & $\begin{array}{l}\text { Personal } \\
\text { Computer } \\
\text { Console (Set-Top) }\end{array}$ \\
\hline
\end{tabular}


Table 3 (Con't). Description of Specific Driving Skills Training Elements, their implementation and difficulties as related to PCs, consoles, and hand-held devices.

\begin{tabular}{|c|c|c|c|c|}
\hline $\begin{array}{l}\text { Training } \\
\text { Elements }\end{array}$ & Definition & Implementation & Difficulties for Devices & Platform(s) \\
\hline $\begin{array}{c}\text { Gap } \\
\text { Judgement }\end{array}$ & $\begin{array}{l}\text { Gap Judgement is the ability to } \\
\text { appropriately assess the safe distance } \\
\text { between the driver's vehicle and other } \\
\text { vehicles which could lead to conflict. }\end{array}$ & $\begin{array}{l}\text { As an example, the trainee is } \\
\text { presented with opposing traffic when } \\
\text { making a left turn. The gaps between } \\
\text { cars in the opposing lane(s) get } \\
\text { progressively larger. }\end{array}$ & $\begin{array}{l}\text { The critical cues for Gap } \\
\text { Judgement are for distant } \\
\text { targets, high resolution is } \\
\text { important. Otherwise, there } \\
\text { may be a ceiling effect in the } \\
\text { performance of all trainees. } \\
\text { Hand-held devices offer low } \\
\text { potential due to insufficient } \\
\text { display resolution. }\end{array}$ & $\begin{array}{l}\text { Personal } \\
\text { Computer } \\
\text { Console (Set-Top) }\end{array}$ \\
\hline $\begin{array}{l}\text { Reaction to } \\
\text { Emergency } \\
\text { Situations }\end{array}$ & $\begin{array}{l}\text { Reaction to Emergency Situations } \\
\text { addresses the ability to react appropriately } \\
\text { in emergency situations. }\end{array}$ & $\begin{array}{l}\text { May be used as the last segment of a } \\
\text { trial involving other training } \\
\text { elements. For example, if warning } \\
\text { about icy bridge is not acknowledged } \\
\text { during Hazard Anticipation, this puts } \\
\text { the trainee in an emergence situation } \\
\text { (i.e., a skid, decreasing gap). }\end{array}$ & $\begin{array}{l}\text { Since highly interactive } \\
\text { simulators are required for the } \\
\text { highest generalizability of } \\
\text { emergency reaction skill } \\
\text { training. Knowledge-based } \\
\text { procedures are more desirable. }\end{array}$ & $\begin{array}{l}\text { Personal } \\
\text { Computer }\end{array}$ \\
\hline
\end{tabular}


Incidental learning can also result in positive transfer. Although motivational aspects of simulated driving games would seem inappropriate for driver training, assuming that the skill integration learned from such highly demanding games seems reasonable would have some benefit to driving. In addition, games which present stimuli with no obvious relationship to driving tasks may nevertheless foster the development of strategies which generalize to appropriate responses in specific traffic scenarios.

\subsection{SIMULATION TECHNOLOGY}

Driving simulation is used in driver training, testing, and research for its uniformity and standardization, economy, and safety. It provides a controlled environment to prevent risks associated with training or testing in actual traffic, and it eliminates extraneous events (e.g., unexpected vehicle movement) that would affect the training/testing protocol. Potential uses for driving simulation devices include human factors research; development and evaluation of training, screening, certification, and licensing systems; and highway and automobile design and design evaluation (Weir and Clark, 1995; Evans, 1991). Today's driving simulation devices range in complexity and cost depending on the application.

This section provides a brief discussion on the history of driving simulation; computer-based instruction (CBI); low-level simulation technology; and mid/high-level simulation.

\section{Driving Simulation}

Driving simulation dates back to the early 1910 s, when the first mechanical and electrical tests were developed to evaluate the skills and competence of public transit operators. Many of these early devices used a moving conveyor belt protocol. Various stimuli were placed on these moving conveyor belts to test subjects' responses as the stimuli moved though the field of view. By the late 1920s, scale model vehicles were mounted on these conveyor belts, which were painted with the images of a roadway. By the 1930s, dummy automobiles were used to test for braking reaction, steering, speed and timing estimation, and other abilities. Mechanical moving scenes were used. A device used for measuring driver's reactions was also developed at this time for the University of California at Berkeley for the California Department of Motor Vehicles (Marowitz, 1991). Driving simulation at Berkeley resumed after World War II, using a device in which the subject sat behind the wheel and viewed filmed road scenes projected on a screen in front of a car body (Wachtel, 1995).

By the 1950s, conveyor belt systems were still being used, but were gradually being replaced by two other types of simulation approaches: (1) point light source or shadow-casting, and (2) film. Point light source simulators used a clear plexiglass disk approximately 4 feet in diameter. Road markings and scale models of roadside features could be placed on the surface of the disk and, through use of a point light source, appeared as dark silhouettes against a bright roadway surface. The subject sat in a vehicle cabin mockup and controlled acceleration and brake responses which in turn controlled the disk's rotation speed. In addition, steering wheel inputs controlled the angular motion of the rotating disk (Barrett, Alexander, and Forbes, 1973). Towards the latter half of the 1950 s, the filmed approach to driving simulation became predominant. In this approach, a filmed driver's-view image was projected on a screen, sometimes accompanied by a sound track of road sounds. Subjects sat in a car mockup or an actual vehicle cab, and had use of controls, however, 
their control inputs did not change the driving scenes (Wachtel, 1995). Aetna Life and Casualty was one of the first companies to license manufacturers to produce driver training simulator systems using film in this time period (Doron Precision Systems, Inc., 1995).

By 1961, film approach simulators were in use at several locations, including: Ford and General Motors, the American Automobile Association, and Aetna (Marowitz, 1991). Other projection system type simulators were also developed during this time, including those by Rockwell Manufacturing Company, U.S. Armed Forces, Liberty Mutual Insurance Company, Ohio State University, Goodyear Aerospace Corporation, and Miles Electronics Ltd. (Hulbert and Wojcik, 1964). A literature review, which covered the time period of the 1950 s and 1960 s revealed that most studies were employing a wide variety of visual displays for the filmed approach, including: TV projected image, TV monitors, videotape, direct optical, film, and the point-light source rear projection simulator. These early studies examined the effects of alcohol and drugs, emergency responding, speed judgment, steering, vehicle lighting and visibility, and physiological conditions. Field validations were also conducted to make comparisons between data obtained in the simulators and in real world settings. Variables measured included speed, steering, braking, signaling, lane position, stopping distance, reaction and detection time, eye movements, and tracking accuracy (Barrett, et al., 1973). By 1970, it was reported that 28 simulator devices were in use throughout the world (Hulbert and Wojcik, 1972). Only one study was identified from these early literature reviews that identified comparisons between younger and older driver performance; the variables measured included speed, braking, steering, galvanic skin response, and breathing rate (Case, Hulbert, and Beers, 1970).

By the mid-1970s, use of film projection technology continued to incorporate approaches to give the systems a degree of interactivity, so that the driver's actions on the simulator controls could have some influence on the road scene being observed. These approaches included controlling film playback speed based on subject's accelerator/brake action, using multiple camera cars to create views from multiple lanes for lane changing maneuvers, and filming multiple routes to handle subject's route choices at intersections using a computer interface between the simulator and driver controls. However, it was realized that photographic imagery was very limiting (i.e., the original recorded film footage has fixed traffic behavior, thus the subject cannot effect any change in the scene); and in order to obtain a higher degree of interactivity, synthetic models of roadway environment (either terrain or computer-generated images) were needed (Wachtel, 1995).

Terrain models were used extensively in the 1970s. They involved using miniature reproductions of the roadway, environment, and other roadway users with an optical system and a mechanism for moving the optics through the model. The optical system can be moved along the model's roadways under computer control on command of the experimenter and the resulting driver's-eye view filmed or videotaped for later playback. Sophisticated vehicle and operator actions can be simulated by pivoting the lens. Other objects in the scene can be moved with hidden wires or magnets. The most sophisticated applications of this technology allow the subject to drive through the model in real time by operating the controls (steering wheel, brake, and accelerator) that maneuver the gantry-mounted camera over the terrain board (Wachtel, 1995).

By the early 1980s, computer generated imagery was being introduced more extensively in driving simulation research. Throughout this decade, improvements in the accessibility of highspeed, low-cost computers and graphics processors, coupled with powerful image-rendering 
software, opened the door to a form of interactive driving simulation to anyone or any organization with a personal computer. The evolution of computer-generated image systems went through several stages in the 1980s, from images being very angular and lacking shading and detail to the appearance of photo-driven texturing (Marowitz, 1991; Wachtel, 1995). The best of these images appears quite realistic, though at a significant software development cost.

In summary, today's driving simulators range in complexity from low-level, part-task simulators, which use a personal computer or graphics workstation, CRTs, customized interfaces, and maybe a simple cab and controls, to mid and high-level simulators which have complex system architecture (component computer processing platforms, real time operational mode, and data communication protocols), visual image generators (large screen graphical display to portray the out-of-the-window roadway environment), motion systems [actuators, attitude (tilt and yaw), or 6 degree of freedom hexapod], cab (complete or modified car body with relatively complete interior), vehicle dynamics (for response to steering, brake, and accelerator inputs), and a data acquisition system (Weir and Clark, 1995).

\section{Computer-Based Instruction}

Computer-based instruction (CBI) describes a training or education program whose primary delivery of instruction is by computer. It includes not only traditional instruction over a remote terminal or stand alone PC, but also instruction delivered by computer-controlled devices beyond the basic central processing unit, including: videodisc, simulators, and CD-ROM (Brock, 1994). $\mathrm{CBI}$ programs are also known as courseware and are referred to by a variety of other names, including computer-assisted instruction (CAI), computer-aided instruction (CAI), computer-assisted learning (CAL), and several others (Alessi and Trollip, 1991). A brief discussion on CBI is presented here to provide some insight into potential training procedures, formats, and simulation applications that might be useful for training elements.

The earliest CBI programs began in the 1960s. They included some graphics, and students were guided through instructional programs based on their individual interactions with the system. In the 1960s and 1970s, most of the instructional computing took place on large mainframe computers. Commercial applications appeared, where time-shared interactive computer systems were linked with the video capability of television. With the invention of the microcomputer near the end of the 1970s, a rapid spread of computing occurred for instructional purposes (Alessi and Trollip, 1991).

Today, with personal computer (PC) technology available, using mainframes for CBI is less appealing. The issue is not that PCs can train better, but that the instruction (on floppy disk) can be distributed more efficiently from a shipping (low mailing costs) and user accessibility standpoint. With the emergence of videodisc technology, the CBI environment can be enhanced tremendously. This technology allows higher quality visual displays, and provides the ability to store digital video imagery which can be randomly accessed for both still and moving pictures. In addition, computergenerated imagery can be overlaid onto the video imagery to provide even more flexibility than one would have from the videodisc alone. Another advantage of videodisc programs is that they can provide examples of many sorts of task performance. The user can observe an entire operation, observe it again on a step by step basis, then perform some sort of simulation of the same operation, and finally receive feedback on his or her performance. The quality of the video makes for realistic 
visual cues and simulation opportunities. There are distribution limitations with videodisc, but this can be overcome with the now-popular CD-ROM medium, which can deliver sound, pictures, moving pictures and graphics through the PC (though not as well as imagery from videodisc or videotape). The CD-ROM provides the opportunity for individuals to play games as they learn, similarly to the way one can learn by watching television (Brock, 1994). Unlike watching television, which is passive, computer aided instruction requires overt responding, which research has shown produces higher achievement than programs that require only student attention, listening, and relatively passive responding. In addition, CAI provides drill and practice exercises and immediate feedback which can enhance learning (Vargas, 1986).

Computer-assisted instruction (CAI) is a form of CBI that is often used in conjunction with other instructional systems, and has been traditionally used with remote terminals and PC-based systems (Eberts and Brock, 1987). In most CAI applications, the computer displays a lesson (or other instructional program) on a screen, and a user responds to questions by typing answers or touching the screen. This system provides immediate feedback and analyzes each response. This type of instruction provides use of a branching program that supplies extra information and asks extra questions when errors are made. Some programs even give hints about why an answer was wrong and what is needed to correct it (Coon, 1992).

There have been hundreds of research studies attempting to prove that using a computer to teach something is better than using traditional approaches (i.e., book, teacher, film, etc.). The consensus of opinion is that there is a very small positive effect in favor of CBI (Kulik, Kulik, and Bangert-Drowns, 1985; Alessi and Trollip, 1991). School children and adults seem to do especially well with CAI because of the rapid feedback and individualized pacing. CAI has been found to speed training in the military and in business, as well (Coon, 1992). Despite the fact that it is difficult to compare CAI with other instructional techniques because there are no clear methods to evaluate or define whether a good CAI lesson is better than a good conventional lesson, the advantages of CAI can be objectively evaluated in terms of cost per contact hour and reduction in instructional time due to individualization. In addition, several features of CAI systems increase training effectiveness, including using and replicating the most optimal instruction strategies on a large scale, immediate positive reinforcement, privacy and ability to self-pace, high validity to specific real-world operating environments in many cases, and flexibility to customize lessons to meet a user's learning characteristics (Eberts and Brock, 1987). Vargas (1986) notes that computers have the flexibility to teach effectively, however, they will only do so if they adopt the features shown to be necessary for learning: (1) a high rate of relevant responding; (2) appropriate stimulus control; (3) immediate feedback; and (4) techniques of successive approximation.

The simplest CAI consists of self-paced drill and practice. In this format, users answer questions similar to those found in printed workbooks. This method provides instant correct answers; and the computer can provide additional information, such as time to complete assignment, percentage correct answers, and past performance scores. Higher-level CAI programs include instructional games and educational simulations. Instructional games use stories, competition with a partner, sound effects, and game-like graphics to increase a user's interest and motivation (Alessi and Trollip, 1991). In educational simulations, users face problems in an imaginary situation. Users "see" the effects of their choices and can respond appropriately (Coon, 1992). 
Simulation with CAI can be a powerful technique when used to teach or train some aspect of the world by imitating or replicating it. Simulation has several advantages over conventional instructional systems in that it enhances motivation, there is better transfer of learning, and it is more efficient. Users are not only better motivated, but simulation provides the user with the opportunity to learn by actually performing the activities to be learned in a context that is similar to the real world. Simulations are useful for all instructional phases of learning: presenting information, guidance in acquiring the information skill, providing practice to enhance retention and fluency, and assessing learning (Alperson and ONeil, 1990; Alessi and Trollip, 1991).

Simulation CAI formats are usually divided into two main groups, those that teach about something (physical and process) and those that teach how to do something (procedural and situational). Physical simulation formats represent physical objects or phenomenons (e.g., wave motion), while process simulation formats represent a concept that does not manifest itself very well (e.g., how the economy works). The purpose of a procedural simulation format is to teach a sequence of actions that is a procedure (e.g., how to troubleshoot a fuel system). Finally, situational simulation formats deal with the attitudes and behaviors of people in different situations. Unlike procedural simulations, which teach sets of rules, situational simulations usually allow the user to explore the effects of different approaches to a situation, such as handling a classroom situation (Alessi and Trollip, 1991). Keeping the present research objectives in mind, procedural simulation formats are applicable to rules-of-the-road and safety knowledge instruction (e.g., knowledge about what various pavement markings and road signs mean). Situational and testing procedural simulation formats would be more useful for instruction in the recognition of hazardous and high risk situations in highway environments, however.

\section{Low-Level Simulation}

Driver behavior, assessment, and training studies using low-level simulation have primarily incorporated personal computer (PC)-based technology with customized interfaces (multi-visual displays, subject (driver) response controls and accessories). Subject (driver) response controls and accessories have included: joysticks (McKnight and McKnight, 1994); steering wheel with response buttons (Brouwer, Waterink, Van Wolffelaar, and Rothengatter, 1991); accelerator and brake pedals (Schiff and Oldak, 1993; Schiff, Arnone, and Cross, 1994); steering wheel with accelerator and brake pedals (Staplin, Lococo, and Sim, 1993; Gianutsos, 1994); self-incorporated unit with seat, instrument panel, steering wheel, and accelerator/brake pedals (Allen, Stein, Aponso, Rosenthal, and Hogue, 1990; Stein, Parseghian, Allen and Haynes, 1990); full vehicle cab with complete instrument panel and steering wheel, accelerator, and brake pedals (Triggs and Drummond, 1993; Fraser, Hawken, and Warnes, 1994); and a proposed head-mounted-display with steering wheel, accelerator and brake pedals using a virtual environment system currently under development (Levine and Mourant, 1995). These studies examined the effects of visual and cognitive impairments, alcohol and fatigue levels, and other aging characteristics on several driving performance measures. Comparisons of older versus young drivers were made in several of the studies, however the young

driver cohort groups were not teenagers. For the virtual environment system mentioned, the researchers have pointed out that the device could be used in driver education and training to illustrate different driving scenarios or environmental conditions (Levine and Mourant, 1995). 
Most of these aforementioned studies (see summary Table 4) incorporated driving controls in an attempt to create an "in-vehicle" environment for the subject (driver). These controls help to establish face validity to the real driving world, using low cost technology. Despite the fact that most of the customized interfaces are probably still above the cost and accessibility criteria envisioned for this project, the PC-based systems and interface systems used in these studies could theoretically be scaled down and redesigned for cost and accessibility purposes.

Some of the research studies that have used PC-based simulation technology have incorporated modified versions of Atari's road race (Hard Drivin') gaming software and hardware. One study has focused on the effects of diminished visual capacities on a multitude of driving performance measures such as speed, steering, accelerator/brake pressure, lane position, "simulator accidents", and response time to landmarks (Szlyk, Severing, and Fishman, 1991). Another study has examined the effects of blood alcohol levels on steering, speed control, and reaction time (Cox, Gressard, Quillian, Westerman, and Gonder-Frederick, 1992).

The Atari simulation device has also been considered for use in driver licensing assessment and training. The California Department of Motor Vehicles (CAL DMV) Research and Development Section plans on using the three screen version of the Atari device for studying the feasibility of simulation in driver licensing assessment (Peck and Wachtel, 1993; Wachtel, 1996). An earlier CAL DMV-sponsored study reported that driver competencies such as knowledge, skill, and habit are appropriate for assessment through simulation. Knowledge competencies involve controlling the vehicle, complying with rules of the road, carrying out safe driving practices and responding to emergencies that involve vehicle control. Skill competencies include the perceptual skills of hazard detection and complex pattern resolution, as well as sensory-motor skills related to basic control and emergency response. Habit competencies could be measured by the use of attention-sharing strategies (McKnight, and Stewart, 1990). In addition, the California Highway Patrol is currently considering the use of the Atari device for training police in pursuit techniques (Wachtel, 1996).

With respect to other low-level simulation technology, the literature/information search did not reveal any past or ongoing studies which examined the effectiveness of self-contained, hand-held simulation devices or set-top gaming platforms for driver training or driver behavior research. However, there are several hand-held devices and set-top gaming systems that have a "car racing" theme. 
Table 4. Driving performance measures of selected low-level simulation studies.

\begin{tabular}{|c|c|c|c|}
\hline Author(s) & Derice. & Equipmenthnterfaces & Driving-Related Measures \\
\hline $\begin{array}{l}\text { McKnight and McKnight } \\
\text { (1994) }\end{array}$ & Automated Psychophysical Test & $\begin{array}{l}\text { MS-DOS-compatible computer, } \\
\text { videodisk player, overlay card, and } \\
\text { joystick }\end{array}$ & $\begin{array}{l}\text { - Sensory } \\
\text { - Attentional } \\
\text { - Perceptual } \\
\text { - } \text { Cognitive }\end{array}$ \\
\hline $\begin{array}{l}\text { Brouwer, Waterwink, } \\
\text { Van Wolffelaar, and } \\
\text { Rothengatter (1991) }\end{array}$ & Dynamic Driving Simulator & $\begin{array}{l}\text { Microprocessor (LSI 11/73) IBM- } \\
\text { compatible, graphic display, and } \\
\text { steering wheel with push buttons }\end{array}$ & $\begin{array}{l}\text { - Lane-tracking } \\
\text { - Visual Attention } \\
\text { - Dual Task }\end{array}$ \\
\hline Schiff and Oldak (1993) & \multirow{2}{*}{$\begin{array}{l}\text { Computer-Video Assessment (Easy } \\
\text { Driver) System }\end{array}$} & \multirow{2}{*}{$\begin{array}{l}\text { Macintosh, TV monitor, MIDI } \\
\text { interface, brake pedal, accelerator pedal, } \\
\text { and laserdisc player }\end{array}$} & \multirow{2}{*}{$\begin{array}{ll}\text { - } & \text { Driving Speed } \\
\text { - } & \text { Reaction Time } \\
\text { Hazard Detection }\end{array}$} \\
\hline $\begin{array}{l}\text { Schiff, Arnone, and } \\
\text { Cross (1994) }\end{array}$ & & & \\
\hline $\begin{array}{l}\text { Staplin, Lococo, and Sim } \\
\text { (1993) }\end{array}$ & $\begin{array}{l}\text { Part-Task Vehicle Simulator } \\
\text { System }\end{array}$ & $\begin{array}{l}\text { IBM PC/AT, micro-processor } \\
\text { controlled integrated slide projection } \\
\text { system, projection screen, steering } \\
\text { wheel, brake pedal, and accelerator } \\
\text { pedal }\end{array}$ & $\begin{array}{l}\text { - Visual Detection } \\
\text { - Visual Recognition } \\
\text { - Sognitive Response } \\
\text { - } \text { Secctive Attention }\end{array}$ \\
\hline Gianutsos (1994) & Elemental Driving Simulator & $\begin{array}{l}\text { IBM-PC compatible, switch interface, } \\
\text { steering wheel, accelerator pedal, }\end{array}$ & $\begin{array}{ll}\text { - } & \text { Cognitive } \\
\text { - } & \text { Tracking Task } \\
\text { - Reaction Time } \\
\text { - } \\
\text { - } & \text { Attententional Focus }\end{array}$ \\
\hline
\end{tabular}


Table 4 (Con't). Driving performance measures of selected low-level simulation studies.

\begin{tabular}{|c|c|c|c|}
\hline Author(s) & Device & Equipmentinteriaces & Driving Related Measures \\
\hline $\begin{array}{l}\text { Allen, Stein, Aponso, } \\
\text { Rosenthal, and Hogue } \\
(1990)\end{array}$ & \multirow[t]{2}{*}{$\begin{array}{l}\text { PC-based Part Task Driving } \\
\text { Simulator (STI) }\end{array}$} & \multirow{2}{*}{$\begin{array}{l}\text { IBM PC-compatible, CRT bus- } \\
\text { compatible expansion cards, steering } \\
\text { wheel, accelerator pedal, brake pedal, } \\
\text { and horn }\end{array}$} & \multirow{2}{*}{$\begin{array}{l}\text { - } \text { Steering } \\
\text { - } \text { Speed Control } \\
\text { : } \text { Response Time } \\
\text { - } \text { Lanided Attention } \\
\text { Losition }\end{array}$} \\
\hline $\begin{array}{l}\text { Stein, Parseghian, Allen, } \\
\text { and Haynes (1990) }\end{array}$ & & & \\
\hline $\begin{array}{l}\text { Triggs and Drummond } \\
\text { (1993) }\end{array}$ & STI's system & $\begin{array}{l}\text { STI's system, vehicle cab, steering } \\
\text { wheel, accelerator pedal, and brake } \\
\text { pedal }\end{array}$ & $\begin{array}{l}\text { - } \text { Steering } \\
\text { - } \text { Speed Control } \\
\text { - } \text { Response Time } \\
\text { - } \text { Divided Attention } \\
\text { - Lane Position }\end{array}$ \\
\hline $\begin{array}{l}\text { Levine and Mourant } \\
\text { (1995) }\end{array}$ & $\begin{array}{l}\text { Northeastern University Virtual } \\
\text { Environment Simulator }\end{array}$ & $\begin{array}{l}\text { 486-DX2/66 PC, Spea Fire graphics } \\
\text { card, graphics workstation, steering } \\
\text { wheel, accelerator pedal, and brake } \\
\text { pedal }\end{array}$ & $\begin{array}{ll}\text { - } & \text { Steering } \\
\text { - } & \text { Speed } \\
\text { - } & \text { Braking }\end{array}$ \\
\hline $\begin{array}{l}\text { Fraser, Hawken, and } \\
\text { Warnes (1994) }\end{array}$ & Semi-Realistic Driving Simulator & $\begin{array}{l}\text { RISC-based PC, videodisc player, } \\
\text { video screen, vehicle cab, } \\
\text { steering wheel, accelerator pedal, } \\
\text { brake pedal, speedometer, } \\
\text { cancellation switch, and warning panel }\end{array}$ & $\begin{array}{l}\text { - } \text { Speed } \\
\text { - } \text { Braking } \\
\text { - } \text { Selcondary Task } \\
\text { Performance }\end{array}$ \\
\hline
\end{tabular}




\section{Mid/High-Level Simulation}

Many mid-level simulators are used in the commercial driver training market by secondary and commercial driving schools, hospitals and rehabilitation centers, the military, government agencies and police departments. Ashman (1994) reported that many authorities in traffic safety education maintain that driver simulator methods of instruction can be effective in helping drivers attain a variety of cognitive, perceptual-motor, and knowledge-based learning related to desirable driving performance. Most of the driver training simulators involve non-interactive simulation and present a trainee or group of trainees a film- (or video) projected moving scene (from the vehicle viewpoint). Trainees respond to the stimuli (traffic environment) shown, but the display does not respond to the driver's control inputs. The film/video is generally shot from a vehicle moving at a given speed, however, the film can be replayed faster or slower to simulate different driving speeds. The projection speed is controlled by the trainer operating the simulator but does not vary in response to trainee input. Film or video display offers a high degree of fidelity, which the computer generated imagery technology cannot match. However, one of the greatest limitations of noninteractive simulators is the lack of control the trainee has over the simulated vehicle (Marowitz, 1991). Costs for these simulators vary depending on the number of options, projector/data collection and control consoles, cars (cabs), and films purchased. These types of simulators might be useful in providing driver training in a large-scale classroom type environment.

In the U.S. there are primarily two manufacturers of mid-level, noninteractive driver training simulators: Doron Precision Systems, Inc., (Binghamton, NY) and Simulator Systems International, Inc. (SSI) (Tulsa, OK). Doron acquired the Singer Company's driving simulator hardware business and Allstate Insurance Company's driving simulation film library in the early 1970s to become the first company to offer complete simulation-aided driver training systems. Doron currently offers a full line of land vehicle (i.e., passenger car, van, truck, and school bus) driving simulation systems for driver training, testing, and screening. Systems are available for training new drivers, special populations, and experienced drivers for skills enhancement training. These simulators are fixedbase with optional motion-base available, use front-projected road scenes, and provide computer output of driving performance. For novice drivers, Doron offers simulation programs covering startup procedures, turning, hazard identification, decision-making, visual scanning, communicating with other drivers, parking, rural and interstate driving, adverse conditions, crash avoidance, route planning, and using mirrors in vans (Doron Precision Systems, Inc., 1995).

Simulator Systems International, Inc. (SSI) manufactures a noninteractive driving simulator which uses a fixed-base platform, with front-projected driving scenes, and computer output of driving performance. They entered the simulation business in the late 1970 s under the name Instructional Systems Development Corporation in cooperation with employees of Burtek, Inc., a flight simulator company. They offer several driver training programs that can be used for novice as well as experienced and professional drivers. Their simulator uses an IBM compatible operating system to enhance software and other program capabilities (Simulator Systems, Inc., 1995).

These noninteractive simulators are useful in providing instruction, practice and assessment of the knowledge, perceptual skills, and habits that influence the selection of an appropriate response to a particular highway traffic situation (McKnight and Stewart, 1990). The literature/information search conducted in Task 2 of this project did not uncover any research studies that evaluated the effectiveness of these simulators. 
The truck industry also uses mid-level simulators for training. Doron markets a fully interactive system (L-300), complete with a full-scale tractor-trailer cab (with controls and instrument panels), with audio and video generated from a model board (diorama complete with a driving range resembling an industrial area) in an adjoining room. The simulator allows trainees to practice all basic low-speed maneuvers, especially docking, backing up, and parallel parking (Doron, 1995). Professional Truck Driving Simulators (a joint venture of FAAC Inc., and Perceptronics) offers a truck driving simulator (TT150) complete with a mock truck cab containing a steering wheel, seat, clutch, and all the necessary levers. A large 180 degree panoramic view of the road is created with three large graphic displays, which use computer-generated imagery, and an audio system to simulate sound and vibration (Stadden, 1991). Another truck driver training simulator in the U.S. is Digitran, Simulator System's SafeDrive 1000 Truck Driving Simulator. There are also several truck driver training simulators in England (Transportation Research Laboratory, Crowthorne), Sweden (Swedish Road and Traffic Research Institute, Likoping), Switzerland (Oerlikon-Contraves, Zorich), France (Thomas - CSF, Cergy Pontoise), and Germany (AITEC Gmbh \& Co., Dortmund and Atlas Elektronik Gmbh, Bremen) (Robbins, 1996).

Weir and Clark (1995) recently published the results of a survey on the description and facilities of mid- and high-level simulators in the world. Their study identified: Virginia Polytech Institute (Blacksburg, VA), Federal Highway Administration's HYSIM (McLean, VA), Trygg Hansa (Linkoping, Sweden), Hughes HTSC (Los Angeles), GM-SEC (Troy, MI), Ford Motor Co. (Dearborn, MI), Dynamic Research, Inc. (Torrance, CA), Mitsubishi Motors (Okazaki, Japan), JARI (Tsukuba, Japan), University of Iowa (Iowa City, IA), Illusion Technologies (location not identified), FAT (Werthoven, Germany), Chrysler Corporation (Auburn Hills, MI), INRETS (Cedex, France), BMW AG (Munich, Germany), and the Mazda Motor Corporation, Toyota Central R \& D Labs, Inc., and the Shibaura Institute of Technology in Japan. The UMTRI driving simulator also fits in this category (Green and Olson, 1989).

The most advanced, high-level simulators are operated by numerous specialized computer programs and have the highest fidelity visual and motion systems. The visual systems have at least a 180-degree front field of view and some rear field of view, high resolution, texturing, and highly detailed scenery. The motion bases are capable of large longitudinal and lateral motion, with a highfrequency motion system for simulating road bumps, vibrations, and variations in road surfaces. They include complete vehicle dynamics consisting of components for longitudinal and lateral directional handling, drive train, and suspension characteristics. Some cab configurations are available with control loading (steering wheel, brake pedal, accelerator, and switch feel), audio systems, ventilation, nonintrusive monitoring instruments, and research instrumentation. In Europe, Sweden's VTI Simulator, Germany's Daimler-Benz simulator, and the planned French SARA simulator are in this category. In the U.S. at the University of Iowa, there are plans for developing the National Advanced Driving Simulator (NADS), which is intended to be the most sophisticated driving simulator in the world, and will be designed to accommodate large movements in both $\mathrm{x}$ and y axes, a feat no other driving simulator has yet accomplished. It will also have a high-frequency motion system capable of simulating certain aspects of road roughness and a visual system with a 360-degree field of view (Diewald, 1995).

A wide variety of driver, vehicle, and roadway related studies are accomplished with the mid-and high-level driving simulators. From the perspective of studying driver behavior, these simulators are useful for addressing the effects of alcohol and drugs, aging factors, fatigue, mental 
workload, emotional state, vigilance, personality factors, physical and mental deficiencies, other medical conditions, risk taking proclivity, training programs, regulations and warning $\mathrm{s}$, instructions and other procedural factors. In addition, these simulators are used to evaluate detection and recognition of roadway and environment variables (such as signs, pedestrians, and obstacles) (Weir and Clark, 1995). The UMTRI simulator has been used for studying the effectiveness of alertness devices, detection of brake lamps by distance and type, driver preference for secondary controls, glare sources on discomfort ratings, and several others relating to instrument panels and driving controls (Green and Olson, 1989).

Mid- and high-level driving simulators are useful for defining training programs and validating the training process. However, the accessibility and cost of these devices limit their application for lowcost highly accessible training for young and novice drivers. 


\subsection{EVALUATION OF SOFTWARE AND HARDWARE AND OTHER TECHNOLOGY FOR SIMULATION}

This chapter identifies the current software and hardware that can be used with the recommended training elements for training novice drivers. Key factors to consider when evaluating the applicability of a potential hardware platform are discussed, as well as a look at several possible technologies which can be used for the type of training intended (e.g., platforms (personal computers, consoles, hand-held devices), peripherals (helmet mounted displays, gloves, goggles), and other technologies (cable modem, PC/TV). Current display technology is also described, which must be considered in selecting devices for each of the training elements.

\subsection{CURRENTLY APPLICABLE SOFTWARE}

The literature review and follow-up information-searching activities revealed only a few products currently on the market that met the low-cost and accessibility criteria established for the project's recommended training elements. These products fall into the "knowledge elements" category, and primarily cover defensive driving, general driving skills, and rules-of-the-road topics. The National Safety Council's (Itasca, II) $D D C-P C$ training program is available on disk and can be used with almost any IBM or IBM-compatible personal computer (PC). The program is geared for novice as well as experienced drivers. It is a leased program, which costs about $\$ 400$ to $\$ 500$ per year. Three other products, License to Drive, Right-Of-Way, and Winter Driving Course, by Janus Interactive (Beaverton, OR), RM Communications Group Inc., (New York, NY), and Marshall's New Media Ltd. (Coquitlam, British Columbia, Canada) respectively, are geared primarily for novice drivers, and are available on CD-ROM for use with all leading IBM or IBMcompatible and Macintosh systems. However, these CD-ROM products require higher-level processing and storage systems with sound cards to run more effectively. These software products range between $\$ 25$ and $\$ 75$.

In addition, there are other "knowledge" type driver training IBM-compatible software products on the market, but they are geared for the driver trainer or the parent, rather than for the novice driver. One such product, Hartley Courseware's (Fullerton, CA) Driving (\$200) is geared for driver education instructors. Other products are geared for parents of novice drivers. The American Automobile Association recently released Teaching Your Teen to Drive (CDROM/handbook- \$14.95). The parent involvement instructional package is designed to be used as a stand-alone driver education program or in conjunction with a driver education course. The product is advertised as a "traffic safety education program aimed at helping parents with the important job of teaching their teenagers to drive" (AAA, 1996a). Another product is Russel S. Floyd's (Jericho, VT) A Parent's Survival Guide to Driver Education (\$5). This product is a diskette version of the handbook he has developed from his years of experience as a driver education instructor. Driver education instructors can also take advantage of another PC-based software product which measures young drivers' high-risk attitudes. The Young Driver Attitude Scale is available from the American Automobile Association Foundation for Traffic Safety (AAAFTS) (located in Washington, D.C.) at no cost.

A product still being developed that might meet some of the recommended training goals (other than knowledge-based products) is a CD-ROM to be released by AAAFTS (Washington, D.C). It is a multi-media program to train young and novice drivers in decision-making and 
identifying high-risk situations. The product will encourage teens to develop the specific driving skills that are often problems for this age group. There are four levels of decision-making in the training program. In the first two levels, users must identify potential dangers. The third level requires the teen to choose a specific action. The fourth and most difficult level asks the user not only to make a safe choice but to make that choice in time to prevent a dangerous outcome (AAA, 1996b).

The AAAFTS program uses full-screen, full-motion video that requires a $486,90 \mathrm{MHz}$ or better PC, with an IBM M-Motion Video Adapter, Level III Videodisc, and MPEG 1 board. Many households cannot economically afford PCs with all of these accessories (roughly $\$ 2,000$ to $\$ 2,500$ ). However, it should be noted that many new computer games use full-motion video; and the likelihood of consumers purchasing home computers equipped to run this type of program will increase over the next several years.

\subsection{EVALUATION PROCEDURES FOR HARDWARE PLATFORMS}

Update rate, horizontal field of view, horizontal angular resolution, and interactivity are key factors to consider when evaluating the applicability of a potential hardware platform for the recommended training elements. Because of the unique requirements of each training category, there will undoubtedly be some training elements for which even the poorest quality platforms (namely, the hand-held devices) can be used for novice driver training. At the other extreme, the PC is expected to be nearly 100 percent applicable; that is, virtually all of the training elements can be implemented on a PC platform. Using the parameters and procedures outlined below, it should be possible to make objective evaluations about the relative applicability of potential platforms.

For an evaluation, a figure of merit calculation can be used to rank-order potential device platforms. To calculate a figure of merit, the minimum requirements for each recommended TTP and each of the parameters listed below must be specified based on expected properties of visual scenes. For each platform, the maximum capability must be determined from product literature, or estimated based on available product specifications.

\section{Update Rate}

Update rate refers to the number of frames of the training stimulus that are (or can be) presented per second (frames per second or fps). For the recommended training elements, an update rate of 24 frames per second (fps) or lower is adequate to eliminate temporal artifacts (such as "jumpiness" of a target on the screen). However, for training elements involving simulated steering maneuvers, update rates higher than $24 \mathrm{fps}$ may be required. For the platforms, update rate takes into account processing bottlenecks of the platform including the central processing unit (CPU) and random access memory (RAM), storage device, display card, and other hardware involved in producing the visual display. 


\section{Horizontal Field of View}

Horizontal field-of-view (HFOV) is the angular subtense (in degrees) of an image for a display viewed at a specified distance. HFOV must be specified for each recommended training element based on the angular eccentricities of all task-critical scene elements. For device platforms, HFOV must be specified for a 'typical' viewing distance. In practice, viewing distance should be restricted using a chin rest (and perhaps a head rest). Furthermore, it is anticipated that the viewing distance may need to be adjustable to optimize the relationship between resolution and HFOV among TTPs

\section{Horizontal Angular Resolution}

Horizontal angular resolution (HAR) is the angular subtense (in degrees, or minutes of arc) of the smallest detail in an image. The minimum HAR requirements for the recommended training elements vary between 1 minute of arc (which can be detected by an observer with 20/20 acuity) and 10 minutes of arc. Low-cost platforms will not meet the 1 minute arc requirement. Fortunately, most of the scenarios described in Chapter 2 do not require 1 minute arc high resolution. In addition, the safety relevance of a target requiring 20/20 acuity must be questioned. Such targets are typically either too small or too distant to pose an immediate threat to a driver if undetected.

The HAR capability for a platform should be obtained using two different procedures. For the pixel-based estimate, divide the HFOV by the number of pixels or the horizontal resolution in TV lines, whichever is lower, in the display. A second estimate is needed because pixel-based estimates will tend to overestimate actual HAR. The second estimate is obtained using the specification for dot pitch of the display (usually specified in millimeters). Divide the dot pitch by the viewing distance and take the inverse tangent of this ratio to obtain the angular subtense of the smallest detail in the image. Compare the two estimates and use whichever is lower as the HAR for a particular platform.

\section{Interactivity}

For the purposes of this project, interactivity is defined as the quantity and quality of auditory/visual feedback that correlates with user responses so as to simulate behind-the-wheel driving. In order to be considered an interactive simulation, a training program must have at least one response that satisfies this definition. At the low fidelity end of the interactive response continuum, a simple button press can be used to simulate an interactive brake response (in this case, the button press freezes the scene). Since all platforms can implement this level of response fidelity, it is not anticipated that this will distinguish among targets. Instead, somewhat higher response fidelity will be used to distinguish among platforms. For example, a higher fidelity braking response would allow the driver to control the deceleration in proportion to the pressure applied to a brake pedal. A somewhat more difficult interactive response to implement is a steering task. In most cases, implementing a high-quality steering response requires the use of computer graphics images (as is typical in video arcade games).

The following two interactive response categories are discussed in the evaluation of potential training platforms: (1) simulated vehicle speed control (required to simulate brake and accelerator responses) and (2) simulated vehicle direction control (required to simulate navigation tasks, turning, 
lane changing and other tasks that require steering wheel inputs). The training requirements for these two types of responses can be determined from the scripts described previously.

Assessing the interactive response capability of platforms depends on whether computer graphics or actual video are used as stimuli. As a general rule, the ability to implement interactivity in a low-cost training platform, including development costs, requires the use of computer graphics images. Although creative script development can reduce the costs when using actual road scene video, this approach is not recommended. Thus, if the use of actual video in the training is proposed, it is unlikely that the platform can be used to implement either of the interactive response categories. If computer graphics are proposed, the capability for implementing higher quality or more response categories is more likely.

\subsection{PLATFORMS AND OTHER DEVICES AND TECHNOLOGES}

This section discusses hardware devices which can be used for the recommended training elements. The following devices and systems are reviewed: personal computers (PCs); console (settop) platforms; hand-held devices; virtual environment devices; cable modem systems; and other miscellaneous devices.

\section{Personal Computers}

The PC platform is probably the most well-suited environment for supporting any type of novice driver training or instructional program that is being recommended in this study. PCs can support large, high-resolution color displays (addressed in next section); use a wide variety of inexpensive software development toolkits and programming languages; and are easily adaptable for interfacing with peripherals that might be well suited for driver training (i.e., steering wheel, accelerator and brake pedals).

They are also easily accessible. PCs are fairly common in many learning environments (i.e., schools, libraries) and in an increasingly larger number of households. A recent survey reported that PCs can now be found in 35 percent of the nation's homes, and are most prevalent in homes where there are children. The survey found PCs present in about 16, 37, and 72 percent of homes where the annual income was less than $\$ 30 \mathrm{~K}, \$ 30 \mathrm{~K}$ to $\$ 50 \mathrm{~K}$, and above $\$ 50 \mathrm{~K}$, respectively (Kanaley, 1996). In addition, thePC is becoming more economical for the average American; a typical home computer can now be purchased for between $\$ 1 \mathrm{~K}$ and $\$ 2 \mathrm{~K}$. There are almost 23 million households with PCs (Sawyer, 1996).

Another advantage of a PC is that program manufacturers, developers, and distributors recognize a market for educational products (programs). This is highly evident in retail computer stores where there are dozens of instructional and educational kits available for use on the PC in disk or CD-ROM format. The PC user is often familiar with the educational options for the computer (e.g., math and reading games for elementary school aged children) and could easily justify acquisition of driver training programs for the teenagers of the family.

Current peripherals that support car racing PC games include Formula T2 (Thrustmaster), which comes with a 9-inch steering wheel, gear shif, brake and gas pedal device for around $\$ 100$; and Pedals (CH Products) which comes with a brake and gas pedal for around \$50. 


\section{Console (Set-Top) Platforms}

The console (set-top) platform is much less expensive than the PC. Current and new generation systems cost between $\$ 100$ and $\$ 500$, not including a monitor (television). Recent public opinion surveys have shown that about 45 percent of households have video games that connect to a television (Roper Center for Public Opinion Research, 1995). Sawyer (1996) reports that there are about 27 million households with consoles; in these households, 9.6 million have a PC, as well. The survey data suggests that consoles are already very popular in households. Availability and accessibility of using these devices for novice driver training probably will not be a concern.

However, there are several limitations with this platform, starting with the fact that any type of product (training or gaming) developed for these platforms needs to be licensed and approved through the platform manufacturer. Another major dilemma is the fact that most programs which run on console (set-top) platforms are games, and it appears this trend will continue. Only a few educational-oriented products have been developed for this market. At one time there were several educational products for this platform, however, this is not the present case. A recent visit to retail stores identified only two products on console platforms, with specific educational intent: chess and a quiz game based on the television show "Jeopardy." Manufacturers of console platforms and their software developers are focusing specifically on game development. It would take an enormous effort to convince these manufacturers and product developers of the marketing potential of any type of training product for their systems. Using consoles should not be totally ruled out, however. There are about two dozen games with car racing themes. Many of these games can even be used with inexpensive (less than $\$ 100$ ) steering wheel, and brake and accelerator pedal peripherals. Some of these racing games, like Papyrus Design Group Inc.'s NASCAR Racing game can even be played on the Internet with other users. There are actually racing leagues, where users can meet racing club members on the Internet and stage a simulated race with each other (Kanaley, 1996). The software has already been developed for these games; there should not be much of a development hurdle for making multi-user training "games" to simulate the real-world driving environment.

The original video game platforms of choice in the late 1970s included Atari 2600 with Intellivision, Colecovision, and a few others. They were 8-bit computers. The next generation in the mid-1980s featured Nintendo Entertainment System and the Sega Master System, followed by Sega Genesis and Super Nintendo. These were 16-bit computers. The new generation of console (set-top) platforms has moved to 32-bit (Atari's Jaguar, Panasonic's 3DO, Sony's Playstation, and Sega's Saturn) and 64-bit (M2 and Ultra 64) levels. Currently, three major platforms are, and will be, the dominant players on the market for awhile. They are the Sony PSX Playstation, Sega Saturn, and Nintendo's Ultra 64 (Sawyer, 1996).

Sony's PSX Playstation represents the consumer electronics and entertainment company's first effort in the console market. They have primarily devoted their efforts to developing computer and video game software. However, their 32-bit console has been quite successful. Recent sales figures from 1995 estimate over 4 million console units sold worldwide. In addition, they have garnered significant third-party (software developer) support with about 470 licensees worldwide. Sony has several types of peripherals for the Playstation including a mouse, head-to-head cable for using two TV monitors, a four controller unit, and an analog joystick (Sawyer, 1996; Willcox, 1996). They also have a steering wheel, and brake and gas pedal devices for their systems for around $\$ 70$. 
Sega's Saturn is their 32-bit console entry. Though not as successful as Sony's Playstation, the recent success of their arcade products may boost their sales. The Saturn has several types of peripherals aside from the normal joypads and joysticks, including a steering wheel setup for their driving games. Sega has always been a major creator of these types of games (Sawyer,1996; Willcox, 1996).

Nintendo's Ultra 64 is intended to be so superior in quality to the other consoles, that it will redefine consoles and virtually eliminate all competition. Nintendo has teamed up with Silicon Graphics, Inc., a leader in graphical workstations, to produce the ultimate 64-bit console. It will be the only console remaining that still uses cartridges rather than CD-ROM. The peripherals include a highly advanced joystick, which involves a digital gamepad (useful for arcade-style responses) with an analog joystick device (useful for flight simulation-style games) on the same controller. The controller also has ports for SRAM cartridges, in order to save game information (Sawyer,1996; Willcox, 1996).

At this time, the Sony Playstation and Sega Saturn cost $\$ 199$. Last year they were $\$ 100$ to $\$ 200$ more. CD-ROMS for these consoles range from $\$ 35$ to $\$ 50$. Nintendo plans on selling their Ultra 64 at $\$ 249$ in the Fall of 1996, and some are forecasting game cartridges that cost between $\$ 60$ and $\$ 90$ (Willcox, 1996).

Another 64-bit console, the M2 platform by Matsushita/Panasonic, will also be on the market soon. This next-generation 64-bit system will have potential rendering speed of 100 million pixels per second and 1 million polygons per second. The M2 will probably come with the usual array of joysticks (both digital and analog), mouse, and keyboard. The 3D graphics can provide an amazing virtual reality experience. It is suspected that the major PC-virtual reality vendors may produce some VR peripherals for this system.

\section{Hand-Held Devices}

Hand-held gaming devices (such as those by Nintendo and Sega) are familiar to many households with youngsters. The advantage of this type of product is its low cost to the consumer buying off the shelf $(\$ 10$ to $\$ 50)$. However, there are significant physical limitations of the device, which include a low resolution, monochrome display, and limited user controls that may not adapt well to other interfaces, especially peripherals such as steering wheels, brake and accelerator pedals. There are also other drawbacks, relating to whether or not the product will require manufacturer permission, licensing fees, and expensive software development toolkits; there may even be a need to create a new device, which will have hardware manufacturing development start-up costs, in addition to the software development costs. Like the console platform, hand-held devices are primarily used for games, and it would probably take an enormous effort to convince manufacturers of hand-held devices and their software developers to produce educational/training products.

Nevertheless, there are several hand-held devices on the market with car racing themes and the ability to create driver training applications using this technology are not unsurmountable. Yet, it will most likely require new software and hardware development which will require substantial funding resources. 


\section{Virtual Environment}

Virtual Reality (VR) has become a common technology term. However, because of the lack of specificity resulting from the widespread use of this term for many different systems and applications, the term virtual environment (VE) will be used in the context of this report. A VE is defined as a system which immerses the user in a computer-generated environment using, in addition to high-speed computer graphics technologies, head-mounted displays (HMDs) and sensors that detect body movement, such as head trackers and gloves that detect finger movements (Levine and Mourant, 1995).

In the gaming world, VE devices have come of age in terms of being affordable to the household consumer. The push for VE devices is just beginning, but it is already quite established in other parts of the gaming industry. There are immersive VE theme parks, and manufacturers of these centers have generated enough profits to afford the large hardware capital required to develop state-of-the-art immersive VE devices. It will not be too far off into future where this technology will be in the average household (Sawyer, 1996).

There are technological problems with the current batch of VE devices. First, the graphics are orders of magnitude poorer than what can be obtained on the other platforms. Furthermore, these VE systems slow update rates for the graphics, which significantly limits the applicability of the device as a training platform. These shortcomings can be readily overcome using faster CPUs and graphics accelerators that cost much more. However, reductions in the cost of today's state-ofthe-art VE technology are redefined on an almost monthly basis.

In terms of using VE technology for novice driver training purposes, it is possible to discuss the potential benefits of future low-cost VE devices. In terms of technological capability, it is conceivable that $\mathrm{VE}$ will one day be entirely immersive, that is the visual information received from the VE will eventually be indistinguishable from behind-the-wheel driving. However, the effects of user inputs to the VE (i.e., steering, braking, and accelerator control reposes of the user) will never be rendered instantaneously, since, there is a finite amount of time required to recompute a graphics image based on a user's input. Whether this lag will be undetectable as computer processing speed increases is unknown. The amount of VE lag is also influenced by the total number of pixels processed in the image, which relates to the field-of-view versus resolution tradeoff. VE technology also has the potential benefit of allowing multiple users to interact within the VE. Instead of the trainee responding to events that originated in the computer software, the trainee responds to other users whose responses are unpredictable, similar to actual on-road driving.

There are several types of VE hardware currently on the market, including: head mounted displays, glasses, gloves, joysticks, and vests. The most common VE device is the head mounted display (HMD). There are two main types currently available, those with motion tracking and those without. All HMDs incorporate LCDs to present a field of view directly to the player. The screens are the same as those used in small LCD televisions or camcorders. The typical pixel matrix of these displays is 320 horizontal by 240 vertical and 256 colors. Several major PC-and console-based VE HMDs are currently available, including Seventh Sense (Virtual Entertainment Systems, Inc.), Virtual I*glasses (Virtual I-O), CyberMocxx (VictorMaxx), and VFXI Head Mounted System (Forte Technologies, Inc.). These products range in price from $\$ 500$ to $\$ 900$. In addition, there are 
discernible image quality differences among all the devices, and the motion tracking HMDs are known to cause motion sickness (Sawyer, 1996).

Another hardware VE device is 3D shutter glasses that produce depth by controlling retinal disparity. Shutter glasses are much cheaper (around $\$ 200$ and less) than HMDs and can also be combined with an outside head tracking device to enable a HMD capability as well. There are a number of companies making 3D glasses, including: Reveal Computer Products; Logitech; Stereo graphics, who has on the market CrystalEyes and the SimulEyes VR stereo-viewing systems; and Vrex Inc., who has VR Surfer, which is a wireless, stereo 3D eyewear that works with both a TV and a computer (Sawyer, 1996; AV Video, 1996).

There are also VE hardware devices that do not incorporate a viewing component. One such device is a VE data glove. The PC Powerglove (Abrams/Gentile Entertainment) offers six degrees of tracking, finger bend sensing, feedback sensors, and sweat sensors. Another product is the 3SpaceGlove (3Space), which includes a modification to the original Mattel Powerglove and a conversion kit to make it work with the PC. Other non-viewing type VE devices include joysticktype/"spaceball" input devices and vests. Products such as Spaceball Avenger (Spacetec IMC Corp.), Total Control Joystick (Total Control) and Batter Up! and PC Golf (Sports Sciences) exist which allow six-way movement in the game world. Sports Sciences products allow the user to swing a VE bat or golf club that simulates the trajectory of the baseball/golf ball onto where the ball would land in the baseball field or golf course. There are also vests on the market that will vibrate when explosions erupt in the games that are being played. VE vests currently available include Aura Interactor (Aura Systems Inc.,) and ThunderSeat (ThunderSeat Technologies) (Sawyer, 1996).

$\mathrm{VE}$ is currently being used in at least one driving simulator application for the rehabilitation and assessment world. The driVR driving simulator (Imago Systems, Inc.) incorporates basic personal computer technology as the simulation platform along with a head-mounted display. The driVR system provides a fully interactive simulation. The client steers the vehicle with a steering wheel that clamps to a desk and uses a set of pedals to control the speed of the vehicle. The client wears a pair of goggles that displays an image corresponding to the angle of rotation of their head. The use of these goggles affords the user a $360^{\circ}$ view of the vehicle and landscape. Engine sounds which correspond to the vehicle motion are heard through the earphones incorporated in the headset. The price of the software and support package are $\$ 8,200$.

\section{Cable Modem}

Most computers are connected to the world by a phone line. Waiting for files to download can be time-consuming. However, cable modem technology has changed all of this. With cable modem, large files that would take over one hour to download can now be done in less than one minute. Cable modem provides the fastest way to deliver kilobits per second to the PC. It can provide 1,000 kilobits per second, compared with conventional phone modem and ISDN connection which provide only 28.8 kilobits per second and 128 kilobits per second, respectively (Rozansky, 1996).

On the Internet, speed is critical, with developers beginning to build up Web sites with multimedia content, and computers that are being designed to function as television sets. Cable 
modem will be the connection of choice for interacting with the Internet. In the computer game/educational world, companies are seriously interested in developing online games, because of the potential for continuous revenue on the Net. Online gaming (and online educational training for that matter) can feature interactive communication, where the product users can become a perpetual focus group, helping games (and in this project's case, training products) to evolve (Rose, 1996).

As processing delays decrease with cable modem and Internet gaming technologies, multiplayer gaming could become a great PC application in the immediate future. The implications for the novice driver training world could mean training environments where users are at home "driving" on a virtual environment highway on their PC screen, interacting with other real drivers. Or, driver trainees could download driver training programs onto their PC in a quick, efficient way that will motivate them to practice and get their training hours in much faster.

\section{PC/TV}

One of the latest technologies to reach the consumer is PC/TV. This technology incorporates a large-screen PC that can be used for watching television, playing CDs and digital-videodisk (DVD) games, surfing the Internet, and decoding cable-TV feeds. It is initially intended for "edutainment" applications, such as for a consumer who wants the option to play games with others on a network, send e-mail, surf the Net, but also watch television. For now, the cost of these devices is relatively expensive ( $\$ 4 \mathrm{~K}$ plus). The product is primarily targeted to consumers with medium to high incomes, and with several years of PC experience (Day, 1996).

There are also TV add-on products currently available which add interactive capabilities to a television. There are products available for about $\$ 500$ which include modems, Ethernet ports for connecting to cable modems, infrared remote controls with trackballs, and optional wireless keyboards. Other PC/TV devices will feature a TV, Net box, and DVD player into one device (Day, 1996).

These devices provide another option for increasing accessibility and use of the recommended training elements in the home or in educational environments.

\subsection{DISPLAYS}

Three displays are reviewed: cathode ray tube (CRT); active-matrix liquid crystal display (AMLCD); and a new projector display technology called digital light processing (DLP). These displays can be used with any platform. For this reason, identifying a platform does not completely specify the capabilities of the system in terms of the horizontal field of view (HFOV) and horizontal angular resolution (HAR) features of the display. These HFOV and HAR capabilities, advantages, and disadvantages are discussed for each display type.

For each display type, two display options should be considered. The most common display option is a computer monitor. The other display option is projection. Projectors have the advantage that the display size can be adjusted for viewing distance using a zoom lens. This obviates the necessity to have an adjustable viewing distance to optimize the HFOV and HAR requirements 
among the training elements. Disadvantages include cost, and perhaps space requirements (via minimum projector-to-screen distance). Monitors are lower cost and have a smaller footprint; however, since screen size is fixed, viewing distance would have to be adjusted to optimize HFOV and HAR requirements among training elements.

\section{Cathode Ray Tube}

CRT monitors seem to be the best choice for the current training applications due, in part, to low cost. There are large-screen CRT displays that could be used to meet the HFOV requirements. However, these displays typically have larger dot pitch and cost significantly more. One way to compare quality among CRT monitors is to take the ratio of the active horizontal display size (in millimeters) to dot pitch (also in millimeters). The CRT with the highest ratio has the optimal relationship of horizontal screen size to dot pitch (this number should meet or exceed the maximum pixels per row specified by the manufacturer). This number can then be divided by cost to find the best quality-to-cost ratio. This procedure can be readily used to evaluate all displays. It is believed that CRTs will rank the highest among displays considered here.

In addition to having the highest quality-to-cost ratios, CRTs typically provide good color and contrast fidelity. One shortcoming of CRTs is that they typically have a limited dynamic brightness range. Although there are displays that provide superior dynamic brightness range (such as Hughes/JVC Light Valve), these displays are costly. Because limitations on brightness is a shortcoming of most of the low-cost displays and none of the training elements require a high brightness range, this parameter is not a critical evaluation parameter.

\section{Active-Matrix Liquid Crystal Display}

Liquid crystal displays (LCDs) are like light switches. An LCD uses a voltage signal to block or let light pass through its crystals. Some LCDs use a backlight to provide illumination, while others use a mirror to reflect ambient light back to the viewer (Heald, 1996).

LCDs are the preferred displays on portable computers, mainly because they are energy efficient and lightweight. Other advantages, compared to CRTs, include no harmful emissions and less flicker. The older passive matrix LCDs cannot be used for this application because of the long pixel persistence ("ghosting"). The newer AMLCDs have much shorter pixel persistence due to the way that pixels are addressed.

The typical diagonal display size of directly-viewed LCDs (such as those on notebook computers) is 10 inches. Although this is extremely limited for the current application, recall that LCD projectors can display at a number of screen sizes. HAR for LCDs is comparable to CRTs. For example, there are LCD monitors (e.g., NEC LCD300) with 13 inch active display areas and 0.2 millimeter dot pitch (corresponds to a maximum of about 1,288 pixels per row). However, these LCD monitors are expensive (about $\$ 5,000$ ) relative to comparable 17 inch CRTs.

LCDs have some drawbacks that should be considered when choosing a display for training. First, LCDs used in portable PCs are notorious for a limited field of view. However, new LCDs 
used with desktop PCs and TVs are much better, and have a horizontal viewing angle of 140 degrees and an optimal viewing angle of more than 70 degrees (Heald, 1996). Second, the brightness of the display is very sensitive to the viewing angle. This is not a serious problem for single-viewer applications (such as training), but is important for multiple-viewer applications (namely, presentations). Third, the transmittance of LCDs is low due to the requirement to polarize the light. This inefficiency means that more backlighting is needed to bring the image to a given brightness. Additionally, some LCDs suffer from pixelation (which is the visibility of the gaps between individual pixels), - lack of color saturation, and inferior color contrast. The prablems associated with the requirement for polarizing the light exiting a LCD-type display may be resolved with advances in LCDs. For example, LCDs are being developed that do not require polarization filters. Also, a new type of passive-matrix display is being developed by InFocus Systems and Motorola that has fast response time and lower cost.

\section{Digital Light Processor}

A digital light processor is used to project a TV signal onto a screen. It contains the electronics, light source, optics, and digital micromirror devices (DMDs) necessary to project a digital image. This is a relatively new projector display technology built around Texas Instruments DMDs. At this time, it is unknown whether any manufacturers are developing computer monitors using DMDs. However, based on current technological advance; it is reasonable to assume that DLP monitors will eventually be readily available, and will ultimately become the format of choice for consumers because the images they produce can be extraordinary (Heald, 1996).

The HFOV and HAR of DLP displays is based on the DMD array. Arrays as large as 2048 x 1152 pixels have already been produced. DLP projectors incorporating $800 \times 600$ (pixel) DMD arrays are widely available. It should be noted that the apparent resolution of such projectors, when compared to $800 \times 600$ (pixels) LCD projectors, is higher due to the narrower gaps between pixels. In other words, at the same viewing distance, the pixelation of LCDs is much more noticeable than DLPs. As the technology matures, even larger arrays will be produced, with resultant increases in both HFOV and HAR. DLP projectors also offer extremely high brightness and superior color contrast.

Current DLP projectors are more costly than either CRT- or LCD-based projectors of similar quality; however, there are reasons to believe that DLP/DMD will eventually replace these display types. First, DMD is a true digital technology. To understand this advantage, it is necessary to describe the technology. Each micromirror is a semiconductor light switch. Mirrors (16 x 16 microns) are fabricated on hinges which, in tum, sit on static random access memory (SRAM). Each of these mirrors is capable of switching a pixel of light on or off by rotating the mirror on its hinge under control of the semiconductor SRAM substrate. In other words, digital video does not need to be converted to an analog NTSC format in order to be displayed; light is directly controlled by digital electronics. A second advantage of DMD is that pixels can be addressed in parallel. Because of this, the entire array of pixels does not need to be updated on every scan of an image. In other words, with $\mathrm{DMD}$, it is possible to address only those pixels that change from frame-to-frame. This can result in significant reduction in required processing speed. Thus, DLP/DMD brings an alldigital-display closer to reality with existing computer processing capabilities. 
The implication of this technology (i.e., an all digital approach) for training development is that it is relatively less expensive and more efficient because there is no need to acquire accessory hardware components (e.g., separate overlay boards, video converters) to create and mix video with graphics for training scenes. This process can be done simply using computers. From a user's perspective, the display will have much higher fidelity and brightness than the other two displays. 


\subsection{RESULTS OF WORKSHOP}

A workshop was held on May 16 and 17, 1996, at the Maritime Institute of Technology and Graduate Studies Conference Center, Linthicum Heights, MD. Contractor staff, the NHTSA COTR, and panelists convened to discuss the various issues associated with determining feasible simulation and other electronic device technology to use in training novice drivers. The principal investigator moderated the workshop with assistance from the program manager and the senior experimental psychologist. A workshop coordinator was present as well as an in-house expert in software/hardware issues.

Panelists (see Appendix A) were given a copy of the literature review approximately six weeks prior to the workshop. Panelists were asked to provide a one to two page summary of their comments about the report before the workshop. The purpose of this exercise was to get panelists' views of the key issues that would most likely be brought up for discussion at the workshop, and to incorporate their suggestions into the final report.

General comments of the literature review concerned issues relating to the definition of simulation and other electronic devices, as well as clarifying what is low, mid, and high level simulation. Other issues concerned the most practical learning environment, trainee interactivity, most suitable peripherals, and feedback mechanisms, and the need to address transfer of training.

For specific training target procedures, panelists felt there was a need to prioritize the training elements. Additions or modification were also suggested for the following: attention sharing/allocation/prioritization; hazard anticipation (traffic interactions); headway choice (using multi-task environment); influence/response to traffic control devices; risk perception, risk-taking, and decision-making skills; scanning behavior with timing (glance sharing); situational awareness; speed estimation; and vehicle handling under degraded conditions.

For simulation and other electronic device issues, there was a concern that it would be very difficult to meet all three of the following platform characteristics, "low-cost," "widely available," and "high-quality". Other issues related to the appropriate criteria for platform selection; other platform selection criteria (e.g., open vs. closed loop system design), immediate feedback of results; and response modality and fidelity.

\subsection{WORKSHOP AGENDA AND ACTIVITIES}

The workshop consisted of a day and a half of activities (see Appendix B). The first day consisted of the following: introduction of panelists and opening remarks by NHTSA COTR and contractor staff; review of project and workshop goals; and review of the literature review report. After the introduction of panelists, which included asking each panelist and contractor staff to identify their background experience as it related to the project, the NHTSA COTR covered NHTSA's current plan for research, development, and evaluation activities designed to restructure and improve novice driver education; and discussed the project's purpose and intent. NHTSA activities do not include developing hardware; however, software development will be considered. In addition, the plan includes identifying the means to make low-cost, readily available training product(s) to enhance novice driver learning. Any program developed would probably become part 
of a graduated licensing program. The moderator reviewed the project objective and scope of work, goals of the workshop; and briefly highlighted the major topics of the literature review.

The next workshop activity involved establishing operational definitions that would be used throughout the workshop. The following terms were discussed: simulator, part-task simulation, interactivity, accessibility, and cost. A general consensus of opinion about the terminology was established and is described in Table 5.

Panelists were then given the opportunity to share their concerns on critical issues important to address. The forum was an open discussion, with each panelist presenting issues, followed by subsequent discussions with the other panelists, contracting staff, and the NHTSA COTR. Panelist concerns reflected some of their comments identified prior to the workshop, but also included additional opinions. A summary of their comments is provided and categorized under the following topics: general training, simulation and other electronic devices, and training target procedures.

Table 5. Definitions of terminology established at workshop.

\begin{tabular}{|c|c|}
\hline Simulator & $\begin{array}{l}\text { electronic device that can contribute to the learning/training of young and } \\
\text { vice drivers. The device needs to be useable with currently available hardware } \\
\text { atforms. It is not essential that the viewing screen have high fidelity. The device } \\
\text { eds to have some level of interactivity with the trainee, but high face validity is } \\
\text { t essential. The device needs to be widely accessible, and relatively low-cost. }\end{array}$ \\
\hline $\begin{array}{l}\text { Part-task } \\
\text { simulation }\end{array}$ & $\begin{array}{l}\text { art-task simulation, re-creates only some elements of the driving task (e.g., a } \\
\text { ogram that requires a trainee to respond using only a brake pedal). Because of } \\
\text { veral factors (i.e., cost, accessibility, limits of viewing screens) it is not likely that } \\
\text { of the driving task functions will be used together in the program. }\end{array}$ \\
\hline Inter & $\begin{array}{l}\text { The device needs to meet some level of interactivity. This can be simply } \\
\text { responding to either questions with alphanumeric choices using the keyboard or } \\
\text { responding to the program with other peripheral equipment connected to the device } \\
\text { (i.e., a joystick, steering wheel, brake/accelerator pedals). High face validity is also } \\
\text { not essential. }\end{array}$ \\
\hline Acce & $\begin{array}{l}\text { The device will need to be accessible to almost everyone (i.e., } 15 \text { to } 18 \text {-year old } \\
\text { population across all economic levels). Accessibility can mean being able to use } \\
\text { the device at home on the family personal computer, or being able to access the } \\
\text { device at school, in a library, through a bookstore or video rental store, or even at } \\
\text { a mall or driver training/exam center, could also be an option. }\end{array}$ \\
\hline Low cost & $\begin{array}{l}\text { The device should be in a cost range that almost everyone can afford. The program } \\
\text { could be less than } \$ 50 \text {, like most gaming products today (given a PC or set-top } \\
\text { platform is already accessible). However, devices using peripherals and high } \\
\text { fidelity screens are also a possibility, although the cost could reach } \$ 1,000 \text {. Higher } \\
\text { range costing devices would be less accessible to the majority of the trainees. }\end{array}$ \\
\hline
\end{tabular}


Training programs have to be interesting or users will get bored, include some way to reward "boring," safe-driving; be validated; measure performance and show consequences of action; and incorporate peer influence. There is also a need to look at the most appropriate gaming strategies and a need to mix incidental and intentional learning.

For devices, panelists commented that certain simulators (usually those with poor visual and motion fidelity) can be problematic because of user proneness to motion sickness; and there is a need to address the assumption that behavior can be shaped with part-task simulation. High fidelity does not have to be a goal, but high transfer does.

Panelists commented that training for hazard anticipation, hazard detection, avoidance training and situational awareness were high priority. In addition, visual performance in degraded visibility, gap judgement, responding to emergency situations, and headway/speed choice are also important to consider. Training should improve decision-making skills.

\subsection{SUMMARY AND RECOMMENDATIONS}

The workshop served as an effective forum for the expression of ideas and concerns by experts in the fields of simulation, driver training, and learning theory. A multitude of critical issues and research suggestions were voiced. These can be categorized under the following topics: training elements, platform and display attributes, training scenario (software) development, instructional/learning applications, and research needs.

There was general agreement among workshop participants about what are the most common problems of young and novice drivers. However, there were long discussions about what were the higher priority training areas. For the most part, agreement was reached for including several training elements. These include: hazard anticipation/situational awareness, central (foveal) visual performance/useful field of view, scanning behavior, task sharing/divided attention, self monitoring requirements, and knowledge elements. Lower priority training concepts suggested included: peripheral visual field sampling; performance degradation due to alcohol/drugs or environmental conditions; speed or headway choice; and components of actual vehicle maneuver execution (such as in an emergency situation). There are constraints (e.g., platform attributes) associated with each of these training elements.

There was broad consensus that using the personal computer (PC) is an optimal strategy, in terms of its high accessibility, low cost, and applicability to most training elements. However, the use of other platforms (e.g., set-top and hand-held) and simulators cannot be ruled-out, since hardware development costs may not be significantly higher. The desirable screen/display size for devices is 30 inches or larger. Video and graphic inputs are necessary. The devices should be accessible in all types of settings (e.g., home, school, library, etc.). The display resolution should be greater than VGA ( 640 horizontal by 480 vertical pixels) with at least $60 \mathrm{~Hz}$ frame rate. The platform will be most accessible if it functions as a general purpose system, with a specialized driver training application realized through dedicated 'control box' and software. In addition, display attributes (i.e., size, resolution) warrant more careful consideration for platform selections.

The discussion of software development issues did not focus on the types of software applications or hardware/software interfaces necessary to develop devices. Instead, the software 
There was strong interest in the instructional/learning component of the training elements and the simulator and other electronic device applications. Although not the primary focus of the project, issues relating to adolescent development--apart form driving per se--need to be considered due to the impact that such issues have on the effectiveness of any training program targeted to young and novice drivers. In addition to age, gender and cross-cultural differences were mentioned as important to consider in training program development.

A large and diverse set of suggestions were offered by the workshop participants regarding needed research to facilitate the development of training elements with appropriate devices. These suggestions were categorized into four topic areas (1) training validity/effectiveness, (2) platform/display, (3) marketing, and (4) learning instruction.

\section{Training Validity/Effectiveness}

Suggestions concerned the following: the examination of transfer effectiveness with low fidelity displays; the comparison between trainee performance using part-task simulators and onroad, instrumented vehicles; the determination of the duration of training effect (those effects which can be measured); and the determination of feedback and its effect on changing behavior.

\section{Platform/Display}

The suggestions regarding research initiations consisted of the following: the determination of the most appropriate input/output measures for devices, determine the best way to examine driver behavior across multiple operators using current technology (as in a virtual environment scenario) and examine all elements of gaming systems that can be incorporated with positive outcomes.

\section{Marketing}

Primary suggestions involved the determination of how training elements can best be marketed to parents (i.e., as an educational tool, or gaming instrument) and what platforms are most acceptable and accessible to parents/guardians.

\section{Learning/Instruction}

The greatest number of suggestions regarding the research required to facilitate the development of training programs using devices, fell into this category. The following is a list of the main concerns and suggestions from the workshop:

- Determine what techniques will produce reliably and desirable peer influences on safe driving behavior (settings and external rewards need to be looked at).

- Determine relative influences of instructional versus motivational components in driver training.

- Examine if the instructional setting (home vs. school) changes platform applications. 
- Determine level of flexibility in training approach to accommodate gender and cultural differences.

- Determine the level of (a given) skill that should be trained. (Need to consider large differences in abilities of each trainee).

- Examine age and developmental phases of individuals. Are there differences among the target groups (15 to 18 year olds)? What can be trained at the different levels of development?

- Examine situational awareness issues.

- Determine how best to combine intentional and incidental learning goals in the same training program.

- Determine how best to train strategic and tactical goals conveniently in the same training program.

- Examine best way to make the learning experience challenging and motivating.

- Identify what training concepts can motivate and what will be socially acceptable.

- Ensure feedback does not disrupt learning. 


\subsection{RECOMMENDATIONS}

This chapter recommends training elements to use for simulation and electronic device applications, software development applications (including hardware ramifications), and research.

\subsection{TRAINING ELEMENTS}

The literature review identified a list of training elements based on the historical driving performance records of young and novice drivers. The training elements were divided into three categories: general driving abilities; specific driving abilities; and knowledge. From panelists, contractor, and Government review of this list and discussions at the workshop, the training elements were modified and new training elements suggested. The resulting list was divided into most and least amenable to devices.

The recommended training elements share the requirement for several common human performance attributes. These are:

- Situational awareness (SA): All training elements should require SA for optimal performance. SA is central to performance of complex tasks such as driving. Although it has been defined in various ways, the definition that will be used is based on Endsley (1995): SA is the perception of environmental elements within a specified spatio-temporal volume, the comprehension of their meaning, and the projection of their status in the near future. Some of the trainee feedback and evaluation criteria are aspects of SA.

- Divided attention: Selected training elements should be conducted with concurrent tasks and information sources. These elements should provide strategies that will result in the efficient and effective allocation of attention.

- Selective attention: All training elements should be presented within a driving context. Trainees must learn how to select relevant information embedded within a visually rich scene and in the presence of a number of distractors.

- Workload variation: Training elements should use implemented using different driving scenarios that encompass a wide range of information processing demands. This can be accomplished by varying the amount and type of uncertainty, degree of visual complexity, number of distractor targets, number of concurrent tasks and information sources, and the presentation rate of various stimulus events. In addition, for each training element, it is recommended that trainees "graduate" to more difficult levels as their performance begins to asymptote at a given difficulty level.

- Psychomotor coordination: Because of the importance of response fidelity, the responses required in the training must be valid representations of driving. Training scenarios that require trainees to coordinate among two or more responses in parallel are highly desirable.

It should also be noted that all of the specific driving abilities identified in the literature review, with the exception of hazard anticipation, were judged to be less applicable by the expert 
panelists at the workshop. This may be attributed, in part, to one of the central goals of the novice driver training; namely, emphasis on process vs. content. For example, it was generally acknowledged that the largest benefit using low-cost simulation can be obtained by making trainees aware of the process of making headway/speed choices (namely, what information is monitored, how the information is interpreted, and what are the appropriate vehicle maneuvers) as opposed to making "correct" headway/speed choices for a particular simulated driving speed. Thus, the criticism is aimed at the implementation of the specific driving abilities training elements, not the importance for novice drivers. If the specific driving abilities training elements can be implemented with an emphasis on process, it is assumed that such training elements would be acceptable. Furthermore, as will be seen in the detailed discussion of the training elements, there is sufficient overlap so excluding certain training elements identified in the literature review will not necessarily exclude the training benefits that would have come from those elements.

For each training element, separate training protocols are discussed. Nevertheless, there is overlap among training elements with respect to the specific driving scenarios that are simulated. For example, depending on the particular emphasis and timing of events within the scenario, a leftturn maneuver might be considered as a visual scanning training element or a hazard anticipation training element. Definitions and general storyboard concepts for each training element will be discussed. What follows is a multiple-phase script that is general enough to apply to all of the recommended training elements.

(1) Instruction phase: This phase provides a general description of the training procedure, the performance goals, any unique response instructions required for the element, practice, and the feedback that will be provided. Graphics, text, and auditory instruction formats should be used as needed. The overlays should have the look and feel of an on-board advisor/instructor. The instruction phase needs to be automatically presented at the beginning of the training session and repeated at the request of the trainee at any time.

(2) Preparation phase: This phase provides a driving context for the trainee. Responses will be monitored during this phase.

(3) Learning phase: The onset of the learning phase is determined by the earliest point at which a piece of information is provided to the trainee. The learning phase consists of an activity or series of activities that will require a response (or responses) from the student. Depending on the activity and driving situation portrayed, the type of response required from the student will vary. For example, the response could be knowledge based, or performance based, and timed or not timed. A knowledge based response might include selecting an answer to a question about the situation. A performance based response might include selecting (or performing) a driving behavior in response to the situation. Performance responses generally include headway (steer straight, right or left), or speed (maintain, slow/stop, or accelerate).

It should be noted that the limited resolution of video requires some type of graphic overlay when presenting text information. Also, the speed adjustment response requires that the playback medium have multiple playback speeds or that the scenes be manipulated digitally in real-time using CGI/overlay techniques. Multiple scenes videotaped at different actual speeds during videotaping is not feasible. 
Response interfaces that are not simulations of behind-the-wheel driving responses should use separate inputs. For example, responses during knowledge-based training should use well-marked number keys and functions keys on a keypad that is physically separate from driving simulator inputs (such as the accelerator, brake, and steering inputs). This will minimize response interference problems caused by inconsistent stimulus-response mapping. This keypad should also be used for inputs to questions that may be required during the feedback phase of driver training.

4) Feedback phase: Auditory and/or visual feedback via the simulated on-board advisor/instructor should be provided to trainees after each scenario. Other types of feedback can be provided to the trainee during a scenario only if it is part of the simulated driving task, or is used as a distractor. In addition, feedback will be provided for overall performance following the completion of each training element and again after completing all training elements. It will be important to ensure that the feedback does not disrupt learning.

To enhance the general "look and feel" of the various training elements, the training programs need to:

- Identify techniques which will produce reliable and desirable peer influences on safe driving behavior.

- Identify the relative influences of instructional versus motivational components in driver training.

- Accommodate gender and cultural differences in the training approach.

- Determine how to best combine intentional and incidental learning goals.

- Determine how to best train strategic and tactical goals used.

The assumptions for minimum system specifications in recommending training elements and that would be needed in developing the training element scenarios are: A platform that provides a 60 degree horizontal field-of-view (FOV), $30 \mathrm{~Hz}$ update rate (non-interlaced), and $800 \times 600$ pixel resolution (or greater). Such a platform would be adequate to implement the recommended training elements.

\section{Training Elements Most Amenable to Simulation and Other Electronic Device Technology}

The following training elements are considered to be essential elements of novice driver training and are presumed to be within the capabilities of existing low-cost hardware and software technology. The former criterion was determined in the literature review and the latter criterion was established at the workshop. Although the training elements are loosely ordered in descending importance, all are believed to contribute significantly to safe driving, and should be considered for further development. 


\section{Hazard anticipation}

Hazard anticipation is the ability to make appropriate speed and headway responses in anticipation of potential hazards or changing demands. Thus, trainees develop the ability to predict the status of individual and environmental elements in the "near" future. It is important to note that this training element develops the ability to identify and react appropriately to potential hazards. Thus, the scoring of this training element is based on responses prior to the presentation of an actual hazard situation." Although the dividing line between actual/potential hazard is sometimes difficult to define, scenarios can be designed so that the hazard onset is abrupt. For example, when approaching a signalized intersection, hazard onset can be abrupt in that objects can appear from behind buildings (or other visual obstacles) near the intersection. The potential hazard interval is the time between when the intersection is visible in the road scene and the onset of an actual hazard. If an appropriate response (i.e., reducing speed) is not recorded within this interval, then it must be assumed that no hazard anticipation has occurred. Example scripts for two hazard anticipation scenarios follow:

(1) Intersection conflicts: One context that might be used is a narrow city street. On the approach to a signalized intersection, a pedalcyclist appears from behind a building near the lane of travel. Just prior to the appearance of the pedalcyclist, trainees are presented with one or more distractor stimuli on the opposite side of the road (such as debris falling out of the building) or an in-vehicle warning. The speedometer should be present at all times. The first exposures may involve the trainee not reacting in time to avoid collision and the feedback would give explicit information about what cues could have been used to anticipate this hazard. If trainees modify their behavior based on this feedback, collisions should be averted on subsequent hazard exposures (uncertainty must be maintained by using different hazard stimuli, road scenes, hazard onsets, and hazard locations).

(2) Degraded road conditions: Similar scenario as in \#1, except that the context is highway driving on wet pavement. Hazard onset is cued by the onset of brake lights from vehicles in the lane of travel. Distractors could include accidents in opposing lanes, police car parked on the shoulder, or any other face valid distractor.

\section{Visual scanning behavior}

Visual scanning behavior is a driver response requiring combinations of eye, head, neck, and upper torso movements to foveally acquire information from areas in the road environment where actual or potential hazards exist. The general recommended approach in implementing this training element involves two stages: experimenter-cued scans followed by trainee-initiated scans. During the experimenter-cued stage, a methodology similar to a scanning probe technique described by Ziskind (1991) should be used initially to guide the scanning behavior. In this method, lightemitting diodes (LEDs) are placed at various locations in a vehicle and specific LEDS are activated in sequence to prompt the driver to scan to that location, such as to the driver's side mirror, if the maneuver involves changing lanes. One modification to this technique is the use of acuity targets, which require foveal acquisition for accurate detection. This ensures foveation has occurred, since an objective measure of scanning behavior cannot be obtained nor can an instructor be present to verify correct scanning behavior has occurred. After demonstrating a criterion level of proficiency during experimenter-cued scanning, trainees will be presented with trainee-initiated scanning trials 
in which the trainee is presented with a conflict situation. Example scripts for two visual scanning behavior scenarios follow:

(1) Lane change: For the experimenter-cued trials, a sequence of scans (driver side mirror probe target $\rightarrow$ left outside probe target $\rightarrow$ left blind spot probe target) should be specified by the probe target. Trainees should be allowed at least 1 second to respond to successive probes. For trainee-initiated trials, the primary conflict situation is an object in the apparent projected path of the vehicle. Prior to making a maneuver to avoid this object, the trainee must make appropriate scans to detect a second conflict vehicle.

(2) Left turn: Similar to the previous scenario except that the primary conflict object is an oncoming vehicle and the secondary conflict object is a pedestrian or pedalcyclist approaching, and then entering the intersection.

The probes in this training element do not require multiple screens or additional hardware. For example, it is acceptable to use graphic overlays to simulate a mirror view. It may also be possible to simulate direct looks to the side and rear of the vehicle by scrolling the video appropriately. The probe targets should be embedded in each view. Also, the scrolling capability should be provided to the trainee automatically during experimenter-cued trials and requested by the trainee via a button press in trainee-initiated scans. The training can cycle between experimenter-cued and trainee-initiated trials depending on performance on each.

\section{Foveal/peripheral visual performance}

This is a combination of useful field of view (UFOV), central, and peripheral training elements defined in the literature review. The minimum requirements for field of view (FOV) and resolution defined earlier drive the training element scenarios that will be developed for this training element. Targets need not be representative of actual targets. Hence, they may be gratings, LandoltCs, or other standard vision screening stimuli. These targets must overlay actual dynamic road scenes, but do not need to appear to be part of the road scene. Scenarios that require presentation of targets at/near the normal visual acuity limits and 60 degree horizontal FOV cannot be included in the training program.

It is recommended that three combinations of foveal peripheral tasks (i.e., foveal + foveal, foveal + peripheral, peripheral + peripheral) be presented to the observer. Definitions and example scenarios for each of the three pairings follow:

(1) Foveal + foveal: This training scenario is designed so that two foveal tasks are presented concurrently and they must be processed sequentially due to the requirement to refixate. For example, trainees might be asked to detect changes in a grating target area (such as presence/absence, orientation, or contrast) in one location of the scene while making a decision about when it is safe to make a lane change or a left turn. Because the horizontal pixel resolution of the system is roughly 800 pixels (which is 4.5 minutes of arc per pixel for a 60-degree horizontal FOV), and because 4.5 minutes of arc can be resolved at an eccentricity of about 15 degrees, the foveal tasks must be separated by at least 20 degrees. This should be sufficient to allow the observer to refixate, assuming that the contrast of the critical feature is modulated along the horizontal axis of the display. 
(2) Foveal + peripheral: This is similar to the UFOV paradigm, in which peripheral targets are detected/recognized, while criterion performance for a concurrent foveal task is maintained. For example, the foveal grating task described previously might be paired with a peripheral motion detection task located near the lower edge of the screen. These targets should be presented in the presence of a dynamic highway road scene and located relative to this scene; namely, foveal task near the focus of expansion and peripheral task near the end of the lane markings (lower left or lower right screen location). It should be noted that the peripheral task can be performed using foveal vision. However, doing so will inevitably result in poorer performance on the foveal task due to the resolution demands of the grating and the angular displacement of the two tasks.

(3) Peripheral + peripheral: In this training element scenario, two concurrent tasks are presented that can be performed adequately using peripheral vision only. As an example, two peripheral motion detection tasks, described previously, could be utilized. The target locations for each peripheral task should be displaced horizontally to maximize dual-task decrements that would result if fixation were located somewhere other than the middle of the screen.

\section{Knowledge elements}

Whenever feasible, knowledge elements and rules of the road should utilize simulation techniques in the training procedure. The following are examples of training elements which train decision-making processes that can be simulated using all of the platforms under consideration, and learning is likely to be highly generalizable to behind-the-wheel driving behavior/performance.

(1) Hazard avoidance: Trainees are presented with information (via radio, or simulated TV broadcast) about a number of different possible hazards that increase the accident risk or require the use of alternate routes. In subsequent trials they are presented with the opportunity to obtain the same information. Their subsequent behavior is monitored to determine how the information affected their decisions. This scenario is distinguished from hazard anticipation in terms of the amount of time between current status and potential hazard. Specifically, the prediction of individual and environmental elements is longer term for hazard avoidance compared to hazard anticipation scenarios.

(2) Vehicle control: The vehicle control rule "steer where you want the vehicle to go" can be taught using simulation techniques. Trainees can be presented with actual video segments of a car entering a skid on a closed test track. Different perspectives could be presented (such as a wide-angle overhead view, driver's view of the road, a view of the driver's gas/brake/steering control responses, and/or a roadside view) on the same screen. Video segments can be used as study aids or evaluation tools with appropriate programming. The trainee learns how a vehicle responds in many different conditions in a way that is unambiguous and more interesting than just reading the information. 


\section{Training Elements Least Amenable to Simulation/Electronic Device Technology}

Scripts for the following training elements are not provided because they were determined to be less appropriate for low-cost novice driver training at this time. However, the basis for exclusion is described as well as implications for the overall effectiveness of the novice driver training.

\section{Peripheral visual performance}

The simultaneous requirement for large FOV and high resolution, as specified in the literature review, is the primary basis for excluding this training element. Nevertheless, some aspects of peripheral visual performance are included in the aforementioned Foveal/Peripheral and Scanning Behavior training elements.

\section{Performance degradation}

This training element was proposed as a means of simulating various conditions of driver impairment that are associated with high accident risk among novice drivers. Two degraded conditions were proposed for this simulation: (1) physiological effects of alcohol, and (2) reduced visibility during nighttime driving. Goggles would be used to induce diplopia, defocus and disorientation, simulating the effects of alcohol. Neutral density filters would be used to obtain representative brightness levels for nighttime road scenes, simulating reduced visibility. The primary basis for excluding this training element is feasibility. Using goggles or some other piece of hardware external to the display will certainly increase overall system cost and make the system too cumbersome for general purpose use. In addition, it may require the presence of an instructor. Fortunately, some aspects of this training element may be addressed using a knowledge-based Training element.

Two other shortcomings of this training element that were discussed at the workshop are worth noting because of their more general implications for the entire training program. First, this training element was criticized because trainees could readily defeat the simulation by simply looking around the goggles. The second criticism was that trainees might be motivated to compensate for the artificially-induced degradation by exerting more effort which, in turn, could possibly result in little or no change in performance. Although these are certainly valid criticisms, they are not insurmountable. In fact, without the appropriate hardware setup and training protocol, these same criticisms could be applied to all training elements. For example, certain training elements require the trainee to view the stimuli from a specific viewing distance. If the viewing distance is not maintained, trainees may be able to artificially improve their performance on some training elements (particularly the tasks requiring foveal acquisition) by moving closer to the display. Although this may be an adaptive strategy during training, this strategy is clearly ineffective during behind-the-wheel driving.

The second criticism (namely, variation in allocation and level of effort) can be addressed using a crude assessment of the performance operating characteristic for dual-task results. If singletask performance for each task is less than perfect and the tasks cannot be processed in parallel, then exerting more effort in one task will result in poorer performance in the other task during dual-task trials. Since it is recommended that the training elements use at least two concurrent tasks, it is very 
likely that the performance under multiple-task conditions will result in decrements which would require the student to repeat the element.

\section{Speed and headway choice}

Speed and headway choice are grouped together since the stimulus information that must be monitored in both instances is very similar. The distinction between these two training elements is based primarily on the presence/absence of a visual stimulus that should be recognized as a potential hazard. Speed choice is made in the absence of any lead vehicles or any other obstacles that pose an imminent threat to the driver. Headway choice, on the other hand, is the decision about what is a safe following distance for a lead vehicle that is initially moving at the same apparent speed and then abruptly reduces speed. Speed choice requires much better SA since there is no observable hazard stimulus during the time the speed choice is being made (i.e., much more top-down processing is required). Operationally, both types of choice require the trainee to monitor current individual factors (e.g., alertness, workload) and environmental (e.g., speed of vehicle, road conditions), and make appropriate responses based on this information.

The primary basis for rejecting this training element is that simulators, especially low-cost simulators, lack validity with respect to speed and distance perception. Specifically, speed estimates obtained in simulation may, as indicated in time-to-collision judgments estimated as speed measures, will vary significantly from estimates obtained during the identical conditions encountered in the field. This is even true for simulators using correct perspective views of the driving scene (Staplin, Lococo, and Sim, 1993).

One way to deal with this shortcoming is to emphasize the process of making speed/headway choices. For example, rather than requiring trainees to estimate speed, provide this information to the trainee via a simulated speedometer using a graphic overlay. Although the stimulus conditions are certainly less than optimal, trainees can still make judgements about "safe" headway/speed by applying principles acquired during knowledge-based training. This emphasizes the process of making decisions based on information rather than what is the "correct" decision. In any event, it is recommended that this training element be incorporated into the hazard anticipation training element. Also, it is generally recommended that explicit speed information be provided for all training elements, and that at no time should trainees be asked to estimate speed.

\subsection{DEVELOPMENT OF NEW SOFTWARE}

Given the limited availability of current training products which can be used for novice driver training, it is apparent that practically all of the recommended training elements will have to be developed. Before making specific recommendations for hardware and software applications, programming languages that could be used to develop the applications, will be reviewed. 


\section{Programming Languages}

There are several programming languages that can be used for developing applications. The more popular languages include assembly, $\mathrm{C} / \mathrm{C}^{++}$, Delphi, and Visual Basic. Table 6 provides a comparison of programming languages that can be used for training program and game development. Sawyer (1996) reports that for game development, $\mathrm{C} / \mathrm{C}^{\text {t+ }}$ is the dominant language. Originally developed by AT\&T Labs as the language for its UNIX operating system, C has long been an important development tool. Because it represents the ultimate in performance, assembly language coding was dominant in game development until recent improvements in computer processing speed. The chief drawback of assembly language programming is that software development takes very much longer than with high level languages such as $C$. Assembly language can be embedded in all other languages for functions requiring high speed (e.g., graphics functions). Delphi is a specialized Windows version of Pascal. Visual Basic is a version of Basic that runs under Windows and has software libraries that greatly simplify development of Windows user interfaces

Table 6. Programming languages. *

\begin{tabular}{|c|c|c|c|c|c|c|}
\hline Product & Speed & Portability & $\begin{array}{l}\text { Authoring } \\
\text { Platform }\end{array}$ & $\begin{array}{l}\text { Ease of } \\
\text { Use }\end{array}$ & Cost & Future? \\
\hline $\mathrm{C} / \mathrm{C}++$ & fast & $\begin{array}{l}\text { highly, need } \\
\text { to do } \\
\text { rewrite for } \\
\text { different } \\
\text { platforms }\end{array}$ & $\begin{array}{l}\text { highly } \\
\text { accom- } \\
\text { modative }\end{array}$ & $\begin{array}{l}\text { slightly } \\
\text { difficult }\end{array}$ & up to $\$ 1 \mathrm{~K}$ & $\begin{array}{c}\text { continue to } \\
\text { dominate }\end{array}$ \\
\hline Assembler & fastest & somewhat & $\begin{array}{l}\text { highly } \\
\text { accom- } \\
\text { modative }\end{array}$ & difficult & $\begin{array}{c}\text { usually } \\
\text { included } \\
\text { with } \\
\text { hardware }\end{array}$ & $\begin{array}{l}\text { still required } \\
\text { for some } \\
\text { functions }\end{array}$ \\
\hline Delphi & $\begin{array}{l}\text { fast, but } \\
\text { slower } \\
\text { than C }\end{array}$ & $\begin{array}{l}\text { Windows } \\
\text { products } \\
\text { only }\end{array}$ & $\begin{array}{l}\text { Windows } \\
\text { only }\end{array}$ & $\begin{array}{l}\text { somewhat } \\
\text { easy, } \\
\text { especially } \\
\text { for Pascal- } \\
\text { trained } \\
\text { users }\end{array}$ & $\$ 500$ & solid \\
\hline $\begin{array}{l}\text { Visual } \\
\text { Basic }\end{array}$ & $\begin{array}{l}\text { situation- } \\
\text { ally slow }\end{array}$ & $\begin{array}{l}\text { Windows } \\
\text { based } \\
\text { environ- } \\
\text { ments only }\end{array}$ & $\begin{array}{l}\text { Windows } \\
\text { only }\end{array}$ & easy & $\begin{array}{l}\$ 200 \text { to } \\
\$ 1 \mathrm{~K}\end{array}$ & solid \\
\hline
\end{tabular}

* Based on Sawyer (1996). 


\section{Authoring Packages}

Several off-the-shelf, multimedia authoring packages are suitable for device development. These packages offer cross-platform development schemes. However, these products are not as fast as programming languages and are limiting across certain application types. The more common packages available to date include Director, mTropolis, Oracle Media Objects, Strata Media Forge, and QuarkImmedia. A comparison of authoring packages for game development is presented in Table 7. Director (Macromedia, Inc.) is the most well-known. Director can animate text and graphics, create hot-spots, and perform all of the other standard multimedia functions. Another package is mTropolis (mFactory), which is only available in an authoring form for Macintosh. It delivers true object orientation, and allows developers to easily introduce their own objects and $\mathrm{C} / \mathrm{C}++$ programs. The Oracle Media Objects (Oracle Corporation) application consists of one or more distinct screens that a user interacts with; each screen contains its own graphical layer, as well as various objects that are linked and controlled by a rich high-level scripting language. This application provides a number of mechanisms to extend and customize its capabilities. MediaForge (Strata, Inc.) is a Windows 95/NT-based authoring package. It is billed as a full 32-bit authoring, event-driven, multi-threaded multimedia authoring environment. It comes with over 100 special effects, an embedded Visual Basic editor, support for OLE controls, and is highly extendible. QuarkImmedia (Quark, Inc.) is an authoring tool that sits on top of QuarkXPress, which provides the tool with lots of excellent layout and graphical capabilities. It supports digital video, sound, animation, hot-spots, and includes a comprehensive scripting language, database connectivity, online functions, and an Xtension technology to add personal features (Sawyer, 1996).

There are also several storyboard software products to help the developer with writing scripts, visualizing shots or planning production from start to finish. These products use text, graphics, and organizational tools to help visualize production before shooting. Many of these products include logging capability. There are about 20 pre-production storyboard software packages on the market (McCleskey, 1996).

\section{Product Development Costs}

At this time, only general development cost estimates can be given for any one of the recommended training elements. A more-defined training element with a detailed script and storyboard is needed for software developers to provide more realistic cost estimates.

Visual Software Solutions, Inc. (Media, PA) provided cost estimates for PC, console, and hand-held applications for a training element relating to hazard anticipation. They were provided with a specification sheet for the training element with very general storyboard phases (instruction, preparation, response, and feedback), storage requirements, and example hazard anticipation scenarios.

For PC-based applications, Visual Software Solutions, Inc., estimated that it would cost approximately $\$ 144 \mathrm{~K}$ to produce a draft CD-ROM. However, this does not include the testing and documentation required to turn it into a commercial product. It also does not include professional videotapes of the various scenarios nor music and exotic sound effects. If extensive testing and revisions are required, the budget for this phase could double. Production costs of the CD-ROM also need to be included. A CD-ROM mastering house can produce a platter for approximately $\$ 2$. 
If a manual and a box are included, production costs could increase the product cost to $\$ 10$ per unit. Visual Software Solutions, Inc., estimated that if the training product is sold at $\$ 50$ per unit, the development costs could be recouped with a sale of 10,000 units (Brachman, 1996). In other words, it would take an investment of approximately $\$ 500 \mathrm{~K}$ to break even

Table 7. Authoring packages used for game development. *

\begin{tabular}{|c|c|c|c|c|c|c|}
\hline Product & Speed & Portability & $\begin{array}{l}\text { Authoring } \\
\text { Platform }\end{array}$ & $\begin{array}{l}\text { Ease of } \\
\text { Use }\end{array}$ & Cost & Future? \\
\hline Director & $\begin{array}{l}\text { situation- } \\
\text { ally slow }\end{array}$ & $\begin{array}{l}\text { highly } \\
\text { (Windows, } \\
\text { Mac, SGI, } \\
\text { consoles, } \\
\text { Internet) }\end{array}$ & $\begin{array}{l}\text { Windows } \\
\text { and Mac }\end{array}$ & $\begin{array}{c}\text { somewhat } \\
\text { easy }\end{array}$ & $\$ 1 \mathrm{~K}$ & $\begin{array}{c}\text { current } \\
\text { authoring } \\
\text { package } \\
\text { leader, } \\
\text { especially with } \\
\text { Internet }\end{array}$ \\
\hline mTropolis & $\begin{array}{c}\text { fastest } \\
\text { authoring } \\
\text { product }\end{array}$ & highly & $\begin{array}{c}\text { Mac, } \\
\text { Windows } \\
\text { on way }\end{array}$ & complex & $\$ 5 \mathrm{~K}$ & $\begin{array}{l}\text { new, powerful, } \\
\text { but uncertain }\end{array}$ \\
\hline $\begin{array}{c}\text { Oracle } \\
\text { Media } \\
\text { Objects }\end{array}$ & $\begin{array}{l}\text { situation- } \\
\text { ally slow }\end{array}$ & highly & Mac & complex & $\begin{array}{c}\text { free for } \\
\text { now }\end{array}$ & $\begin{array}{l}\text { free, but } \\
\text { uncertain }\end{array}$ \\
\hline $\begin{array}{c}\text { Strata } \\
\text { Media- } \\
\text { Forge }\end{array}$ & $\begin{array}{l}\text { situation- } \\
\text { ally slow }\end{array}$ & $\begin{array}{c}\text { somewhat } \\
\text { high }\end{array}$ & $\begin{array}{l}\text { Windows } \\
95 / \mathrm{NT}\end{array}$ & complex & $\$ 1.5 \mathrm{~K}$ & $\begin{array}{l}\text { good, but } \\
\text { uncertain }\end{array}$ \\
\hline $\begin{array}{c}\text { Quark- } \\
\text { Immedia }\end{array}$ & slow & $\begin{array}{c}\text { somewhat } \\
\text { high }\end{array}$ & $\begin{array}{c}\text { Mac with } \\
\text { Quark- } \\
\text { XPress }\end{array}$ & $\begin{array}{l}\text { easy for } \\
\text { Quark- } \\
\text { Xpress } \\
\text { users }\end{array}$ & $\begin{array}{c}\text { \$3-4K } \\
\text { since } \\
\text { Quark- } \\
\text { XPress and } \\
\text { Quark- } \\
\text { Immedia } \\
\text { needed }\end{array}$ & uncertain \\
\hline
\end{tabular}

* Based on Sawyer (1996).

Development time depends on many factors relating to the type of training product being developed. Sawyer (1996) estimated that it would take a development team three to four months to flesh out an entire idea before programming even begins. Visual Software Solutions, Inc., estimated it would take roughly 26 man-weeks for programming to produce a CD-ROM (Brachman, 1996). Once the product is complete, it needs to be tested. There are usually two testing phases: Alpha, where design changes and other more substantive problems are addressed; and Beta, where only bugs and minor flaws are fixed. Testing can take a few months or more depending on the complexity of the training product. Sawyer (1996) noted that in the gaming world, time to develop a game from the original concept to full production can take anywhere from 12 to 24 months. 
For console (set-top) devices, software development costs will be similar to PC-based software development, with the exception of additional costs associated with paying substantial licensing fees to the parent company of that particular console platform. (For instance, Sega and Sony charge licensing fees of $\$ 5$ and $\$ 7$ per game sold, respectively. It is purported that Nintendo will charge around $\$ 35$ to $\$ 38$ for making and licensing each cartridge.) Consoles have recently become more accessible to developers, partly because the tools have improved and the machines have gotten faster, allowing for PC-knowledgeable developers to port their games to the console platform. Development of a training product requires a specific development kit ( $\$ 8 \mathrm{~K}$ to $\$ 10 \mathrm{~K}$ ) for that console and the necessary hardware to run it. These setups usually consist of a $\mathrm{C}$ compiler, an assembler and debugger, a large number of libraries for graphics and sound, and specially-tailored hardware that mimics the console's operating system on the developer's computer (Sawyer, 1996). Visual Software Solutions, Inc. estimated that the actual design effort for putting the training product onto a cartridge for a console device could range anywhere from $\$ 100,000$ to $\$ 300,000$, depending on the richness of the graphics, music, complexity of the background, and interaction with the user. Cartridges can be made for between $\$ 5$ and $\$ 15$ per cartridge in quantities of 1,000 or more. This means that the total training product kit can be sold for between $\$ 25$ to $\$ 50$, which is standard for the market (Brachman, 1996).

Development time for products that use consoles should not be substantially different than for those products developed for the PC. However, there is probably more front end time in dealing with the console manufacturer or established game/training product publisher and setting up the appropriate development platform.

Development costs and time for development for hand-held devices can be quite different than those for PC-based and console platform development. For one thing, there are limitations on what training elements can be developed for hand-held devices because of the limited display features. This limits the types of static images that can be created, which can substantially reduce the programming development costs. Visual Software Solutions, Inc., estimated that development costs could range from $\$ 25,000$ to $\$ 50,000$, depending on the number of buttons added to the platform or additional space allocated to the display. In addition, the prototype device could cost as little as $\$ 5,000$ to develop and be manufactured for as little as $\$ 5$ to $\$ 10$ per unit, in quantities of 1,000 or more (Brachman, 1996). Hand-held gaming devices range in price from $\$ 10$ to $\$ 100$.

\section{Ramifications for Hardware Selection}

A primary consideration in the development of software applications is the target platform itself. In this context, the term platform refers to both the hardware and, if appropriate, software operating system, on which the training element application will run. As noted in Chapter 4, there are essentially three classes of platforms to be considered: (1) IBM-compatible Personal Computers (PC) running the DOS or Windows operating systems; (2) Apple Macintosh Personal Computers (Mac) running Apple's Operating System; and (3) the unique hardware environments of the various hand-held and set-top gaming devices which run custom applications (i.e., games) exclusively.

Where possible, software development is easiest -- and, therefore, fastest and cheapest -when performed on the target platform itself. This approach is referred to as a native development environment. For example, while it may be possible to develop a software application for a PC using a Mac in a so-called cross-platform development environment, the complications associated 
with transferring the software from the development system to the target system then testing and debugging it would render this procedure costly. All software development for PCs is therefore done on PCs themselves, just as Mac software is developed exclusively on Macs. Since, by definition, hand-held and set-top gaming devices are not general purpose computers, development of software to run on these devices must be done in a cross-platform environment. In addition to the difficulties associated with operating in a cross-platform development environment, expensive cross-compilers and hardware support tools must be purchased in order to develop and test software for the hand-held and set-top gaming systems. Native compilers are much more readily available and much cheaper, particularly for PC software development.

Many of the training applications envisioned in this project share the performance requirements of gaming software; namely, a high level of interactivity with the user as manifested by high quality graphics and prompt response to user inputs. In order to accomplish the desired level of interactivity, training applications must interact intimately with the target device's hardware. For platform development therefore, two additional factors besides the software development environment must be considered: the availability of documentation of the target computer's hardware and the degree to which the platform's hardware is standardized. These factors are summarized in Table 8.

Table 8. Comparison of hardware standardization and documentation availability for candidate hardware platforms.

\begin{tabular}{|c|c|c|}
\hline Hardware Platforms & Hardware Standardization & $\begin{array}{l}\text { Level of } \\
\text { Documentation }\end{array}$ \\
\hline PCs & Very Low & Easy \\
\hline Mac & High & Difficult \\
\hline $\begin{array}{l}\text { Hand-held/ } \\
\text { Set-top }\end{array}$ & $\begin{array}{c}\text { Very High } \\
\text { (for any given device) }\end{array}$ & Very Hard and Expensive \\
\hline
\end{tabular}

One of the PC's greatest strengths and a major factor in its domination of the personal computer market, is its open architecture, which is a system design that supports after-market, addon hardware (via expansion slots) and whose hardware specifications have been widely published. Users can choose from a wide variety of video cards, sound cards, hard disks and network cards as well as CD-ROM drives and tape backup units. Furthermore, the PC has hosted six generations of microprocessors (the chip that forms the heart of the computer) spanning a range of performance of approximately four orders of magnitude.

Unfortunately, the PC's open architecture is a double-edged sword to the software developer. While hardware documentation is in the public domain and available at most local bookstores, the proliferation of hardware configurations is a significant complication. Faced with similar problems, game developers generally specify a minimum hardware and software configuration needed to run their product (e.g., 486 - $66 \mathrm{MHz}, 8 \mathrm{MB}$ RAM, quad-speed CD-ROM drive, super VGA graphics, 16-bit Sound Blaster compatible sound card, etc.) A similar approach may prove necessary for 
training element applications developed for the PC. By the end of this year, the minimum standard will most likely include a $60 \mathrm{MHz}$ Pentium with $8 \mathrm{MB}$ RAM, a quad-speed CDROM drive, 16-bit sound card, and a specialized 3-D graphics acceleration card (Sawyer, 1996).

Since Apple, until very recently, has been very reluctant to license the Mac hardware architecture to after-market equipment vendors, there is little or no variability in Mac hardware configurations of concern to a developer. One of the big attractions of the Macintosh has always been that, since Apple was in complete control of the hardware configuration,-any add-on equipment purchased by the user was essentially guaranteed to work. The relative consistency of hardware configurations greatly simplifies the task of a developer, assuming the availability of documentation of the Mac's hardware. Fortunately, this documentation is significantly easier to come by due to Apple's decision, early in 1995, to license businesses interested in producing Macintosh clones.

The potential developer of hand-held/set-top software is in a similar situation. The good news is that, for a given device type (e.g., Gameboy, Sega, etc.) there is no variation in the device hardware. A training application written for Gameboy is guaranteed to run on all Gameboys. The bad news is that the documentation needed to develop the software is available only from the device's manufacturer and only after payment of a substantial licensing fee. Furthermore, the device manufacturers typically charge a royalty for each software unit sold. Combined with the expense of cross-compilers and in-circuit emulators, these licensing fees and royalties result in a much higher startup cost compared to PC development (Brachman, 1996; Sawyer, 1996).

\section{Recommendations for Novice Driver Training Applications Development}

Recommending a platform for novice driver training applications involves reconciling a series of conflicting goals. The ideal platform should be low cost, widely available during the projected life of the driver training software, and inexpensive to develop software for; it should support high fidelity display devices and commercially available vehicle-like controls; and it should provide sufficient processing power to eliminate temporal artifacts during dynamic scenes. Unfortunately no single platform meets all these goals.

Hand-held gaming devices, while low in cost, suffer from poor display fidelity, are among the most expensive devices for which to develop software, and have unique hardware designs which are rendered obsolete every few years by advances in technology. In addition, the processing speed of these devices is marginal for most of the training applications. Given that the sole advantage of these devices is their low cost, they are not suited for training applications envisioned in this report; consequently they cannot be recommended as a platform.

Set-top devices share many of the drawbacks of the hand-held gaming devices but trade-off a higher price for an improved display and greater processing power. However, an education/training product will probably be a difficult sell to set-top platform manufacturers who are primarily interested in games. Moreover, due to the proliferation of different consoles and their questionable availability during their desired lifetime, these devices are unsuitable as a platform.

While considerably more expensive than hand-held and set-top devices, Macs have several advantages over these platforms. Development of software applications for the Mac is considerably easier and cheaper than for the hand-held and set-top devices. Also, the Mac directly supports 
large, high quality displays and has a stable hardware configuration. One factor significantly reduces the desirability of the Mac as a platform for novice driver training applications, however. While the Mac is popular in schools, which is one of the likely venues for novice driver training applications, the installed base of PCs outnumbers that of Macs about ten to one, overall (Hartsook, 1996). While Macs represent a good platform on which to build novice driver training applications, the PC is a superior alternative today. However, this is changing as Mac clone sales continue to increase; the Power PC has a 12 to 18 month performance edge over Intel chips at half the cost; and, as always, Macs are generally easier to use than PCs. Furthermore, the distinction between PC and Mac is narrowing as hybrid Macs (namely the Power PC) is capable of running both PC and Mac applications.

At this time, the choice of a hardware platform on which to host a driver training application is the IBM-compatible PC. While the multitude of possible hardware configurations is a potential issue, the fundamental hardware architecture has remained unchanged since the arrival of the original IBM PC fifteen years ago. Today's $200 \mathrm{MHz}$ Pentium Pro still runs every piece of software developed for the original PC, albeit several thousand times faster. Like the Mac, the PC supports high fidelity display devices and realistic driving controls, and PCs made within the last few years provide plenty of CPU "horsepower" to achieve desired levels of display and user response performance. As mentioned previously, documentation of the PC's hardware is readily available at low cost as are software development toolkits. While PCs cost considerably more than hand-held and set-top gaming devices, the great demand for PCs has driven the cost down precipitously in recent years. In any case, PCs almost always cost much less than Macs of equivalent performance.

Specifying the hardware is necessary but not sufficient to define the target platform. Given the choice of the PC, one must also select a target operating system. The purpose of an operating system is to present a standard, hardware-independent interface to application software running on the computer. While this would seem to eliminate problems of hardware configuration, software games (and the applications envisioned in this report) represent the most demanding type of software with respect to computer performance. As the operating system introduces an additional "layer" of software between the application and the hardware, most software games bypass the operating system and access the hardware directly, electing to trade more complex software development and, in some cases, fewer compatible hardware configurations for improved performance. In addition, some advanced forms of software operations may not be directly supported by older operating systems, forcing game developers to come up with their own software functions. Recent advances in CPU power have started to render performance issues moot, however, making the advantages of a hardware-independent interface as provided by an operating system more attractive.

Having selected the $\mathrm{PC}$ as the hardware platform, there are a multitude of operating systems from which to choose: DOS, Windows 3.1, Windows for Work Groups, Windows 95, Windows NT, $\mathrm{OS} / 2$, and UNIX. While most games have been developed to run under DOS as it is the easiest to bypass for direct hardware access, the focus of game developers seems to be shifting to the Windows family of operating systems, to take advantage of their multimedia support, of which Windows 95 's is the strongest. Among the operating systems available for the PC, Windows 95 is the clear choice as a host operating system for applications development. Microsoft, the developer of Windows 95 and the industry leader in operating systems and applications, is positioning Windows 95 as the platform of choice for game development. Coupled with recent increases in CPU power, Microsoft's Windows 95 gaming extensions greatly reduce the need for game developers to deal with hardware 
devices directly in order to achieve desired rates of display updates and response to user inputs. This allows games (and device applications) to be written for a much broader range of hardware configurations. Also, nearly all of the desirable features of the renowned Macintosh user interface have been incorporated into Windows 95 , thereby eliminating the last real advantage of Macs over the PC. This should serve to further increase the availability of PCs relative to Macs.

While Windows 95 has not achieved the degree of market penetration Microsoft had hoped for, essentially all new PC applications are being written to expect Windows $9 \overline{5}$ as the host operating system. Furthermore, given that the gap between submission of this report and completion of the development of the novice driver training applications is likely to be several years, Windows 95 is expected to be the dominant PC operating system when recommended training applications are introduced.

\subsection{RESEARCH NEEDS}

Novice driver training should be based upon well-documented, robust research findings with clear implications for driver performance, behavior, and safety. To this end, the training elements discussed in previous sections have considered: (1) accident analyses and human factors research findings; (2) fundamental learning principles that pertain to the development of effective computeraided instruction, feedback and evaluation; and (3) software/hardware constraints on simulation fidelity. During the process of developing the initial specifications for the training elements, a number of shortcomings of existing research have been identified.

The human factors, hardware, and software research needs discussed next are judged to be critical because of their impact on the validity of novice driver training. In this context, validity refers to the degree to which a trained driver manifests the same behavior/performance as an experienced driver under similar circumstances. Of particular relevance for novice driver training is the extent to which the behavior/performance of trainees is different from a comparison group (including, for example, experienced drivers, novice drivers that undergo standard driver training, and/or longitudinal assessment of trainee's performance). Differences can be quantified in terms of a net time savings in reaching a criterion level of safe driving skills. The following items are some of the factors that are considered important for training: (1) presentation of realistic, representative driving scenarios via the control of sensory, perceptual, cognitive, and motor workload; (2) higher exposure rates to safety-critical events relative to actual driving; and (3) direct feedback on particular training scenarios and overall performance, which facilitates the learning process. Without discounting the possibilities of benefits associated with existing software applications for driver training, a better understanding of the following issues is essential for increasing the efficacy of future novice driver training using devices.

\section{Human Factors Research Needs}

Three topic areas are covered within this section: (1) structure and content of trainee feedback, which includes a discussion of the "criterion problem", incentive issues, incidental learning effects, and training situation awareness; (2) transfer of training, which includes a discussion on fidelity and transfer-of-training and fidelity and cost factors; and (3) validation of novice driver training devices. 


\section{Structure and content of trainee feedback}

A critical component of novice driver training that could have significant payoffs if it is implemented correctly is in the area of trainee feedback and evaluation criteria. Feedback can impact learning rate (and thus training time) and perceived "fairness" of evaluation criteria. From the perspective of licensing agencies and driver educators, the evaluation criteria must discriminate "good" from "bad" trainees, and the training must have a lasting, quantifiable benefit for drivers. It should also be noted that incorporating the ideal feedback and evaluation system within novice driver training does not necessarily translate into higher cost as it would for other factors such as the degree of simulator fidelity. These factors, in turn, suggest a higher benefit-cost ratio when resources are devoted to improving the structure and content of feedback and evaluation rather than improving fidelity. This section addresses some of the critical factors relative to feedback provided to trainees and the criteria used to evaluate trainers.

Criterion problem. A key issue with driver training is what may be referred to as the "criterion problem." The question of what constitutes a safe driver (or a model driver) has been debated for years. Measures of accidents and violations are commonly used because access to these records is, for the most part, easily available. For many reasons, however, these measures can be problematic. For one, accidents are relatively rare events, and although young, novice drivers as a group have far higher incidents of crashes in their first years behind the wheel (Hans, 1994; Smith, 1994; IIHS, 1995), the accident involvement for any one driver is not likely to be high. Further, one does not want to wait for an accident to occur before judging that the training has been insufficient. Second, accidents are often multi-causal, and police accident reporting processes vary greatly from one jurisdiction to another. Violations, too, are relatively infrequent, and their relationship to "safe driving" behavior is far from certain. One may ask, is the high-accident, low-violation driver safer than the high-violation, low-accident driver? In many fields in which a performance examination must be taken to obtain a license, this exam may be thought of as the final stage of the training process. Unfortunately, too many training programs become oriented toward passage of the exam. This is also true with the driving world. The driver licensing road test varies considerably from state to state, but rarely represents more than a very small portion of the driving task. For example, very few driving tests are conducted at night in adverse weather, or with high speed and heavy traffic conditions. These are often typical conditions novice drivers are likely to encounter immediately after obtaining a license. Studies (McRae, 1969; Peck and Wachtel, 1993) have shown that results of the drive test are poor predictors of safe driving habits. Should driver training then be validated against road test scores? The "criterion problem" must be addressed when developing any training programs for novice drivers.

Incentive issues. Some critics (Evans, 1991; Stadden, 1991; Wachtel, 1993) of driver training in general, and simulator-based training in particular, have stated their belief that no valid training can ever occur in simulators because the situation is not real -- there is always an "OFF" switch if things get tough, and the trainee knows full well that the consequences of poor performance are insignificant. This may not be true if training is linked to advancement into the next stage of a graduated licensing program. At the same time, it has been demonstrated (Kater, 1983), particularly for high fidelity simulation, across many different industries, that the trainee can become fully involved with the illusion being created for his or her benefit, to the extent that perspiration, stress, and "white knuckles" are common sights in the training environment. Even with low fidelity simulation, it is not only the adequacy of the simulator models that can create an appropriate 
learning environment, but, perhaps more importantly, the instructions provided to the trainee, the incentives built into the training system to reward good behavior and punish bad behavior, and the overall environment within which the training occurs.

Although much is known about the role of instructional set and incentive programs for increasing external validity in simulator-based training environments (Zeitlin, 1993), more needs to be known about the specific design of instructions and incentives for novice driver training, commonly held teenage attitudes about risk taking, sensation-seeking, and.peer pressure, all of which may conspire to make the job of the trainer (training program) more difficult.

Incidental learning effects. Incidental learning is a side-effect of training that is caused by uncontrolled variables in the training protocol. Incidental learning may or may not impact transfer of training, and when it does, it may have a positive or negative impact. There is an open question about the importance of incidental learning and its effects and need for its control in a training environment. For example, although it is easy to criticize the popular racing games complete with "crash and burn" scenarios as reinforcing skills and attitudes that are detrimental to driving safety, there is a contrary position that is equally plausible. Namely, that there is no substitute for first-hand experience, and that it is better to enable a novice driver to experience a simulated crash as the consequence of poor judgment, skill, decision-making, or situational awareness, than it would be for the same driver to encounter that consequence in the real world. Further, despite a commonly held belief that these competitive racing simulations have no socially redeeming value, they may well prove to facilitate the training of certain judgments and skills that are useful in an actual driving environment. Proper lookout behavior and appropriate gapacceptance judgments, to cite two examples, are necessary skills for safe driving performance, and the importance of these skills--even though perhaps not the absolute skill levels--may be trained incidentally (or channeled so as to be trained intentionally) even in games of speed and competition.

"Incidental learning" effects must be addressed when developing any training programs for novice drivers. An additional effort is needed to determine the appropriateness of currently available driving games. The scenarios for these games should be analyzed to see what can be extracted that could be useful for novice driver training.

Use of non-driving tasks. Some researchers have suggested that the use of training tasks with low face validity (for example, using a non-driving theme video game) should not be automatically ruled-out as potential training targets (Gopher, Weil, and Bareket, 1994). While nondriving tasks do not have the "look-and-feel" of a driving simulation, any increase in transfer of training (when compared to an appropriate control group) that can result from their use would suggest that the non-driving training task and behind-the-wheel driving share common information processing mechanisms. This is analogous to using motor imagery (MI) to train athletes. Although MI seems to have little to do with making an appropriate overt response for any sport, research suggests that MI and motoric responses share the same neural processes (Annett, 1995). For driver training, non-driving tasks that train the cognitive responses should be researched.

However, before any non-driving tasks are considered for novice driver training, research is needed to determine those non-driving tasks that result in an increased transfer of training. 


\section{Process versus content learning}

It is useful to distinguish between training that focuses on process versus content learning, for all of the technical approaches to driver training that have been discussed in this document. Content learning includes all knowledge-based training and other training procedures in which the trainee learns facts related to the driving environment. The trainee learns rules-of-the-road, how to respond in emergency situations, and other essential facts about driving for which there is typically a correct and an incorrect answer.

Process learning involves a driving application whose purpose is to learn higher-order cognitive strategies related to the driving task. In a typical process-type training procedure, there may not be a single correct answer. For example, if the training has to do with training "safe" headway choice, there is no single correct response since "safe" headway during actual driving depends on many factors (e.g., driver, roadway, weather, etc.). It should be emphasized that the training of "safe" headway choice using driving simulations does not necessarily require high display fidelity. A requirement for high display fidelity places emphasis on the veridicality of speed perception mechanisms which may not be predictive of actual driver behavior and/or driver safety. Instead, process-type training emphasizes situational awareness which involves continually monitoring relevant traffic information (e.g., signs, radio broadcasts, road conditions, lead vehicles) and processing the information to make near-term decisions about potential hazards. Fortunately, the presentation of such information does not necessarily require high display fidelity and needed driver changes.

Content and process learning should be used together to reduce training time and improve the training benefit. For example, trainees can be given instructions on information processing strategies, and how to use information to make decisions, followed by testing to evaluate their knowledge retention. Subsequent to this content-based training, process-based training using driving simulations could be used to train the underlying cognitive processes.

Although content learning is essential in any driver training program, research emphasis should be placed on developing process/strategic learning procedures that have a quantifiable benefit in terms of reducing training time and/or increasing transfer of training.

Training situation awareness. More than perhaps any other type of skilled operator performance, situation awareness is central to the driving task. A driver must not only be aware of the relationship between the vehicle (and its functioning) and the natural environment (i.e., roadway, weather, visibility, etc.) but, significantly, must be continuously cognizant of the actions of traffic on all four sides of his or her vehicle. This traffic includes drivers of widely varying skills and attitudes, vehicles of divergent performance characteristics, and the interactions of these noncontrollable factors with your vehicle. When coupled with the increasingly invasive distractors present in the driving environment (internal distractors such as other passengers, sound systems and cellular phones; and external distractors such as roadside billboards and highway work zones), situation awareness becomes, in many ways, the integration of all mandatory driver training.

Adequate measures of situation awareness in a driving environment have yet to be developed for novice driver training programs. 


\section{Transfer of training}

All of the training elements recommended would involve use of part-task simulation. As the term implies, only a part of the complex driving task is involved in this type of simulation training. It may be noted that full-task simulation was not within the range of consideration, for this project; it is prohibitively expensive to obtain and to operate, and is not expected to be cost-effective for novice driver training in the foreseeable future. Devices to be considered will have a restricted range of systems and subsystems; and, within these constraints, issues of degree of simulation and how it affects transfer of training are important to discuss.

Fidelity and transfer-of-training. A discussion of simulation fidelity must distinguish between physical and functional fidelity. Physical fidelity refers to the extent to which the training device recreates the actual appearance, fit, and physical features of the actual device being represented. In the case of an automobile, high physical fidelity would apply to a training simulator that utilizes an actual car body and its interior, complete with all functioning displays and controls. A lesser degree of physical fidelity might involve a mock-up of an actual vehicle, with generic displays and controls representative of a vehicle's dashboard. Computers, set-top, and even handheld device platforms with peripherals that represent vehicle controls (such as steering wheels, brake and acceleration pedals) would be considered devices with a low level of physical fidelity. However, there is little evidence in the literature (Flexman and Stark, 1987; Jones, Hennessy, and Deutsch, 1985) to support the fact that a high degree of physical fidelity is necessary to have effective training.

Functional fidelity, may be thought of as the extent to which the training device represents the actual performance or operation of the process being simulated. A high functional fidelity device might convey cues of speed and headway control with a high degree of faithfulness to the behavior that would be exhibited under real world conditions. Poor functional fidelity will, at best, fail to provide the trainee with the requisite skills and judgment needed in critical driving situations. At worst, it will provide negative training, that is, it will equip the trainees with knowledge, skills, and abilities that are inappropriate for the behaviors that will be required on the road. For example, if the goal is to train the response to the onset of a skid, it is critical that the training device provide the visual (and if possible the proprioceptive cues) that are correct for the trainee's inputs to steering, accelerator and brake. If there is no feedback to the trainee, the device may offer little training benefit; and if it provides incorrect feedback, it may provide negative training. Such training would reinforce cognitive and motor behaviors that would not help (and might worsen) an actual skid.

The degree of functional fidelity necessary to benefit trainees needs further investigation for devices used to train novice drivers.

Fidelity and cost factors. In simulation, higher fidelity normally is achievable only at higher costs. However, costs to achieve such fidelity are decreasing rapidly, especially for visual fidelity that relies on computer-generated images, instead of film or video. In addition, although the price to achieve functional fidelity in vehicle dynamics is also dropping rapidly, motion systems for simulation which provide a reasonable degree of fidelity will remain above reasonable costs for the intended scope of this project. 
Increasingly, devices are being developed which provide a better simulation of motion systems. These systems offer degrees of functional fidelity in critical aspects of the driving task at a fraction of the cost and complexity of a true motion system. Game manufacturers have begun to introduce in their video-arcade products true force-feedback mechanisms that provide realistic steering feel in response to driver inputs to lane changing, overtaking, and comering maneuvers.

However, the research questions remain the basic ones that are frequently brought up in the field of simulation. How much fidelity is enough to provide "training value?"' Studies of training simulator validity demonstrate that high fidelity, full scope devices are not always needed for training, and when they are, they prove valuable only under certain circumstances (Semple, 1981; Stein, Parseghian, Allen, and Hayes, 1990). For example, such high- end simulators are best used toward the end of a systematic training program, when it becomes necessary to integrate the knowledge, skills, and abilities already leamed to a full-scale environment, typically with other participants and complex hazards. It has been shown that, other things being equal, learning proceeds most efficiently when part-task training is accomplished first, with each phase of the program building on what has been learned previously (Stammers, 1984; Wachtel, 1993; Hays and Singer, 1989). In addition, the introduction of too complex a training scenario, and too realistic a training device early in one's course of instruction, can be detrimental to the trainee because the very complexities of the learning environment detract from the trainee's ability to attend to the task at hand (Gilliom, Spears, Demuth, Eddy, Hanley, Holmbeck and Fishburne, 1985; Wachtel, 1991).

Research is needed to develop requirements for the fidelity and scope of the devices to be used at each training level, within a graduated licensing system for novice drivers.

\section{Validation of novice driver training devices}

It is generally agreed that simulators, whether used for research, training, or evaluation, must be demonstrated to be valid and of value before they should be used. However, while considerable attention is given to issues of simulator validity, it must be kept in mind that a simulator is a tool, i.e., a " means to an end," and that more attention must be paid to additional criteria factors in the determination of validity. While simulation procedures must be validated to ensure their appropriateness to the training process, validity also depends on the training methods used and the choice of criterion variables and statistical analyses employed to evaluate the effectiveness of that training. This includes questions concerning statistical significance and power, and the attendant difficulties in applied training research of small sample sizes and confounding variables which increase the risk of concluding that there are no training benefits to a particular approach when, in fact, there are.

Simulation must also have the proper construct validity, which refers to the adequacy of the measures chosen to represent the factors of interest. A concept such as safe driving performance is multidimensional, with many different variables which can be selected to represent it. To a great extent, simulators today are capable of being programmed to record a wide array of measures; and the trainer must ensure the appropriateness of those measures chosen. Depending upon how safe driving performance is operationalized, certain measures, such as speed variance, lane deviations, or following distances, may or may not be appropriate measures to ensure construct validity. If inappropriately chosen, or if incorrectly matched to an operational definition of safe driving, the simulation may not prove valid, despite the fidelity of the functional models. A key question is 
whether a relationship exists between the main factors of interest. For example, "How much of a difference must be observed in pre- and post- training performance before we are willing to conclude that the training has made a difference?"

Another concern with simulation-based training is internal validity. This issue addresses the question of whether observed differences (benefits) after training can be properly attributed to the training procedure, or whether these observed differences might instead be attributable to some other factor, perhaps not under the control of the trainer. These secondary or extraneous variables may confound the conclusions reached, by obscuring the relationship between the factors of interest.

The final step requires generalization from the training research to the population. Too many training validity studies (Leonard and Wierwille, 1975; O'Hara, 1986) have sought to demonstrate training benefits measured on the training device before and after the training intervention. What is important is a measure of the training benefits when applied to the real world. This raises the "criterion problem," essentially a question of external validity. Although external validity is often thought to be synonymous with fidelity, it is not. While it is true that the realism of the simulation influences the transferability of simulator-based training results to the actual automobile, it is also affected by factors associated with the training research methodology. Subtle differences in operational and psychological factors between simulated and real-world exercises can substantially affect the generalizibility of findings. Enhancing the similarity of the way in which trainees must respond in the training setting to that in the real world is likely to enhance transfer of training, particularly in the latter stages of training. Regardless, because trainees (almost) always know that the training environment is not the real thing, they may react differently. For example, they may be less safety conscious and more willing to experiment and take risks than they would be in the real world, and this is likely to decrease measures of transfer of training. Even so, this must be considered in light of some of the advantages of training with simulation, this includes: (a) trainees can "learn by doing," (b) trainees can be made aware of the effects of their actions, even if they do not fully realize the consequences of those actions, and (c) the trainee can be exposed to hazardous scenarios in the safety of the simulated training environment. This can be a positive aspect of handson training, particularly when integrated with appropriate lesson plans that permit the simulationbased training to be put in its proper context.

Another important aspect that may affect the generalization from simulated to real world environments is the range of conditions that are trained. Typically, because of time and cost limits, the simulated training conditions are designed to encompass only a small, hopefully representative, sample of the conditions that may be encountered in the real world. For example, the training universe may represent only "typical" streets and intersections, a subset of lighting and weather conditions, and particular, high-likelihood/high-risk traffic interactions. The simulated vehicle and its controls, especially in moderate cost simulators, is also likely to be representative only of a generic automobile. Since every vehicle on the road has its own unique characteristics, and since roadway, traffic and weather conditions reflect essentially infinite variability, one must work particularly hard to maximize the extent to which the simulation represents the universe of conditions of interest in the real world.

Although most training devices are capable of data collection and analysis, and although certain performance data are commonly collected during driver performance research projects, there is no consensus about the priorities for dependent variable measures to be collected, the 
frequency and precision of this data, or its meaningfulness with regard to measurement of safe driver performance.

\section{Hardware Needs}

Research questions pertaining to simulation hardware address questions both of fidelity and scope of simulation. The two simulation subsystems that are most responsible for initial costs are the motion system and the visual system. These are discussed next. In addition, the issue of simulator sickness is frequently a topic of discussion; and will be briefly addressed in the context of the devices recommended.

\section{Motion system}

The lowest cost devices generally have no motion capability at all. The first steps in adding "motion" to a simulation platform might involve a subwoofer mounted inside the vehicle's seat to convey some non-specific rumble and vibration to represent road surface irregularities. Above this, devices to move the trainee's seat and controls in response to acceleration, braking, and turning maneuvers might be used. Beyond this level, motion platforms might make the entire body of the simulated vehicle move in response to vehicle-roadway interactions. At this point, costs to develop more sophisticated motion cues become quite prohibitive for devices at the intended level of this project.

There is very little evidence to indicate a positive correlation between the availability of motion and the training effectiveness of a driving simulator (Stadden, 1993). Research is needed to establish this connection, if any, and to identify the level of motion that may be needed for training benefits to be maximized.

\section{Visual system}

Since the driving task is predominantly visual, some form of visual display system is imperative for devices that simulate the traffic scene. The costs of visual display system hardware are related to both the fidelity of the visual images that can be presented (i.e., their detail and clarity, the speed of updates, the complexity of the scene that can be presented, etc.); and the scope of the simulation that is supported (i.e., the extent of the horizontal and vertical field of view, the capacity to produce visual scenes representative of different times-of-day and different weather conditions, the capability to support views through simulated rear- and side-view mirrors, etc.).

It is obvious that simulations of limited-scope simply cannot be used to train knowledge, skills, and abilities that the visual system does not support. For example, one cannot teach backing or parallel parking maneuvers unless the simulation supports rear views (directly and through mirrors); and one cannot train proper lookout behavior at intersections unless the visual system supports a sufficiently wide field of view to permit the trainee to see cross traffic at representative real-world angles and distances.

There has been little systematic research undertaken to demonstrate the relationship between training effectiveness and simulation visual system characteristics. Research questions must address 
the need for enhanced simulation visual display capabilities when measured against the criterion of training effectiveness,

\section{Simulator sickness}

Simulator sickness is a potential problem with any simulation that involves motion. Although much is understood about the etiology of simulator sickness, the problem continues to affect a measurable percentage of individuals who participate in simulation-based training, testing or research. It is known that simulator sickness affects younger persons to a far lesser degree than it does older individuals (Hein, 1993; Wells, 1993; Nilsson, 1993). Simulator sickness can occur with simulators at any price and level of sophistication. In addition, it has been known to have differential effects with "identical" simulators when used in different settings.

Simulator sickness is a concern for several reasons, including: (a) it can adversely affect the course of training; (b) it can cause some trainees to drop out of the program or refuse to participate; (c) it increases the costs and time for training; and (d) it may raise a question of ethics.

Research is needed into the incidence of simulator sickness for devices of given design and operational characteristics, as well as the settings in which they are used, how they are programmed to present the training program, and how trainees are permitted (or encouraged) to practice and to learn how to use the simulator. Tradeoffs between different approaches to hardware development and implementation should be examined for their potential effects on simulator sickness

\section{Software Needs}

A tremendous amount of development activity has recently gone into ever more realistic driving simulation software oriented toward the game and competition markets made available for home use on set-top devices by firms such as Nintendo, Sega, and Sony. In addition, coin-operated arcade games have become increasingly realistic, and this industry has begun to evolve into the market now known as "location-based entertainment," in which networks of linked games are placed in artificial, but realistic ambient environments (such as race tracks complete with grandstands, scoreboards, and vendors) located in family-oriented gathering places such as shopping malls and amusement and theme parks. For a price, the customer gets to drive a vehicle in real-time competition with other customers, while the "fans" cheer for their heroes from actual grandstands. Although the obvious features and attractions of these products (high speeds, competition, and occasionally, crashes) are antagonistic to the requirements and goals of novice driver training, their high physical and functional fidelity, and increasingly complete scope of simulation, provides basic software that might be used for low-cost training devices.

At least one company has taken coin-operated driving games and systematically removed those characteristics that contribute to its "gameness." Roadside signs encouraging high speeds were changed to display legal and appropriate speed limits; the appearance of other vehicles was modified from racing cars to passenger sedans, trucks, and buses; the roadway network itself was changed from a race course with hairpin turns to a network of city and suburban streets, as well as freeways complete with interchanges. This modified software has been embedded in the company's arcade game module and has been used by researchers to study the effects of specific visual and medical conditions and driving measures (Szlyk, Severing, and Fishman, 1991; Cox, Gressard, Quillian, 
Westerman, and Gonder-Frederick, 1992). This raises the possibility that software modification could be undertaken at a far lower initial cost than the development of new software for driver training.

Because simulation represents an abstraction from reality, and because different simulations perform this abstraction differently, it is likely that training performed on different simulation platforms will not be equivalent. Developing common devices and enabling simulations in different locations to share scenarios, instructions, and scoring, could go a long way toward ensuring a universal, equivalent "baseline" of simulation training.

The military pioneered the networking of simulation at different locations so that "virtual battles" and tactical maneuvers could be conducted by numerous trainees in diverse vehicles at multiple sites in the same real-time environment (Platt and Crane, 1993; Waag and Houck, 1994). Because these simulations are fully interactive with other, instructors can create more complex, realistic scenarios to train the integration of knowledge, skills, and abilities learned previously. This allows training of situation awareness, in a setting that also permits the spontaneity of interaction caused by the presence of other trainees (and, often, an instructor playing the role of a participant) overlaid on the preprogrammed simulation. This technology, generically known as "SIMNET" is now available in the low-cost simulation market. Further, training scenarios developed at one location can, if proven successful, be easily shared with another location merely be exchanging floppy discs or by transmitting the developed scenario electronically to training sites on the network.

Research is needed to better understand the need for such commonality (i.e., sharing of training programs either through products or networking), and the benefits that can accrue from $i t$, while at the same time protecting the proprietary interests that may be held by competing manufacturers of training devices.

The importance of instructional set was discussed earlier with issues of validity. The design and presentation of instructions assumes greater importance when training may be conducted in an unattended setting.

The influence of instructional set on trainee attitude, motivation, and performance must be explored and translated into an implementable installation. 


\subsection{REFERENCES}

AAA (American Automobile Association). (1994). Responsible Driving. Glencoe, McGraw-Hill, New York.

AAA (American Automobile Association). (1996a). "AAA Helps Parents with Teaching Teens to Drive." Traveler, September/October.

AAA (American Automobile Association). (1996b). "Driver Education Computer Program on Target, Teens Say." AAA Foundation for Traffic Safety Progress Report, July/August, 3(4); p. 1.

AAMVA (American Association of Motor Vehicle Administrators). (1989). An Improved Driver Entry System for Young Novice Drivers. U.S. Department of Transportation, National Highway Traffic Safety Administration, Washington, DC.

AAMVA (American Association of Motor Vehicle Administrators). (1995). Guidelines for Knowledge and Skill Testing.

AV Video. (1996). "Manufacturers." AV Video, August, p.78.

Alessi, S. M. and Trollip, S.R. (1991). Computer-Based Instruction: Methods and Development (2nd Ed.). New York; Prentice-Hall.

Allen, R.W., Stein, A.C., Aponso, B.L., Rosenthal, T.J., and Hogue, J.R. (1990). "Low-cost Part Task Driving Simulator Using Microcomputer Technology." Transportation Research Record, 1270.

Alperson, J.R. and O'Neil, D.H. (1990). “The Box Score: Tutorials 2, Simulations 0." Academic Computing, 18-19; pp. 47-49.

Annett, J. (1995). "Motor Imagery: Perception or Action? Special Issue: The Neuropsychology of Mental Imagery." Neuropsychologia, 33(11); pp. 1395-1417.

Ashman, R.D. (1994). "An Alternative Method of Providing Simulation Instruction in Driver Education." ADTSEA Chronicle, Summer 1994; pp. 8-10.

Baron, M.L. and Willigs, R.C. (1975). "Transfer Expectivness of a Driving Simulator." Human Factors, 17(1); pp. 71-80.

Barrett, G.V., Alexander, R.A., and Forbes, J.B. (1973). Analysis of Performance Measurement and Training Requirements for Driving Decision Making in Emergency Situations. National Highway Traffic Safety Administration, Washington, DC.

Basch, C.E., De Cicco, I.M., and Malfetti, J.L. (1987). Perceptions, Attitudes, Motivations, and Behaviors of Drivers 18-22 Years Old. AAA Foundation for Traffic Safety.

Blaauw, G.J. (1982). "Driving Experience and Task Demands in Simulator and Instrumented Car: A Validation Study." Human Factors, 24(4); pp. 473-486. 
Brachman, M. L. (1996). Response Letter, Subject: Software Development Estimates for Selected Training Target Procedure. Visual Software Solutions, Inc., Media, PA., May 7th.

Bragg, W.E. and Finn, D. (1982). Young Driver Risk-Taking Research. National Highway Traffic Safety Administration, Washington, DC.

Brock, J.F. (1994). Instructional Technology: A Review. AAA Foundation for Traffic Safety (unpublished paper).

Brouwer, W.H., Waterink, W., Van Wolffelaar, P.C., and Rothengatter, T. (1991). "Divided Attention in Experienced Young and Older Drivers: Lane Tracking and Visual Analysis in a Dynamic Driving Simulator." Human Factors, 33(5); pp. 573-582.

Case, H.W., Hulbert, S., and Beers, T. (1970). "Driving Ability as Affected By Age." UCLA-ITE Report No. 70-18.

Comsis. (1995). Understanding Youthful Risk Taking and Driving-Interim Report. National Highway Traffic Safety Administration.

Coon, D. (1992). Introduction To Psychology: Exploration and Application. West Publishing Co., St. Paul MN.

Cox, D.J., Gressard, C.F., Quillian, W.C., Westerman, P., and Gonder-Frederick, P. (1992). The Effects of Blood Alcohol Levels on Driving simulator, coordination, and Reaction Time tests in a High Risk Population: Objective and Subjective Measures. AAA Foundation for Traffic Safety, Washington, DC.

Day, R. (1996). "The Great PC/TV Debate." OEM Magazine, July, pp. 22-27.

Diewald, W. (1995). "New Developments in Advanced Driving Simulators." TR. News, 179; pp. 23-26.

Doron Precision Systems, Inc. (1995). Product Material.

Eberts, R. and Brock, J.F. (1987). "Computer-Assisted and Computer Managed Instruction." In: G. Salvendy (Ed.) Handbook of Human Factors, New York: John Wiley and Sons, Inc.

Endsley, M.R. (1995). "Toward a Theory of Situational Awareness in Dynamic Systems." Human Factors, March; pp. 32-64.

Evans, L. (1991). Traffic Safety and the Driver. Van Nostrand Reinhold, NY.

Evans, L. and Wasielewski, P. (1983). "Risky Driving Related to Driver and Vehicle Characteristics." Accident Analysis and Prevention, 15(2); pp. 121-136. 
Farrow, J. (1987). "Young driver Risk Taking: A Description of Dangerous Driving Situations Among 16-19-Year-Old Drivers." The International Journal of the Addictions, 22(12); pp. 1255-1267.

Finn, and Bragg (1986). "Perception of the Risk of and Accident by Young and Older Drivers. “ Accident Analysis and Prevention, 18(4); pp. 289-298.

Flexman, R.E. and Stark, E.A. (1987). "Training Simulators." In: G. Salvendy, (Eds.), Hondbook of Human Factors. John Wiley \& Sons, NY.

Fraser, Hawken, and Warnes. (1994). "Effects of Extra Signals on Drivers' Distance Keeping--A Simulation Study." IEEE Transactions on Vehicular Technology, 45(4); pp. 1118-1124.

Gebers, M.A., Romanowicz, P.A., and McKenzie, D.M. (1993). Teen and Senior Drivers. California Department of Motor Vehicles.

Gianutsos, R (1994). "Driving Advisement with the Elemental Driving Simulator (EDS)." Behavior Research Methods, Instruments, and Computers, 26(2); pp. 183-186.

Gilliom, D.C., Spears, W.D., Demuth, H.J., P.P., Hanley, D.E., Holmbeck, G.E. and Fishburne, R.P., Jr. (1985). A Systematic Determination of Skill and Simulator Requirements for Airline Transport Pilot Certification, Federal Aviation Administration, Washington, DC.

Gopher, D. (1982). "A Selective Attention Test as a Predictor of Success in Flight Training." Human Factors, 24; pp. 173-183.

Gopher, D., Weil, M., and Barket, T. (1994). "Transfer of Skill from a Computer Game Trainer to Flight." Human Factors, 36(3); pp. 387-405.

Green, J. and Olson. (1989). The Development and Use of the UMTRI Driving Simulator. UMTRI pp. 89-25.

Groeger, J.A and Brown, I.D.(1989). "Assessing One's Own and Others Driving Ability: Influences of Sex, Age and Experience." Accident Analysis and Prevention, 21(2); pp. 155-168.

Hans, M. (1994). "Can Graduated Licensing Reduce the Young-Driver Problem?" Traffic Safety, pp. 9-10.

Harrington, D.M. (1972). "The Young Driver Follow-up Study: an Evaluation of the Role of Human Factors in the First Four Years of Driving." Accident Analysis and Prevention; pp. 191-240.

Hartsook, P. (1996). "Why It's Time to Clone The MAC." OEM Magazine, 84; pp. 27-35.

Hays, R.T. and Singer, M.J. (1989). Simulation Fidelity in Training System Design. SpringerVerlag, NY.

Heald, T. (1996). "The Next Wave." Videa, September, pp.32-40. 
Hein, C.M. (1993). "Driving Simulators: Six Years of Hands-On Experience at Hughes Aircraft Company." In: Proceedings of the Human Factors and Ergonomics Society 37th Annual Meeting, Seattle, Washington, October 11-15, pp. 607-611.

Hulbert, S.F. and Wojcik, C.K. (1964). "Driving Simulator Devices and Applications." SAE Report No. 640103 .

Hulbert, S. and Wojcik, C. (1972). "Driving Task Simulation." In: Human Factors in Highway Traffic Safety Research. Edited by T.W. Forbes, Michigan State University, Michigan.

Huston, R. (1986). Teen Driver Facts. California Department of Motor Vehicles, Research and Development Office.

IIHS (Insurance Institute for Highway Safety). (1995). Teenagers.

Insurance Bureau of Canada. (1991). New to the Road. Traffic Injury Research Foundation of Canada. Key Findings and Implications from an International Symposium, February 17-20, 1991.

Jonah, B.A. (1986). "Accident Risk and Risk Taking Behavior Among Young Drivers." Accident Analysis and Prevention, 18(4); pp. 255-271.

Jonah, B.A. (1986). "Youth and Traffic Accident Risk: Possible Causes and Potential Solutions. " Accident Analysis and Prevention, 18(4); pp. 253-254.

Jonah, B.A. (1990). "Age Differences in Risky Driving." Health Education Research: Theory and Practice, 5(2); pp. 139-149.

Jonah, B. and Dawson, N. (1987). "Youth and Risk: Age Differences in Risky Driving, Risk Perception and Risk Utility." Alcohol Drugs and Driving, 3(3-4); pp. 13-29.

Jones, E.R., Hennessy, R.T., and Deutsch, S. (1985). Human Factors Aspects of Simulation. National Academy Press, Washington, DC.

Kanaley, R. (1996). "Driving like a Nascar Pro on a 'Virtual' Racing Circuit." The Philadelphia Inquirer, August 15, pp. F-1, F-7.

Kater, J.M. (1983). "Simulation - A Success Story." Invited Presentation to the Institute of Nuclear Power Operations, Atlanta, GA.

Kimball, K.A., Ellingstad, V.S., and Hagen, R.E. (1971). "Effect of Experience on Patterns of Driving Skill." Journal of Safety Research, 3(3); pp. 129-135.

Konecni, V.J., Ebbesen, E.B., and Konecni, D.K. (1976). "Decision Process and Risk Taking in Traffic: Driver Response to the Onset of Yellow Light." Journal of Applied Psychology, 61(3); pp. 359-367. 
Kulik, J.A., Kulik, C.C., and Bangert-Drowns, R.L. (1985). "The Importance of Outcome Studies: A Reply To Clark." Journal of Educational Computing Research, 1(14); pp. 381-387.

Leonard, J.J., Jr. and Wierwille, W.W. (1975). "Human Performance Validation of Simulators: Theory and Experimental Verification." In: Proceedings - Human Factors Society 19th Annual Meeting. Santa Monica, CA, pp. 446-456.

Lerner, N., Williams, A., and Sedney, C. (1988). Risk Perception in Highway.Driving. Final Report. Publication No. DTFH61-85-C-00143, Federal Highway Administration, U.S. Department of Transportation, Washington, DC.

Levine, O.H. and Mourant, R.R. (1995). "A Driving Simulator Based on Virtual Environments Technology." TRB 74th Annual Meeting, Paper No. 950269.

Lonero, L., Clinton, K., Brock, J., Wilde, G., Wilde, G., Laurie, I., and Black, D. (1995). Novice Driver Education Model Curriculum Outline. AAA Foundation for Traffic Safety. Washington, DC.

Marowitz, L. (1991). Driving Simulator Review. California Department of Motor Vehicles, Sacramento, CA.

Massie, D.L., Campbell, K.L., and Williams, A.F. (1995). "Traffic Accident Involvement Rates By Driver Age and Gender." Accident Analysis and Prevention, 27(1); pp. 73-87.

Mayhew, D.R. and Simpson, H.M. (1996). The Role of Driving Experience: Implications for the Training and Licensing of New Drivers. Insurance Bureau of Cananda.

McCleskey, J. (1996). "Loggers, Scripters, Schedulers and Storyboards." Videomaker, July p. 66.

McKnight, S., and McKnight, J. (1994). "The Automated Psychophysical Test (APT) for Assessing Age-Diminished Capabilities." Behavior Research Methods, Instruments, and Computers, 26(2); pp. 187-191.

McKnight, and Stewart (1990). Development of a Competency Based Driver License Testing System. California Department of Motor Vehicles, June.

McRae, D.J. (1969). The Relation of Licensing Test Scores to Subsequent Driver Performance. University of North Carolina, L.L. Thurstone Psychometric Laboratory, Chapel Hill, NC.

Mourant, R.R. and Rockwell, T.H. (1970). Visual Information Seeking of Novice Drivers. SAE paper 700397. Warrendale, PA; Society of Automotive Engineers; included in the proceedings of the 13th FISITA conference, International Automobile Safety Conference Compendium; pp. 704711.

Mourant, R.R. and Rockwell, T.H. (1972). "Strategies of Visual Search by Novice and Experienced Drivers." Human Factors, 14; pp. 325-335. 
Naatanen, R and Summala, H. (1975). "A Simple Method for Simulating Danger-Related Aspects of Behavior in Hazardous Activities." Accident Analysis and Prevention, 7; pp. 63-70.

Nilsson, L. (1993). "Behavioral Research in an Advanced Driving Simulator - Experiences of the VTI System." In: Proceedings - Human Factors and Ergonomics Society 37th Annual Meeting, Seattle, Washington, October 11-15, pp. 612-616.

O'Hara, J.M. (1986). "The Validity of Simulator Research Studies." Proceedings of the Society for Computer Simulation Multi Conference. San Diego, CA: Society for Computer Simulation.

Peck, R. and Wachtel, J. (1993). New Technology for an Old Problem: A Report of Prospective Study to Evaluate a Simulator-Based Approach to Driver Licensing. Paper presented at the 1993 Annual Meeting of the Transportation Research Board, Washington, DC.

Pennsylvania Department of Transportation. (1992). Teaching Your Teen to Survive the Fatal Five.

Platt, P. and Crane, P. (1993). "Development, Test and Evaluation of a Multiship Simulation System for Air Combat Training." In: Proceedings of the 15th Industry/Interservice Training Systems Conference. National Security Industrial Association, Orlando, FL.

Robbins, J. (1996). "CMV Driver Training Simulators". Federal Highway Administration, OMC fax Transmittal, January 21.

Roper Center for Public Opinion Research. (1995). DIALOG File 468: Public Opinion.

Rose, H.M. (1996). "Multi-Player Games Move to the Internet." Newsmedia, April 22, p. 25.

Rozansky, M.L. (1996). "Up to Speed.” The Philadelphia Inquirer, August 8, pp. F-1, F-3.

Sawyer, B. (1996). The Ultimate Game Developer's Sourcebook. The Coriolis Group, Inc., Scottsdale, AZ.

Schiff, W. and Oldak, R. (1993). Functional Screening of Older Drivers Using Interactive Computer-Video Scenarios. AAA Foundation for Traffic Safety.

Schiff, W., Arnone, W., and Cross, S. (1994). "Driving Assessment with Computer-Video Scenarios: More Is Sometimes Better." Behavior Research Methods, Instruments, and Computers, 26(2); pp. 192-194.

Semple, C.A (1981). "Simulator Training Requirements and Effectiveness Study (Stress)." AFHRLTR-80-63, US Air Force.

Simulator Systems, Inc. (1995). Product Material.

Smith, M.F. (1994). Research Agenda for an Improved Novice Driver Education Program. National Highway Traffic Safety Administration, Office of Program Development and Evaluation, Washington, DC. 
Stadden, K. (1993). "My Accident was Preventable." Heavy Duty Trucking, August.

Stadden, K. (1991). "Simulators: Tools or Toys?" Heavy Duty Trucking, June; pp. 78-88.

Stammers, R.B. (1984). "Instructional Psychology and the Design of Training Simulators." Proceedings of the International Conference on Simulation for Nuclear Reactor Technology. Cambridge, England: Cambridge University Press.

Staplin, L., Gish, G., Decina, L.E., Lococo, K.H., Harkey, D.L., Tarwaneh, M.S., Lyles, R., Mace, D., and Garvey, P. (1996). Synthesis of Human Factors Research on Older Drivers and Highway Safety. Volume II. Publication No. DTFH61-93-C-00074, Federal Highway Administration, Washington, DC.

Staplin, L., Lococo, K., and Sim, J. (1993). Traffic Maneuver Problems of Older Drivers. Publication No. DTFH61-90-C-00008, Federal Highway Administration, Washington, DC.

Staplin, L. , and Lyles, R.W. (1992). "Age Differences in Motion Perception and Specific Traffic Maneuver Problems." Transportation Research Record, 1325.

Stein, A.C., Parseghian, Z., Allen, R.W., and Haynes, J.T. (1990). The Development of a Low-Cost Portable System for the Detection of Truck Driver Fatigue. 34th Annual Proceedings of the Association for the Advancement of Automotive Medicine, Scottsdale, AZ.

Szlyk, J.P, Severing, K., and Fishman, G.A. (1991). Peripheral Visual Field Loss and Driving Performance. AAA Foundation for Traffic Safety, Washington, DC.

Tannahill, W.J., (1985). Provisional Driver Licensing System for Young Novice Drivers. National Highway Traffic Safety Administration, Office of Alcohol and State Programs, Traffic Safety Program, Washington, DC.

Triggs, T.J., and Drummond, A. E. (1993). A Young Driver Research Program Based on Simulation. Proceedings of the Human Factors and Ergonomics Society 37th Annual Meeting.

Vargas, J.S. (1986). "Instructional Design Flaws in Computer-Assisted Instruction." Phi Delta Kappan, June; pp. 738-744.

Wachtel, J.A. (1991). "Are We Training Operators Upside Down?" Proceedings of the Ninth Symposium on the Training of Nuclear Facility Personnel. Oak Ridge, TN: Oak Ridge National Laboratory Report No. CONF-9104135.

Wachtel, J.A. (1993). "Applications of Appropriate Simulator Technology for Driver Training, Licensing and Assessment." Paper presented at the Fifth International Conference on Vision in Vehicles, Glasgow, Scotland.

Wachtel, J.A. (1995). "Brief History of Driving Simulators." TR News, 179; pp. 26-27.

Wachtel, J.A. (1996). Personal Communication. 
Waag, W.L. and Houck, M.R. (1994). "Tools for Assessing Situational Awareness in an Operational Fighter Environment." Aviation, Space and Environmental Medicine, 65(5 Supplement); pp. A13A19.

Weir, D.H. and Clark, A.J. (1995). "A Survey of Mid-Level Driving Simulators." SAE Technical Paper, 950172.

Wells, M. (1993). "The Influence of Complex Systems on Motion Sickness," (Review of presentation by M. Griffin in Armstrong Laboratory Colloquium Series).Gateway, IV (1); pp. 9-11.

Willcox, J.K. (1996). "Nintendo vs. CD-ROM.” OEM Magazine, August, pp.23-32.

Williams, A.F. (1985). "Nighttime Driving and Fatal Crash Involvement of Teenagers." Accident Analysis and Prevention, 14(1); pp. 1-5.

Williams, A. F. (1995). Restrictive Measures for Young, Beginning Drivers. Insurance Institute for Highway Safety.

Young, K., (1993). Workshop to Identify Training Requirements Designed to Reduce Young Driver Risk Taking and Improve Decision Making Skills. National Highway Traffic Safety Administration, Washington, DC.

Zeitlin, L. (1993). Paper presented at the 72nd Annual Meeting of the Transportation Research Board, Washington, DC.

Ziskind, D. (1991). Critical Evaluation of the Secondary Driver Education Program. Pennsylvania Department of Transportation. 


\section{APPENDIX A}

\section{WORKSHOP PARTICIPANTS}




\section{THE SCIENTEX CORPORATION STAFF}

Transportation Safety Division

1722 Sumneytown Pike, P.O. Box 1367

Kulpsville, PA 19443

Phone: (215) 412-4912

Fax: (215) 412-4911

Lawrence E. Decina

Principal Investigator
Dr. Loren Staplin

Project Manager
Al̄bert H. Kirchner, III Computer Engineer
Dr. Kenneth W. Gish

Senior Research Psychologist
Linda M. Montella

Workshop Coordinator

\section{NATIONAL HIGHWAY TRAFFIC SAFETY ADMINISTRATION}

Michael F. Smith

Contracting Officer's

Technical Representative
Office of Research and Traffic Records

400 Seventh Street, S.W., NTS-30

Washington, D.C. 20590

\section{WORKSHOP EXPERT PANELIST PARTICIPANTS}

John F. Brock

InterScience America, Inc.

312 East Market Street, St. G

Leesburg, VA 22075

Phone: (703) 779-8090

Fax: (703) 779-8092

Dr. Neil Lerner

Comsis Corporation

8737 Colesville Road

Silver Spring, MD 20910

Phone:(301) 588-0800

Fax:(301) 588-5922
Deborah A. Quackenbush

Doron Precision Systems

P.O. Box 400

Binghamton, NY 13902

Phone: (607) 772-1610

Fax: (607) 772-6760

Dr. Thomas H. Rockwell

R \& R Research, Inc.

1373 Grandview Ave., \#210

Columbus, $\mathrm{OH} 43212$

Phone: (614) 486-7517

Fax: (614) 486-2060

\section{Jerry A. Wachtel}

The Veridian Group

226 East Montgomery Street

Baltimore, MD 21230

Phone: (410) 727-0499

Fax: (410) 727-0632

Dr. Ginger Watson

The University of Iowa

Cntr. for Computer-Aided Design 208 Engineering Res. Facility

Iowa City, IA 52242

Phone: (319) 335-6396

Fax: (319) 384-0542

\section{Lawrence P. Lonero}

Northport Associates

3625 Alnwick Hill Road

R.R.1 Baltimore, Ontario,

Canada KOK 1CO

Phone: (905) 342-2482

Fax: (905) 342-2347 


\section{APPENDIX B}

\section{WORKSHOP AGENDA}




\title{
National Highway Traffic Safety Administration's Workshop to Determine the Feasibility of New Simulation Technology to Training Novice Drivers
}

Thursday, May 16

\author{
MITAGS Center \\ Linthicum Heights, $\mathrm{MD}$ \\ May $16-17,1996$
}

$\begin{array}{lll}\text { 8:00-8:30 } & \text { Registration } & \\ \text { 8:30-8:45 } & \text { Welcome and Introduction } & \text { M. Smith, L. Decina } \\ \text { 8:45- 9:00 } & \text { Goal of Project } & \text { L. Decina } \\ \text { 9:00- 9:15 } & \text { Goal of Workshop } & \text { L. Decina } \\ \text { 9:15- 10:00 } & \text { Overview of Literature Review } & \text { L. Decina, K. Gish } \\ \text { 10:00- 10:15 } & \text { Break } & \\ \text { 10:15- 12:00 } & \text { Definition of Terms (Open Discussion) } & \text { K. Gish, L. Decina } \\ \text { 12:00-1:15 } & \text { Lunch } & \\ \text { 1:15-3:45 } & \text { Critical Topics (Open Discussion) } & \text { K. Gish, L. Decina } \\ \text { 3:45-4:00 } & \text { Break } & \\ \text { 4:00-4:30 } & \text { Tour of MTAGS' Ship Bridge Deck Simulator } \\ \text { 4:30-4:45 } & \text { Product Demonstration, Free Time } \\ \text { 4:45-6:00 } & \text { Critical Topics (Open Discussion Cont.) } & \text { K. Gish, L. Decina } \\ \text { 6:00 } & \text { Dinner } & \end{array}$

Friday, May 17
8:15 - 8:30 Welcome
8:30 - 9:00 Day One Summary L. Staplin
9:00 - 9:30 Counterpoint/Consensus
9:30 - 11:00 Research Needs L. Decina
11:00 - 11:15 Break
11:15 - 12:00 Research Needs (Con't)
12:00 - 12:30 Closing Statements L. Decina, M. Smith
12:30 Lunch 